\title{
Selected Bibliography of Statistical Literature 1930 to 1957: VI. Theory of Estimation and Testing of Hypotheses, Sampling Distributions, and Theory of Sample Surveys
}

\author{
This is the sixth in a series of bibliographies that deal with various specific subjects in \\ the field of statistics. Given here are approximately sixteen hundred references and titles \\ to important publications dealing with the theory of statistical estimation and testing of \\ hypotheses (parametric case), sampling distributions, and the theory of sample surveys.
}

\section{Lola S. Deming}

(May 22, 1962)

The purpose of any bibliography is to provide a search of the literature for students in a particular field of investigation. This series provides such a service in several of the specific subjects within the very large field of probability and mathematical statistics. Search of the literature in this case has been of a parasitic nature, however, in that two prominent reviewing journals have been used for our source material. Abstracts of original papers appearing in a myriad of technical journals throughout the world and in many languages, have been transferred from the reviewing journals to cards which form a collection of statistical material maintained on a current basis in the NBS Statistical Engineering Laboratory. Zentralblatt für Mathematik was used for this purpose from 1930 to 1939; Mathematical Reviews has been used from 1940 onward. The abstracts have been coded into categories of subject matter following generally, but with some minor deviations, the classification scheme of Mathematical Reviews. One abstract may be classified under several subjects; hence may appear in more than one place in this series of bibliographies. The references given in these published bibliographies were transcribed from the abstracts by means of punched cards thereby necessitating severe and unconventional abbreviations in many cases. The titles were added as each bibliography was compiled.

The present bibliography is a composite of several areas in statistics because of the unusual amount of straddling here. In addition to the papers listed by the reviewing journals directly under these subjects, we have also combed through those classified by Mathematical Reviews under the more general headings General Statistics and Statistical Tests and Related Topics. Papers dealing solely with ranking and paired-comparison techniques, order statistics, and other distribution-free methods have been excluded for the most part, in view of the thorough and extensive coverage of these areas by Savage's ${ }^{1}$ latest bibliography of nonparametric statistics.
The abstracting services of both Zentralblatt für Mathematik and Mathematical Reviews have favored papers and books on theory and methodology rather than applications. Therefore, we do not claim completeness, especially in the more practical aspects of statistics. This becomes particularly evident in the field of sample surveys. Furthermore, there does not seem always to be a clear distinction between writings dealing with sampling in the sense of the theory and methodology of sample surveys and those dealing with sampling distributions of particular functions of sample values in successive random samples of fixed size from a specified probability distribution.

Because of the overlapping nature of the material included in this bibliography, we have made no effort at subclassifying the references.

The organization of information within each entry is:

Author: The author's surname, followed by initials only. In the case of multiple authorships, the journal reference appears with each author's name, but the title of the paper appears with the first author only. The symbol preceding the surname denotes multiple authorship.

Title: Exactly as in the reviewing journal. Titles of separately bound publications (books, reports, theses, etc.) are in italics, followed by the publisher.

Reference to literature: The name of the journal in italics, the number of the volume in bold face, the initial page number, and the date of publication in parentheses comprise the reference to the original article.

Reference to the abstract: The final symbols M (for Mathematical Reviews) and Z (for Zentralblatt für Mathematik) are followed by the volume number and page number of the reviewing journal in which the abstract appears.

1 I. Richard Savage, Bibliography of Nonparametric Statistics published by the Harvard University Press, Cambridge, Mass., 1962. This is a much extended version of his earlier Bibliography of Non parametric Statistics and Related Topics, J. Amer. Statist. Assoc. Vol. 48, pp. 844-906, December 1953. 
Adhikari, B. P., Analyse discriminante des mesures de probabilité sur un espace abstrait, $C$. R. Acad. Sci. Paris 244, 845 (1957).

M 18, 773

- Agarwala, S. P. (See C. Chandra Sekar), Sankhyã 15, 381 (1955).

Aggarwal, O. P., Some minimax invariant procedures for estimating a cumulative distribution function, Ann. Math. Statist. 26, 450 (1955).

M 1\%, 54

Aitken, A. C., Note on the derivation and distribution of Pearson's $\chi^{2}$, Proc. Edinburgh Math. Soc. 6, 57 (1939).

Z 23, 148

Aitken, A. C., On a problem in correlated errors, Proc. Roy. Soc. Edinburgh A 62, 273 (1948).

M 10, 312

Aitken, A. C., On the estimation of many statistical parameters, Proc. Roy. Soc. Edinburgh A 62, 369 (1948).

M 10, 201

Albert, G. E., On the estimation of central intervals which contain assigned proportions of a normal univariate population, Ann. Math. Statist. 22, 596 (1951).

M 13, 479

Albert, G. E., On the computation of the sampling: characteristics of a general class of sequential decision problems, Ann. Math. Statist. 25, 340 (1954).

M 15, 973

Allard, G., Détermination de la valeur la plus probable des grandeurs statistiques. I. Généralités, J. Phys. Radium 8, 212 (1947).

M 9, 295

Allen, S. G., A class of minimax tests for one-sided composite hypotheses, Ann. Math. Statist. 24, 295 (1953).

M 14, 889

Anderson, O., Die Begründung des Gesetzes der grossen Zahlen und die Umkehrung des Theorems von Bernoulli, Dialectica 3, 65 (1949). M 11, 191

Anderson, P. H., Distributions in stratified sampling, Ann. Math. Statist. 13, 42 (1942). M 4, 24

Anderson, R. L., Distribution of the serial correlation coefficient, Ann. Math. Statist. 13, 1 (1942).

M 4, 22

Anderson, T. W., On card matching, Ann. Math. Statist. 14, 426 (1943).

M 5, 208

- Anderson, T. W., (See D. S. Villars), Ann. Math. Statist. 14, 141 (1943).

Anderson, T. W., The non-central Wishart distribution and certain problems of multivariate statistics, Ann. Math. Statist. 1\%, 409 (1946). M 8, 394

Anderson, T. W., A note on a maximum-likelihood estimate, Econometrica 15, 241 (1947). M 8, 593

Anderson, T. W., On the theory of testing serial correlation, Skand. Aktuarietidskr. 31, 88 (1948).

M 10, 312

-Anderson, T. W., The asymptotic properties of estimates of the parameters of a single equation in a complete system of stochastic equations, $A n n$. Math. Statist. 21, 570 (1950).

M 12, 510

Anderson, T. W., Estimating linear restrictions on regression coefficients for multivariate normal distributions, Ann. Math. Statist. 22, 327 (1951).

M 13, 144

Anderson, T. W., Classification by multivariate analysis, Psychometrika 16, 31 (1951). M 12, 842

-Anderson, T. W., Asymptotic theory of certain "goodness of fit" criteria based on stochastic processes, Ann. Math. Statist. 23, 193 (1952). M 14, 298
Anderson, T. W., A test of goodness of fit, J. Amer. Statist. Assoc. 49, 765 (1954).

M 16, 1039

Anderson, T. W., On estimation of parameters in latent structure analysis, Psychometrika 19, 1 (1954).

M 17, 756

Angoff, W. H., A note on the estimation of nonspurious correlations, Psychometrika 21, 295 (1956).

M 18, 343

Annis, M., On statistical estimation in physics, Rev. Modern Physics 25, 818 (1953). M 15, 454

Anscombe, F. J., Sampling theory of the negative binomial and logarithmic series distributions, Biometrika 3\%, 358 (1950).

M 12, 510

Anscombe, F. J., Large-sample theory of sequential estimation, Proc. Cambridge Philos. Soc. 48, 600 (1952).

M 14, 487

Anscombe, F. J., On estimating binomial response relations, Biometrika 43, 461 (1956). M 18, 426

Aoyama, H., On practical systematic sampling, Ann. Inst. Statist. Math. Tokyo 3, 57 (1952). M 14, 487

Aoyama, H., On the chi-square test for weighted samples, Ann. Inst. Statist. Math. Tokyo 5, 25 (1953).

M 15, 240

Aoyama, H., A study of the stratified random sampling, Ann. Inst. Statist. Math. Tokyo 6, 1 (1954).

M 16, 384

Arbey, L., Les erreurs expérimentales en chaînes gaussiennes de trois, Bull. Astr. 1\%, 339 (1954).

M 16, 54

Arley, N., On the mean successive difference estimate of dispersion, Mat. Tidsskr. B 1950, 86 (1950).

M 12, 428

Armitage, P., A comparison of stratified with unrestricted random sampling from a finite population, Biometrika 34, 273 (1947).

M 9, 364

Armitage, P., Sequential analysis with more than two alternative hypotheses, and its relation to discriminant function analysis, J. Roy. Statist. Soc. Ser. B 12, 137 (1950).

M 12, 429

Arnáiz, G., Sampling inspection, Trabajos Estadistica \%, 221 (1956).

M 18, 683

Aroian, L. A., A study of R. A. Fisher's z-distribution and the related $F$-distribution, Ann. Math. Statist. 12, 429 (1941).

M 3, 175

Aroian, L. A., A new approximation to the levels of significance of the chi-square distribution, $A n n$. Math. Statist. 14, 93 (1943).

M 4, 221

Aroian, L. A., Some methods for the evaluation of a sum, J. Amer. Statist. Assoc. 39, 511 (1944).

M 6, 162

Aroian, L. A., Note on the cumulants of Fisher's z-distribution, Biometrika 34, 359 (1947).

M 9, 601

-Aroian, L. A., The effectiveness of quality control charts, J. Amer. Statist. Assoc. 45, 520 (1950).

M 15, 142

Aspin, A. A., An examination and further development of a formula arising in the problem of comparing two mean values, Biometrika 35, 88 (1948).

M 9, 600

Aspin, A. A., Tables for use in comparisons whose accuracy involves two variances, separately estimated, Biometrika 36, 290 (1949). $\quad$ M 11, 527 
Ayant, Y., L'extension à une variable quantique des notions de fonction de corrélation et de densité spectrale, C. R. Acad. Sci. Paris 238, 990 (1954).

M 15, 545

Ayer, M., An empirical distribution function for sampling with incomplete information, Ann. Math. Statist. 26, 641 (1955).

M 1\%, 504

Azorín Poh, F., Conferencias de preparacion matematica y estadistica. (Introductory Lectures in Mathematics and Statistics). (Instituto Nacional de Estadistica, Madrid, 1950).

M 13, 259

Babbar, M. M., Distributions of solutions of a set of linear equations (with an application to linear programming), J. Amer. Statist. Assoc. 50, 854 (1955).

M 1\%, 380

Bacon, H. M., Note on a formula for the multiple correlation coefficient, Ann. Math. Statist. 9, 227 (1938).

Z 19, 354

Baer, R., Sampling from a changing population, Ann. Math. Statist. 16, 348 (1945). M $\quad$ \%, 317

Bahadur, R. R., On a problem in the theory of $k$ populations, Ann. Math Statist. 21, 362 (1950).

M 12, 117

-Bahadur, R. R., The problem of the greater mean, Ann. Math. Statist. 21, 469 (1950).

M 12, 428

Bahadur, R. R., A property of the $t$-statistic, Sankhyā 12, 79 (1952).

M 14, 888

Bahadur, R. R., Sufficiency and statistical decision functions, Ann. Math. Statist. 25, 423 (1954).

M 16, 154

Bailey, N. T. J., Some problems in the statistical analysis of epidemic data, J. Roy. Statist. Soc. Ser. B. 1\%, 35 (1955).

M 1\%, 381

Baker, G. A., The relation between the means and variances, means squared and variances in samples from combinations of normal populations, Ann. Math. Statist. 2, 333 (1931). Z 4, 265

Baker, G. A., Distribution of the means divided by the standard deviations of samples from nonhomogeneous populations, Ann. Math. Statist. 3, 1 (1932).

$\mathrm{Z}$ 4, 265

Baker, G. A., Transformation of non-normal frequency distributions into normal distributions, Ann. Math. Statist. 5, 113 (1934). Z 9, 266

Baker, G. A., Note on the distributions of the standard deviations and second moments of samples from a Gram-Charlier population, Ann. Math. Statist. 6, 127 (1935).

Z 12, 363

Baker, G. A., The probability that the mean of a second sample will differ from the mean of a first sample by less than a certain multiple of the standard deviation of the first sample. Ann. Math. Statist. 6, 197 (1935). Z 13, 174

Baker, G. A., Correlation surfaces of two or more indices when the components of the indices are normally distributed, Ann. Math. Statist. 8, 179 (1937).

Z 18, 226

Baker, G. A., The probability that the standard deviation of a second sample will differ from the standard deviation of a first sample by a certain multiple of the standard deviation of the first sample, Metron 13, 49 (1938).

Z 20, 244
Baker, G. A., Maximum likelihood estimation of the ratio of the components of non-homogeneous populations, Tôhoku Math. J. 4\%, 304 (1940). M 3, 7

Baker, G. A., Test of homogeneity for normal populations, Ann. Math. Statist. 12, 233 (1941). M 3, 7

Baker, G.A., Distribution of the ratio of sample range to sample deviation for normal and combinations of normal distributions, Ann. Math. Statist 1\%, 366 (1946).

M 8, 43

Baker, G. A., The variance of the proportions of samples falling within a fixed interval for a normal population, Ann. Math. Statist. 20, 123 (1949).

M 10, 466

Baldwin, E. M., Table of percentage points of the $t$-distribution, Biometrika 33, 362 (1946) M 8, 42

Bancroft, T. A., On biases in estimation due to the use of preliminary tests of significance, Ann. Math. Statist. 15, 190 (1944).

M 6, 10

-Banerjee, K. (See S. N. Roy) Science and Culture 6, 189 (1940).

Barankin, E. W., Extension of the RomanovskyBartlett-Scheffé test, Proc. Berkeley Symp. Math. Stat. \& Prob., pp. 433-449 (1949). M 10. 467 Barankin, E. W., Locally best unbiased estimates, Ann. Math. Statist. 20, 477 (1949). M 11, 529

Barankin, E. W., Extension of a theorem of Blackwell, Ann. Math. Statist. 21, 280 (1950).

M 11, 732

-Barankin, E. W., On asymptotically normal, efficient estimators. I, Univ. California Publ. Statist. 1, 89 (1951).

M 13, 53

Barankin, E. W., On systems of linear equations, with applications to linear programming and the theory of tests of statistical hypotheses, $U$. Calif. Publ. Statist. 1, 161 (1951).

M 14, 190

Barankin, E. W., Conditional expectation and convex functions, Proc. Second Berkeley Symp. Math. Stat. \& Prob., pp. 167-169 (1951). M 13, 570

Barankin, E. W., Concerning some inequalities in the theory of statistical estimation, Skand. Aktuarietidskr. 34, 35 (1951).

M 13, 142

Barnard, G. A., The meaning of a significance level, Biometrika 34, 179 (1947).

M 8, 395

Barnard, G. A., Statistical inference, J. Roy. Statist. Soc. Ser. B 11, 115 (1949).

M 11, 672

Barnard, G. A., On the Fisher-Behrens test, Biometrika 3\%, 203 (1950).

M 13, 260

Barnard, G. A., The frequency justification of certain sequential tests, Biometrika 39, 144 (1952).

M 14, 65

Barnard, G. A., Sampling inspection and statistical decisions, J. Roy. Statist. Soc. Ser. B 16, 151 (1954).

M 16, 1133

Bartholomew, D. J., A sequential test for randomness of intervals, J. Roy. Statist. Soc. B 18, 95 (1956).

M 18, 243

Bartky, W., Multiple sampling with constant probability, Ann. Math. Statist. 14, 363 (1943).

- Bartlett, M. S., (See J. Wishart). Proc. Cambridge Philos. Soc. 28, 455 (1932).

Bartlett, M. S., On the theory of statistical regression, Proc. Roy. Soc. Edinburgh 53, 260 (1933).

Z 8, 24 
Bartlett, M. S., The problem in statistics of testing several variances, Proc. Cambridge Philos. Soc. 30, 164 (1934).

$\mathrm{Z} \mathbf{9}, 121$

Bartlett, M. S., The vector representation of a sample, Proc. Cambridge Philos. Soc. 30, 327 (1934).

$\mathrm{Z} \mathbf{1 0}, 71$

Bartlett, M. S., Statistical information and properties of sufficiency, Proc. Roy. Soc. London A 154, 124 (1936).

Z 13, 313

Bartlett, M. S., The information available in small samples, Proc. Cambridge Philos. Soc. 32, 560 (1936).

Z 15, 361

Bartlett, M. S., Properties of sufficiency and statistical tests, Proc. Roy. Soc. London A 160, 268 (1937).

$\mathrm{Z} \mathbf{1 6}, 412$

Bartlett, M. S., Sub-sampling for attributes. $J$ Roy. Statist. Soc. Suppl. 4, 131 (1937). Z Z 19, 35

Bartlett, M. S., A note on tests of significance in multivariate analysis, Proc. Cambridge Philos. Soc. 35, 180 (1939).

Z 23, 342

Bartlett, M. S., Complete simultaneous fiducial distributions, Ann. Math. Statist. 10, 129 (1939).

Z 22, 249

Bartlett, M. S., A note on the interpretation of quasi-sufficiency, Biometrika 31, 391 (1940).

M 1, 347

Bartlett, M. S., The statistical significance of canonical correlations, Biometrika 32, 29 (1941).

M 2,235

Bartlett, M. S., A modified probit technique for small probabilities, J. Roy. Statist. Soc. Suppl. 8, 113 (1946).

M 8, 283

-Bartlett, M. S., The statistical analysis of varianceheterogeneity and the logarithmic transformation, J. Roy. Statist. Soc. Suppl. 8, 128 (1946).

M 8, 474

Bartlett, M. S., The general canonical correlation distribution, Ann. Math. Statist. 18, 1 (1947).

M 8, 474

Bartlett, M. S., The use of transformations, Biometrics 3, 39 (1947).

M 8, 593

Bartlett, M. S., Multivariate analysis, J. Roy. Statist. Soc. Suppl. 9, 176 (1947). $\quad$ M 9, 453

Bartlett, M. S., The effect of standardization on a $\chi^{2}$ approximation in factor analysis. (With an appendix by W. Ledermann), Biometrika 38, 337 (1951).

M 14, 66

Bartlett, M. S., The frequency goodness of fit test for probability chains, Proc. Cambridge Philos. Soc. 4\%, 86 (1951).

M 12, 512

Bartlett, M. S., A sampling test of the $\chi^{2}$ theory for probability chains, Biometrika 39, 118 (1952).

M 13, 962

Bartlett, M. S., The statistical significance of odd bits of information, Biometrika 39, 228 (1952).

M 14, 666

Bartlett, M. S., Approximate confidence intervals, Biometrika 40, 12 (1953).

M 15, 142

Bartlett, M. S., Approximate confidence intervals. III, Biometrika 42, 201 (1955).

M 16, 1133

Barton, D. E., On Neyman's smooth test of goodness of fit and its power with respect to a particular system of alternatives, Skand. Aktuarietidskr. 36, 24 (1953).

M 15, 453
Barton, D. E., Tests for randomness of points on a line, Biometrika 43, 104 (1956). M 1\%, 982

Barton, D. E., A class of distributions for which the maximum-likelihood estimator is unbiased and of minimum variance for all sample sizes, Biometrika 43, 200 (1956). M 1\%, 1220

Basu, D., A note on the power of the best critical region for increasing sample size, Sankhyā 11, 187 (1951).

M 13, 480

Basu, D., An example of non-existence of a minimum variance estimator, Sankhyā 12, 43 (1952).

M 14, 996

Basu, D., On symmetric estimators in point estimation with convex weight functions, Sankhyā 12, 45 (1952).

M 14, 1103

Basu, D., On a class of admissable estimators of the normal variance, Sankhyā 12, 57 (1952).

M 15, 142

Basu, D., On the minimax approach to the problem of estimation, Proc. Nat. Inst. Sci. India 18, 287 (1952).

M 14, 666

Basu, D., Choosing between two simple hypotheses and the criterion of consistency, Proc. Nat. Inst. Sci. India 19, 841 (1953).

M 15, 811

Basu, D., On the optimum character of some estimators used in multistage sampling problems, Sankhyā 13, 363 (1954).

Basu, D.. The concept of asymptotic efficiency Sankhyā 1\%, 193 (1956). M 18,607

Basu, D., On statistics independent of a complete sufficient statistic, Sankhyā 15, 377 (1955).

M 1\%, 640

Basu, D., An inconsistency of the method of maximum likelihood, Ann. Math. Statist. 26, 144 (1955).

M 1\%, 170

Bateman, G. I., The characteristic function of a weighted sum of non-central squares of normal variates subject to $s$ linear restraints, Biometrika 36, 460 (1949).

M 11, 608

Bateman, G. I., The power of the $\chi^{2}$ index of dispersion test when Neyman's contagious distribution is the alternate hypothesis, Biometrika $\mathbf{3 \%}, 59$ (1950).

M 12, 117

Baten, W. D., Frequency laws for the sum of $n$ variables which are subject each to given frequency laws, Metron. 10, 75 (1932).

$\mathrm{Z} \mathbf{5}, 256$

Baticle, E., Sur une loi de probabilité a priori pour l'interprétation des résultats de tirages dans une urne, C. R. Acad. Sci. Paris 228, 902 (1949).

M 10, 550

Baticle, E., L'interprétation des résultats d'essais sur échantillon, Génie Civil 12\%, 246 (1950).

M 12, 38

Bayes, T., Two papers by Bayes (Prepared under direction of W. Edwards Deming; U.S. Department of Agriculture, Washington, D.C., 1940).

M 2,108

Beall, G., The transformation of data from entomological field experiments so that the analysis of variance becomes applicable, Biometrika 32, 243 (1942).

M 4, 23

Bejar, J., Remarks on best allocation, Trabajos Estadistica 1, 111 (1950).
M 13, 367 
Belevitch, V., Théorie de l'information et statistique linguistique, Acad. Roy. Belg. Bull. Cl. Sci. 4\%, 419 (1956).

M 18, 79

Bellinson, H. R., The distribution of the estimate of standard deviation obtained by the method of successive differences (Ballistic Res. Lab., Aberdeen Proving Ground, Md., Report 200, 1940).

M 1\%, 37

Bellinson, H. R. (See J. vonNeumann), Ann. Math. Statist. 12, 153 (1941).

Benard, A., Guide to Wilcoxon's test for symmetry, Math. Centrum Amsterdam Statist. Rap. S $\mathbf{2 0 8}$ (M \%6) (1956). M 18, 682

-Bernard, A. (See C. van Eeden), Math. Centrum Amsterdam Statist. Rap. S 209 (VP 10) (1956).

Bennett, B. M., Note on a solution of the generalized Behrens-Fisher problem, Ann. Inst. Statist. Math. Tokyo $\boldsymbol{2}, 87$ (1951).

M 1\%, 842

Bennett, B. M., Estimation of means on the basis of preliminary tests of significance, Ann. Inst. Statist. Math. Tokyo 4, 31 (1952). M 14, 665

Bennett, B. M., On the use of preliminary tests in certain statistical procedures, Ann. Inst. Statist. Math. Tokyo 8, 45 (1956).

M 18, 607

-Berger, A., On distinct hypotheses, Ann. Math. Statist. 20, 104 (1949).

M 10, 723

Berger, A., On uniformly consistent tests, Ann. Math. Statist. 22, 289 (1951). $\quad$ M 13, 143

Berkson, J., Some difficulties of interpretation encountered in the application of the chi-square test, J. Amer. Statist. Assoc. 33, 526 (1938).

Z 19, 177

Berkson, J., A note on the chi-square test, the Poisson and the binomial, J. Amer. Statist. Assoc. 35, 362 (1940).

M 1, 347

Berkson, Estimation by least squares and by maximum likelihood, Proc. Third Berkeley Symp. Math. Stat. \& Prob. I, 1 (1956).

M 18, 945

Bernstein, S., On "fiducial" probabilities of Fisher, Bull. Acad. Sci. USSR Ser. Math. 5, 85 (1941).

M 3, 7

Bhapkar, V. P., A note on $t$ test for paired samples, Calcutta Statist. Assoc. Bull. 5, 142 (1954).

M 16, 384

Bhattacharyya, D. P., Moments of the $D^{2}$-statistic for populations with unequal dispersions, Sankhy $\bar{a}$ 5, 401 (1941).

M 4, 105

Bhattacharyya, A., On a measure of divergence between two statistical populations defined by their probability distributions, Bull. Calcutta Math. Soc. 35, 99 (1943).

M 6, 7

Bhattacharyya, A., On a measure of divergence between two multinomial populations, Sankhya y, 401 (1946).

M 8, 282

Bhattacharyya, A., On some analogues of the amount of information and their use in statistical estimation, Sankhyā 8, 1 (1946).

M 8, 524

Bhattacharyya, A., On some analogues of the amount of information and their use in statistical estimation. II, Sankhyā 8, 201 (1947).

M 9, 365

Bhattacharyya, A., On some analogues of the amount of information and their use in statistical estimation (concluded), Sankhyā 8, 315 (1948).

M 10, 135
Bhattacharyya, A., Unbiased statistics with minimum variance, Proc. Roy. Soc. Edinburgh 63, 69 (1950).

M 1\%, 36

Bhattacharyya, M. N. Estimation from censored bivariate samples, J. Indian Soc. Agric. Statist. 6, 83 (1954).

M 1\%, 639

Bhattacharyya, A., Notes on the use of unbiased and biased statistics in the binomial population, Calcutta Statist. Assoc. Bull. 5, 149 (1954).

M 16, 727

Bhattacharya, P. K. Joint test for the mean and variance of a normal population, Calcutta Statist. Assoc. Bull. 6, 73 (1955).

M 1\%, 757

Bilimowitčh, A. D., Elementare Korrelationstheorie, Zap. russk. naučn. Inst. Beograd 1\%, 45 (1937).

Z 20,146

Billingsley, P., Asymptotic distributions of two goodness of fit criteria, Ann. Math. Statist. 28, 1123 (1956).

M 18, 607

Binet, F. E., The fitting of the positive binomial distribution when both parameters are estimated from the sample, Ann. Eugenics 18, 117 (1953).

M 15, 240

Birnbaum, Z. W. On the distribution of Kolmogorov's statistic for finite sample size, Proc. Seminar on Scientific Computation, pp. 33-36 (IBM CORP, N.Y., 1950).

M 13, 571

Birnbaum, Z. W., On the effect of the cutting score when selection is performed against a dichotomized criterion, Psychometrika 15, 385 (1950).

M 12, 510

Birnbaum, Z. W. On optimum selections from multinormal populations, Ann. Math. Statist. 21, $443(1950)$

M 1\%, 271

Birnbaum, Z. W., On the power of a one-sided test of fit for continuous probability functions, Ann. Math. Statist. $\mathbf{2 4}, 484$ (1953).

M 15, 47

Birnbaum, A., Some procedures for comparing Poisson processes or populations, Biometrika 40, 447 (1953).

M 15, 331

Birnbaum, A., Combining independent tests of significance, J. Amer. Statist. Assoc. 49, 559 (1954).

M 16, 383

Birnbaum, A., Admissible tests for the mean of a rectangular distribution, Ann. Math. Statist. 25, 157 (1954).

M 15, 637

Birnbaum, A., Characterizations of complete classes of tests of some multiparametric hypotheses, with applications to likelihood ratio tests, Ann. Math. Statist. 26, 21 (1955).

M 16, 729

$\checkmark$ Bishop, D. J., A note on certain methods of testing for the homogeneity of a set of estimated variances, J. Roy. Statist. Soc. Suppl., 6, 89 (1939).

Z 21, 147

Bishop, D. J., On a comprehensive test for the homogeneity of variances and covariances in multivariate problems, Biometrika 31, 31 (1939).

M 1, 64

Blackwell, D., On the translation parameter problem for discrete variables, Ann. Math. Statist. 22, 393 (1951).

M 13, 260

Blank, A. A., Existence and uniqueness of a uniformly most powerful randomized unbiased test for the binomial, Biometrika 43, 465 (1956). M 18, 426 
Blum, J. R., Multidimensional stochastic approximation methods, Ann. Math. Statist. 25, 737 (1954).

M 16, 382

-Blum, J. R., Consistency of certain two-sample tests, Ann. Math. Statist. 28, 242 (1957).

M 18, 956

Blyth, C. R., On minimax statistical decision procedures and their admissibility, Ann. Math. Statist. 22, 22 (1951).

M 12, 622

de Boer, J., Sequential test with three possible decisions for testing an unknown probability, Appl. Sci. Research B 3, 249 (1953). M 15, 727

Bose, C., The variance of the forecasted mean value subjecting to two-way fluctuations, Science and Culture \%, 514 (1942).

M 5, 210

Bose, C., Note on the sampling error in the method of double sampling, Sankhyā 6, 329 (1943).

M 5, 210

Bose, C., Note on the expected discrepancy in the estimation (by double sampling) of a variate in terms of a concomitant variate when there exists a non-linear regression between the two variates, Sankhyā 8, 73 (1946).

M 8, 476

Bose, C.. Some further results on errors in double sampling technique, Sankhyā 11, 191 (1951).

M 13, 570

Bose, P. K., Parametric relations in multivariate distributions, Sankhyā 8, 167 (1947). M 10, 135

Bose, R. C., (See S. N. Roy), Sankhyā 4, 535 (1940).

-Bose, P. K., (See S. N. Roy), Calcutta Statist. Assoc. Bull. 1, No. 4, 177 (1948).

-Bose, R. C., (See S. N. Roy), Ann. Math. Statist. 24, 513 (1953).

Bosworth, R. C. L., Bessel's formula in relation to the calculation of the probable error from a small number of observations, J. Proc. Roy. Soc. New South Wales 88, 81 (1944).

M 6, 162

Bouchman, E. N., Diagrams for the number of observations required for determining average values in statistical investigations, Appl. Math. a Mech., Moskau 2, 529 (1939).

Z 23, 243

Bowker, A. H., Note on consistency of a proposed test for the problem of two samples, Ann. Math. Statist. 15, 98 (1944).

M 6, 10

Box, G. E. P., A general distribution theory for a class of likelihood criteria, Biometrika $\mathbf{3 6}, 317$ (1949).

M 11, 447

Box, G. E. P., Non-normality and tests on variances, Biometrika 40, 318 (1953).

M 15, 453

Box, G. E. P., A note on regions for tests of kurtosis, Biometrika 40, 465 (1953).

M 15, 332

$\checkmark$ Box, G. E. P., A confidence region for the solution of a set of simultaneous equations with an application to experimental design, Biometrika 41, 190 (1954).

M 15, 971

Bracewell, R. N., Correcting for running means by successive substitutions, Austral. J. Phys. 8, 329 (1955).

M 1\%, 1101

Breny, H., L'état actuel du problème de BehrensFisher, Trabajos Estadist. 6, 111 (1955).

M 1\%, 868

Bridger, C. A., Note on regression functions in the case of three second order random variables, Ann. Math. Statist. 9, 309 (1938).
Broadbent, S. R., Quantum hypotheses, Biometrika 42, 45 (1955).

M 16, 940

Brodovitskij, K., Sur le problème de ressemblance dans la théorie des échantillons statistiques, Acta Univ. Asiae Mediae. Ser. V-a 20, (1939).

M 8, 475

Brodovitskij, K., Sur les conditions nécessaires et suffisantes pour les probabilités a priori aient une raison d'être, Acta Univ Asiae Mediae Ser. V-a 19, (1939).

M 8, 476

den Broeder, G. G., On parameter estimation for truncated Pearson type III distributions, $A n n$. Math. Statist. 26, 659 (1955). $\quad$ M 1\%, 639

$\checkmark$ Brookner, R. J., (See A. Wald), Ann. Math. Statist. 12, 137 (1941).

Brookner, R. J., Choice of one among several statistical hypotheses, Ann. Math. Statist. 16, 221 (1945).

M 8, 475

Bross, I., Misclassification in $2 \times 2$ tables, Biometrics 10, 478 (1954).

M 16, 942

Brown, G. W., On the power of the $L_{1}$ test for equality of several variances, Ann. Math. Statist. 10, 119 (1939).

Z 22, 249

$\checkmark$ Brown, G. W., Some distributions of sample means, Ann. Math. Statist. 1\%, 1 (1946).

M $\boldsymbol{y}, 463$

Brown, G. W., On small-sample estimation, Ann. Math. Statist. 18, 582 (1947). $\quad$ M 9, 195

Brown, L. M., Some parameters of sampling distributions simply obtained, Edinburgh Math. Notes No. 34, 8 (1944).

M 6, 91

Brown, T. M., Standard errors of forecast of a complete econometric model, Econometrica 22, 178 (1954).

M 16, 55

Brunk, H. D., Maximum likelihood estimates of monotone parameters, Ann. Math. Statist. 26, 607 (1955).

M 1\%, 504

$\checkmark$ Brunk, H. D., (See M. Ayer), Ann. Math. Statist. 26, 641 (1955).

Buch, K. R., A minimum problem in abstract space, Mat. Tidsskr. B 1945, 30 (1945). $\quad$ M 7, 197

Burr, I. W., Calculation of exact sampling distribution of ranges from a discrete population, $A n n$. Math. Statist. 26, 530 (1955).

M 17, 278

Burrau, Ø., The mean error as a measure of uncertainty, Mat. Tidsskr. B 1943, 9 (1943). M \%, 130

Burrau, Ø., On the determination of the mean error, Mat. Tidsskr. B 1945, 97 (1945). $\quad$ M \%, 211

Bystrov, N. F., On some unbiased estimates, Vestnik, Leningrad Univ. 11, 169 (1956).

M 17, 869

Camp, B. H., Methods of obtaining probability distributions, Ann. Math. Statist. 8, 90 (1937).

$\mathrm{Z} \mathbf{1 \%}, 125$

Camp, B. H., Further interpretations of the chisquare test, J. Amer. Statist. Assoc. 33, 537 (1938).

$\mathrm{Z} \mathrm{19,}, 177$

Camp, B. H., Further comments on Berkson's problem, J. Amer. Statist. Assoc. 35, 368 (1940).

M 1, 347

Camp, B. H., Some recent advances in mathematical statistics, I, Ann. Math. Statist. 13, 62 (1942).

M 4, 24 
Camp, B. H., The effect on a distribution function of small changes in the population function, $A n n$. Math. Statist. 1\%, 226 (1946).

M 8, 44

Cansado, E., Conferencias sobre muestreo estadistico. (Lectures on Sampling Statistics), (Instituto Nacional de Estadistica, Madrid, 1950).

-Cansado, E. (See F. Azorín Poh) (Instituto Nacional de Estadistica, Madrid, 1950).

-Carlson, P. G. (See E. J. Gumbel) Metron 18, 113 (1956).

Carpenter, O., Note on the extension of Craig's theorem to non-central variates, Ann. Math. Statist. 21, 455 (1950).

M 12, 621

Carter, W. H., A practical experiment with frequencies and probabilities, J. Inst. Actuar. 64, 465 (1933).

Z 8, 123

Carter, A. H., Approximation to percentage points of the z-distribution, Biometrika 34, 352 (1947).

M 9, 364

Carver, H. C., Fundamentals of the theory of sampling, Ann. Math. Statist. 1, 101 (1930).

Cavé, R., Perfectionnement des méthodes modernes de contrôle statistique par mesures, $C$. R. Acad. Sci. Paris 234, 2145 (1952).

M 13, 853

Čentsov, N., La convergence faible des processus stochastiques a trajectoires sans discontinuités de seconde espèce et l'approche dite "heuristique" au tests du type de Kolmogorov-Smirnov, Teor. Veroyatnost. i Primenen. 1, 155 (1956). M 18, 831

Chakrabarti, M. C., On a special case of the distribution law of the mean square successive difference, Bull. Calcutta Math. Soc. 39, 15 (1947). M 9, 195

-Chakraborty, P. N., (See C. Chandra Sekar), Sankhyā 15, 381 (1955).

Chakravarti, I. M., Use of the analysis of covariance in two-stage sampling, Calcutta Statist. Assoc. Bull. 4, 127 (1952).

M 14, 777

-Chakravarti, I. M., (See C. R. Rao), Biometrics 12, 264 (1956).

Chand, U., Formulas for the percentage points of the distribution of the arithmetic mean in random samples from certain symmetrical universes, $J$. Research Nat. Bur. Standards 43, 79 (1949).

M 11, 259

Chand, U., Distributions related to comparison of two means and two regression coefficients, Ann. Math. Statist. 21, 507 (1950).

M 12, 428

Chand, U., Test criteria for hypotheses of symmetry of a regression matrix, Ann. Math. Statist. 22, 513 (1951).

M 13, 367

Chand, U., On the derivation and accuracy of certain formulas for sample sizes and operating characteristies of nonsequential sampling procedures, J. Research Nat. Bur. Standards 47, 491 (1951).

M 15, 637

Chanda, K. C., Comparative efficiencies of $L$-test and Pitman's test in testing for equality of variances, Bull. Inst. Internat. Statist. 23, 215 (1951).

M 16, 842

Chanda, K., A note on the comparative efficiencies of selection of sampling units with and without replacement, Science and Culture 18, 288 (1952).
Chanda, K. C., A note on the consistency and maxima of the roots of likelihood equations, Biometrika 41, 56 (1954).

M 16, 55

Chanda, K. C., On some aspects of nonregular testing of hypotheses, Calcutta Statist. Assoc. Bull. 6, 95 (1955).

M 1\%, 1220

-Chandra Sekar, C., A method to get the significance limit of a type of test criteria, Sankhya $\mathbf{5}$, 165 (1941).

M 4, 165

Chandra Sekar, C., A note on the inverse sine transformation, Sankhyā 6, 195 (1942).

M 5, 43

$\checkmark$ Chandra Sekar, C., On the power function of a test of significance for the difference between two proportions, Sankhyā 15, 381 (1955). M 17, 758

Chapman, D. G., Some two sample tests, Ann. Math. Statist. 21, 601 (1950). M 13,260

Chapman, D. G. (See Z. W. Birnbaum), Ann. Math. Statist. 21, 443 (1950).

-Chapman, D. G., Minimum variance estimation without regularity assumptions, Ann. Math. Statist. 22, 581 (1951).

M 13, 367

Chapman, D. G., On tests and estimates for the ratio of Poisson means, Ann. Inst. Statist. Math., Tokyo 4, 45 (1952).

M 14, 488

Chapman, D. G., The estimation of biological populations, Ann. Math. Statist. 25, 1 (1954). M 15, 810

Chapman, D. G., Population estimation based on change of composition caused by a selective removal, Biometrika 42, 279 (1955).

M 17, 504

-Chapman, D. G., The estimation of the size of a stratified animal population, Ann. Math. Statist. 2\%, 375 (1956).

M 18, 159

Charnley, F., Some properties of a composite, bivariate distribution in which the means of the component normal distributions are linearly related, Canadian J. Research Sect. A 19, 139 (1941).

M 3, 172

Chassan, J. B. A statistical derivation of a pair of trigonometric inequalities, Amer. Math. Monthly 62, 353 (1955).

M 16, 1090

Cheriyan, K. C., Distributions of certain frequency constants in samples from non-normal populations, Sankhyā \%, 159 (1945).

M 7, 317

$\checkmark$ Chernoff, H., The estimation of the location of a discontinuity in density, Proc. Third. Berkeley Symp. Math. Stat. \& Prob. I, 19 (1956).

M 18, 946

Chernoff, H., Large-sample theory: parametric case, Ann. Math. Statist. 2\%, 1 (1956). $\quad$ M 1\%, 869

Chernoff, H., Asymptotic Studentization in testing of hypotheses, Ann. Math. Statist, 20, 268 (1949).

M 10, 723

-Chernoff, H., A generalization of the NeymanPearson fundamental lemma, Ann. Math. Statist., 23, 213 (1952).

M 13, 963

Chernoff, H., A property of some type A regions, Ann. Math. Statist. 22, 472 (1951). M 13, 142

Chernoff, H., A measure of asymptotic efficiency for tests of a hypothesis based on the sum of observations, Ann. Math. Statist. 23, 493 (1952).

M 15, 241

Chernoff, H., Locally optimal designs for estimating parameters, Ann. Math. Statist. 24, 586 (1953). 
$\downarrow$ Chernoff, H., The use of maximum likelihood estimates in $\chi^{2}$ tests for goodness of fit, $A n n$. Math. Statist. 25, 579 (1954).

M 16, 384

$\checkmark$ Cheston, W., (See M. Annis), Rev. Modern Physics 25, 818 (1953).

Choudhury, P., Sur un test d'indépendance des moyennes et des écarts types d'échantillons extraits d'une population normale, Publ. Inst. Statist. Univ. Paris 1, 41 (1952).

M 15, 810

Choudhury, P., A note on testing of normality, Science and Culture 19, 453 (1954). M 15, 637

Chowdhury, S. B., The most powerful unbiased critical regions and the shortest unbiased confidence intervals associated with the distribution of classical $D^{2}$-statistic, Sankhyā 14, 71 (1954).

M 16, 383

$\checkmark$ Chown, L. N., Rapid methods for estimating correlation coefficients, Biometrika 38, 464 (1951).

M 13, 667

$\checkmark$ Chu, J. T., The moments of the sample median, Ann. Math. Statist. 26, 593 (1955). M 1\%, 502

$\mathrm{Chu}$, J. T., Errors in normal approximations to the t, $\tau$, and similar types of distribution, Ann. Math. Statist. 2\%, 780 (1956).

M 18, 423

Chung, K. L., The approximate distribution of Student's statistic, Ann. Math. Statist. 1\%, 447 (1946).

M 8, 283

Claringbold, P. J., Matrices in quantal analysis, Biometrics 11, 481 (1955).

M 1\%, 982

-Churchman, G. W., (See B. Epstein) Ann. Math. Statist. 15, 90 (1944).

Cochran, W. G., The distribution of quadratic forms in a normal system, with applications to the analysis of covariance, Proc. Cambridge Philos. Soc. 30, 178 (1934).

Z 9, 120

Cochran, W. G., The omission or addition of an independent variate in multiple linear regression, J. Roy. Statist. Soc. Suppl. 5, 171 (1938).

Z 19, 319

Cochran, W. G., The use of the analysis of variance in enumeration by sampling, J. Amer. Statist. Assoc. 34, 492 (1939).

Z 23, 149

Cochran, W. G., Note on an approximate formula for the significance levels of $z$, Ann. Math. Statist. 11, 93 (1940).

M 1, 249

Cochran, W. G., The analysis of variance when experimental errors follow the Poisson or binomial laws, Ann. Math. Statist. 11, 335 (1940). M ?, 111

Cochran, W. G., The distribution of the largest of a set of estimated variances as a fraction of their total, Ann. Eugenics 11, 47 (1941).

M 3, 171

Cochran, W. G., Sampling theory when the samplingunits are of unequal sizes, J. Amer. Statist. Assoc. 3\%, 199 (1942).

M 4, 24

Cochran, W. G., Analysis of variance for percentages based on unequal numbers, J. Amer. Statist. Assoc. 38, 287 (1943).

M 6, 92

Cochran, W. G., Relative accuracy of systematic and stratified random samples for a certain class of populations, Ann. Math. Statist. 1\%, 164 (1946).

M 8, 43

Cochran, W. G., Recent developments in sampling theory in the United States, Proc. Internat. Inst. Statist. III, 40 (1947).
Cochran, W. G., Some consequences when the assumptions for the analysis of variance are not satisfied, Biometrics 3, 22 (1947). $\quad$ M 8, 593

Cochran, W. G., Testing a linear relation among variances, Biometrics $\mathbf{7 ,} 17$ (1951). M 12,725

Cochran, W. G., Sampling Techniques, (John Wiley \& Sons, Inc., N.Y., 1953).

M 14, 887

Cochran, W. G., A test of a linear function of the deviations between observed and expected numbers, J. Amer. Statist. Assoc. 50, 377 (1955).

M 16, 1133

Cohen, A. C., Estimating the mean and variance of normal populations from singly truncated and doubly truncated samples, Ann. Math. Statist. 21, 557 (1950).

M 12, 346

Cohen, A. C., Estimating parameters of logarithmicnormal distributions by maximum likelihood, J. Amer. Statist. Assoc. 46, 206 (1951). M 12, 841

Cohen, A. C., Estimation of parameters in truncated Pearson frequency distributions, Ann. Math. Statist. 22, 256 (1951).

M 12, 841

Cohen, A. C., On estimating the mean and variance of singly truncated normal frequency distributions from the first three sample moments, Ann. Inst. Statist. Math. Tokyo 3, 37 (1951).

M 13, 571

Cohen, A. C., Estimating parameters in truncated Pearson frequency distributions without resort to higher moments, Biometrika 40, 50 (1953).

M 14, 1103

Cohen, A. C., Restriction and selection in samples from bivariate normal distributions, J. Amer. Statist. Assoc. 50, 884 (1955). M 17, 639

Cohen, A. C., Maximum likelihood estimation of the dispersion parameter of a chi-distributed radial error from truncated and consored samples with applications to target analysis, J. Amer. Statist. Assoc. 50, 1122 (1955)

M 1\%, 381

Cohen, A. C., Consored samples from truncated normal distributions, Biometrika 42, 516 (1955).

M 1\%, 279

Conolly, B. W., Unbiased premiums for stop-loss reinsurance, Skand. Aktuarietidskr. 38, 127 (1955).

M 18, 343

Copeland, A. H., Probabilities, observations, and predictions, Proc. Third Berkeley Symp. Math. Stat. \& Prob. II, 41 (1956).

M 18, 940

Cornfield, J., On samples from finite populations, J. Amer. Statist. Assoc. 39, 236 (1944). M 6, 91

Cornfield, J., A statistical problem arising from retrospective studies, Proc. Third Berkeley Symp. Math. Stat. \& Prob. IV, 135 (1956).

M 18, 952

Court, L. M., A reciprocity principle for the NeymanPearson theory of testing statistical hypotheses, Ann. Math. Statist. 15, 326 (1944). M 6, 93

Cox, D. R., A note on the asymptotic distribution of range, Biometrika 35, 310 (1948). $\quad$ M 10, 466

Cox, D. R., Sequential tests for composite hypotheses, Proc. Cambridge Philos. Soc. 48, 290 (1952).

M 13, 854

Cox, D. R., Estimation by double sampling, Biometrika 39, 217 (1952).

M 14, 487

Cox, D. R., Some simple approximate tests for Poisson variates, Biometrika 40, 354 (1953).

M 15, 332 
-Cox, D. R., On the superposition of renewal processes, Biometrika 41, 91 (1954).

M 16, 55

-Cox, D. R., Some quick sign tests for trend in location and dispersion, Biometrika 42, 80 (1955).

M 16, 842

Cox, D. R., A note on the theory of quick tests, Biometrika 43, 478 (1956).

M 18, 426

Craig, A. T., On the distributions of certain statistics, Amer. J. Math. 54, 353 (1932). Z 4, 360

Craig, A. T., The simultaneous distribution of mean and standard deviation in small samples, Ann. Math. Statist. 3, 126 (1932).

$\mathrm{Z}$ 4, 360

Craig, A. T., A certain mean-value problem in statistics, Bull. Amer. Math. Soc. 42, 670 (1936).

Z 15, 118

Craig, A. T., Note on a certain bilinear form that occurs in statistics, Amer. J. Math. 58, 864 (1936).

Z 15, 73

Craig, A. T., On the mathematics of the representative method of sampling, Ann. Math. Statist. 10, 26 (1939).

Z 20, 383

Craig, A. 'T., A note on the best linear estimate, Ann. Math. Statist. 14, 88 (1943). M 4, 280

Craig, C. C., On the frequency function of $x y, A n n$. Math. Statist. \%, 1 (1936).

Z 13, 359

Craig, C. C., Note on the distribution of noncentral $t$ with an application, Ann. Math. Statist. 12, 224 (1941).

M 3, 9

Craig, C. C., On frequency distributions of the quotient and of the product of two statistical variables, Amer. Math. Monthly 49, 24 (1942).

M 3, 171

Craig, C. C., Combination of neighboring cells in contingency tables, J. Amer. Statist. Assoc. 48, 104 (1953).

M 14, 776

Cramér, H., Mathematical Methods of Statistics, (Princeton University Press, Princeton, N.J., 1946).

M 8, 39

Cramér, H., A contribution to the theory of statistical estimation, Skand. Aktuarietidskr. 99, 85 (1946).

M 8, 163

Creasy, M. A., Confidence limits for the gradient in the linear functional relationship, J. Roy. Statist. Soc. B 18, 65 (1956).

M 18, 426

Curtiss, J. H., Generating functions in the theory of statistics, Amer. Math. Monthly 48, 374 (1941).

M 3, 5

Curtiss, J. H., On transformations used in the analysis of variance, Ann. Math. Statist. 14, 107 (1943).

M 5, 128

Curtiss, J. H., A note on some single sampling plans requiring the inspection of a small number of items, Ann. Math. Statist. 1\%, 62 (1946).

M $\boldsymbol{g}, 465$

Curtiss, J. H., Acceptance sampling by variables, with special reference to the case in which quality is measured by average or dispersion, $J$. Research Nat. Bur. Standards 39, 271 (1947).

M 9.366

Dalcher, A., Statistische Schätzungen mit Quantilen, Mitt. Verein. Schweiz. Versich. Math. 55, 475 (1955),

M 1\%, 641

Dalenius, T., The problem of optimum stratification, Skand. Aktuarietidskr. 33, 203 (1950). M 13, 53
-Dalenius, T., The problem of optimum stratification. II, Skand. Aktuarietidskr. 34, 133 (1951).

M 14, 64

Dalenius, T., Eine einfache geometrische Veranschaulichung der Theorie des geschichteten Stichprobenverfahrens, Mitteilungsblatt Math. Statist. 4, 121 (1952).

M 14, 191

Dalenius, T., The multi-variate sampling problem, Skand. Aktuarietidskr. 36, 92 (1953). M 15, 451

-Daly, J. F., (See S. S. Wilks) Ann. Math. Statist. 10, 225 (1939).

Daly, J. F., On the unbiased character of likelihoodratio tests for independence in normal systems, Ann. Math. Statist. 11, 1 (1940).

M 1, 347

Daly, J. F., On the use of the sample range in an analogue of Student's t-test, Ann. Math. Statist. 1\%, 71 (1946).

M $\boldsymbol{\gamma}, 464$

Daniels, H. E., The effect of departures from ideal conditions other than non-normality on the $t$ and $z$ tests of significance, Proc. Cambridge Philos. Soc. 34, 321 (1938).

Z 19, 227

Daniels, H. E., A method of improving certain routine measurements, J. Roy. Statist. Soc. Suppl. \%, 146 (1941)

M 4, 24

Daniels, H. E., A property of the distribution of extremes, Biometrika 32, 194 (1941). $\quad$ M 3, 171

Daniels, H. E., The relation between measures of correlation in the universe of sample permutations, Biometrika 33, 129 (1944).

M 6, 91

Dantzig, G. B., On the nonexistence of tests of "Student's" hypothesis having power functions independent of $\sigma, A n n$. Math. Statist. 11, 186 (1940).

M 1, 348

Dantzig, G. B., On the fundamental lemma of Neyman and Pearson, Ann. Math. Statist. 22, 87 (1951).

M 12, 622

Dantzig, G. B., Linear programming under uncertainty, Management Sci. 1, 197 (1955). M 17, 759

Darling, D. A., (See T. W. Anderson) Ann. Math. Statist. 23, 193 (1952).

- Darling, D. A., (See T. W. Anderson) J. Amer. Statist. Assoc. 49, 765 (1954).

Darmois, G., L'emploi des observations statistiques. Méthodes d'estimation, (Actualités Scient. et Industr. Nr. 356. Statistique Math.: Hermann \& Cie, Paris, 1936).

Z 16, 67

Darmois, G., Les mathématiques de la psychologie, Mémor. Sci. Math. Fasc. 98, (1940). M 3, 170

Darmois, G., Sur certaines lois de probabilité, $C$. $R$. Acad. Sci. Paris 222, 164 (1946). M $\quad$ \%, 462

Darmois, G., Résumés exhaustifs et problème du Nil, C. R. Acad. Sci. Paris 2R2, 266 (1946). M \%, 462

Darwin, J. H., The behaviour of an estimator for a simple birth and death process, Biometrika 43, 23 (1956).

M 1\%, 1102

Das, A. C., A note on the $D^{2}$-statistic when the variances and co-variances are known, Sankhya $\mathbf{8}$, 372 (1948).

M 10, 134

Das, A. C., Two-dimensional systematic sampling, Science and Culture 15, 157 (1949). M 11, 260

Das, A. C., Two-dimensional systematic sampling and the associated stratified and random sampling, Sankhyā 10, 95 (1950).
M 12, 37 
Das, A. C., Systematic sampling. Culture 15, 441 (1950).

II, Science and M 13, 762

Das, A. C., Systematic sampling. III, Science and Culture 15, 491 (1950).

M 12, 510

Das, A. C., On two-phase sampling and sampling with varying probabilities, Bull. Inst. Internat. Statist. Part II, 23, 105 (1951).

M 16, 940

Das, A. C., On some minimum-variance unbiassed estimates, Calcutta Statist. Assoc. Bull. 4, 166 (1953).

M 14, 1103

David, F. N., (See K. Pearson) Biometrika 24, 293 (1932).

David, F. N., On the $P_{\lambda n}$ test for randomness: Remarks, further illustration, and table of $P_{\lambda n}$ for given values of $-\log _{10} \lambda_{n}$, Biometrika $\mathbf{2 6 ,} 1$ (1934).

$\mathrm{Z} \mathrm{9,} 78$

David, F. N., Tables of the ordinates and probability integral of the distribution of the correlation coefficient in small samples, (Cambridge University Press XXXVIII, 55 pp., 1938).

$\mathrm{Z} \mathrm{19,} 74$

David, F. N., On Neyman's "smooth" test for goodness of fit. I. Distribution of the criterion $\psi^{2}$ when the hypothesis tested is true, Biometrika $\mathbf{3 1}$, 191 (1939).

M 1, 153

-David, F. N., The probability integral transformation when parameters are estimated from the sample, Biometrika 35, 182 (1948). M 10,51

David, F. N., Note on the application of Fisher's $k$-statistics, Biometrika 36, 383 (1949). M 11, 447

David, F. N., The moments of the $z$ and $F$ distributions, Biometrika 36, 394 (1949). M 11, 447

David, F. N., Probability Theory for Statistical Methods (Cambridge University Press, 1949).

M 10, 613

David, F. N., The probability irtegral transformation when the variable is discontinuous, Biometrika 3\%, 42(1950).

M 12, 115

David, F. N., A method of investigating the effect of nonnormality and heterogeneity of variance on tests of the general linear hypothesis, Ann. Math. Statist. 22, 382(1951).

M 13, 143

-David, F. N., The effect of nonnormality on the power function of the $F$-test in the analysis of variance, Biometrika 38, 43 (1951). M 13, 53

- David, F. N., The truncated Poisson, Biometrics 8, $275(1952)$.

M 14, 665

-David, F. N., Extension of a method of investigating the properties of analysis of variance tests to the case of random and mixed models, Ann. Math. Statist. 23, 594 (1952).

M 14, 488

David, F. N., The transformation of discrete variables, Ann. Human Genetics 19, 174 (1955).

M 16, 940

-David, F. N., (See D. E. Barton) Biometrika 43, 104 (1956).

David, H. A., A note on moving ranges, Biometrika 42, 512 (1955).

M 1\%, 503

David, H. A., Moments of negative order and ratiostatistics, J. Roy. Statist. Soc. B, 1\%, 122 (1955).

M 17, 278

David, H. A., On the application to statistics of an elementary theorem in probability, Biometrika $\mathbf{4 3}$, 85 (1956).
David, H. A., The ranking of variances in normal populations, J. Amer. Statist. Assoc. 51, 621 (1956).

M 18, 521

-David, H. T., The WAGR sequential $t$-test reaches a decision with probability one, Ann. Math. Statist. 9\%, 797 (1956).

M 18, 345

-Davies, R. O., The statistics of scaled random events, Proc. Cambridge Philos. Soc. 50, 575 (1954).

M 16, 272

Davis, R. C., Derivation of a broad class of consist. ent, Ann. Math. Statist. 21, 425 (1950).

M 12, 116

Davis, R. C., On minimum variance in nonregular estimation, Ann. Math. Statist. 22, 43 (1951).

M 12, 725

Davis, R. C., Note on uniformly best unbiased estimates, Ann. Math. Statist. 22, 440 (1951).

M 13, 259

Davis, H. T., The Analysis of Economic Time Series. (Principia Press, Bloomington, Ind., 1941).

M 3, 176

Deemer, W. I., (See D. F. Votaw) Psychometrika 15, $339(1950)$

- Deemer, W. L., Estimation of parameters of truncated or censored exponential distributions, Ann. Math. Statist. 26, 498 (1955).

M 1\%, 639

-Dehara, S., (See T. Kudō) J. Gakugei Tokushima U. Nat. Sci. Math. 6, 75 (1955).

Delaporte, P., Sur une utilisation systématique de la statistique mathématique en analyse factorielle, Colloq. Centre Nat. Recherche Scientifique, Paris, (1949).

M 11, 448

De Lury, D. B., Note on correlations, Ann. Math. Statist. 9, 149 (1938)

Z 19, 228

Deming, W. E., The Chi-test and curve fitting, J. Amer. Statist. Assoc. 29, 372 (1934). Z 10, 314

De Munter, P., Comparaison d'un ou de plusieurs échantillons $\dot{a}$ un échantillon de référence, Bull. Inst. Agronom. Sta. Rech. Gembloux 2\%, 224 (1954).

M 16, 842

De Munter, P., Fonction de puissance de certains tests du caractère aléatoire d'un échantillon, Acad. Roy. Belg. Bull. Cl. Sci. 42, 291 (1956).

M 17, 1220

De Munter, P., Sur différentes méthodes pour comparer les fonctions de puissance de tests statistiques, Acad. Roy. Belg. Bull. Cl. Sci. 42, 1159 (1956).

M 18, 956

Derksen, J. B. D., Probability-theoretical foundations of "regression-analysis," Nederl. Tijdschr. Naturk unde 8, 37 (1941).

M $\boldsymbol{7}, 317$

Des Raj., On estimating the parameters of normal populations from singly truncated samples, Ganita 3, 41 (1952).

M 14, 569

Des Raj., On moment estimation of the parameters of a normal population from singly and doubly truncated samples, Ganita 4, 79 (1953).

M 15, 241

Des Raj., On estimating the parameters of bivariate normal populations from doubly and singly linearly truncated samples, Sankhya $\mathbf{1 2}, 277$ (1953). 
Des Raj., On estimating the parameters of binormal populations from linearly turncated samples, Ganita 4, 147 (1953).

M 16, 498

Des Raj., Estimation of the parameters of type III populations from truncated samples, J.Amer. Statist. Assoc. 48, 336 (1953).

M 14, 1103

Des Raj., Truncated sampling from distributions admitting sufficient statistics, Sankhȳa 14, 169 (1954).

M 16, 603

Des Raj., On sampling with varying probabilities in multistage designs, Ganita 5, 45 (1954).

M 1\%, 170

Des Raj., Ratio estimation in sampling with equal and unequal probabilities, J. Indian Soc. Agric. Statist. 6, 127 (1954).

M 18, 682

Des Raj, On the method of overlapping maps in sample surveys, Sankhyā 1\%, 89 (1956). M 18, 606

Des Raj, A note on the determination of optimum probabilities in sampling without replacement, Sankhyā 1\%, 197 (1956).

M 18, 771

Des Raj, Some estimators in sampling with varying probabilities without replacement, J. Amer. Statist. Assoc. 51, 269 (1956.)

M 18, 521

Diananda, P. H., Note on some properties of maximum likelihood estimates, Proc. Cambridge Philos. Soc. 45, 536 (1949.)

M 11, 191

Dieulefait, C. E., Note on a method of sampling, Ann. Math. Statist. 13, 94 (1942).

M 4, 24

Dixon, W. J., Further contributions to the problem of serial correlation, Ann. Math. Statist, 15, 119 (1944).

M 6, 6

Dixon, W. J., Analysis of extreme values, Ann. Math. Statist. 21, 488 (1950).

M 12, 428

Dodd, E. L., Internal and external means arising from the scaling of frequency functions, Ann. Math. Statist. 8, 12 (1937).

Z 16, 365

Dodd, E., Some internal and external means arising from the location of frequency distributions, Acta Univ. Asiae Mediae. 23, 8 pp. (1939).

M 8, 523

Dodge, H. F., A sampling inspection plan for continuous production, Ann. Math. Statist. 14, 264 (1943).

Donsker M. D. Justification and extension of Doob's heuristic approach to the KolmogorovSmirnov theorems, Ann. Math. Statist. 23, 277 (1952).

M 13, 853

Doob, J. L. Probability and statistics, Trans. Amer. Math. Soc. 36, 759 (1934).

$\mathrm{Z} \mathbf{1 0}, 173$

Doob, J. L., The limiting distributions of certain statistics, Ann. Math. Statist, 6, 160 (1935).

Z 12, 268

Doob, J. L., Statistical estimation, Trans. Amer. Math. Soc. 39, 410 (1936).

$\mathrm{Z} \mathbf{1 4}, 169$

Doob, J. L., Heuristic approach to the KolmogorovSmirnov theorems, Ann. Math. Statist. 20, 393 (1949).

M 11, 43

Doob, J. L., Application of the theory of martingales, Colloq. Internat. Centre Nat. Rech. Sci. Paris 13, 23 (1949).

M 11, 444

-Doornbos, R., A slippage test for a set of Gammavariates, Math. Centrum Amsterdam Statist. Afdeling. Rep. 187 (VP 4) (1956). M 17, 641
Doornbos, R., Significance of the smallest of a se of estimated normal variances, Statistica, Neerlandica 10, 117 (1956).

M 18, 158

Doss, S., Sur une estimation exhaustive pour la moyenne d'une variable aléatoire obéissant à la loi de Laplace dans un espace de Banach, Publ. Inst. Statist. Univ. Paris 3, 135 (1954). M 16, 728

Douglas, J. B., Fitting the Neyman Type A (two parameter) contagious distribution, Biometrics 11, 149 (1955).

Downton, F., A note on ordered least-squares estimation, Biometrika 40, 457 (1953). M 15, 331

Downton, F., Least-squares estimates using ordered observations, Ann. Math. Statist. 25, 303 (1954).

M 15, 810

Dressel, P. L., Statistical seminvariants and their estimates with particular emphasis on their relation to algebraic invariants, Ann. Math. Statist. 11, 33 (1940).

M 1, 249

Dressel, P. L., A symmetric method of obtaining unbiased estimates and expected values, Ann. Math. Statist. 12, 84 (1941). M 2,233

-Dresselaers, C., Tests de signification pour hypothèses composées unilatérales, Acad. Roy. Belgique Bull. Cl. Sci. 3\%, 449 (1951).

M 13, 260

Drion, E. F., Estimation of the parameters of a straight line and of the variances of the variables, if they are both subject to error, Nederl. Akad. Wetensch. Proc. Ser. A 54, 256 (1951). M 13, 144

Dugué, D., Sur le maximum de précision des estimations gaussiennes à la limite, $C$. R. Acad. Sci. Paris 202, 193 (1936).

$\mathrm{Z}$ 13, 124

Dugué, D., Sur le maximum de précision des lois limites d'estimations, $C . R$. Acad. Sci., Paris 202, 452 (1936).

$\mathrm{Z} \mathrm{13,} 174$

Dugué, D., Sur certains modes de convergence de lois d'estimation, C. R. Acad. Sci., Paris 20\%, 1732 (1936).

Z 14, 29

Dugué, D., Application des propriétés de la limite au sens du calcul des probabilités à l'étude des diverses questions d'estimation, J. École Polytechn. 4, 305 (1937).

$\mathrm{Z}$ 18, 34

Dugué, D., Eléments limités stochastiques, Bull. Inst. Internat. Statist. 24, 60 (1954). M 16, 941

Dumas, M., Note sur les séries de mesures appartenant à une loi de Gauss. Présomptions permises et interprétation des résultats, Mém. Artillerie Franc. 16, 599 (1937).

Z 18, 158

Dumas, M., Sur une loi de probabilité à priori conduisant aux arguments fiduciaires de Fisher, Revue Sci., 85, 3 (1947).

M 9, 48

Dumas, M., Interprétation de résultats de tirages exhaustifs, C. R. Acad. Sci., Paris 228, 904 (1949).

M 10, 550

Dumas, Les épreuves sur échantillon, (Centre National Recherche Scientifique, Paris, 1955). M 1\%, 170

Dupač, V., Stochastic numerical methods, Casopis Pěst Mat. 81, 55 (1956).

M 18, 336

Durbin, J., The geometry of estimation, Biometrika 38, 150 (1951).

M 13, 144

Durbin, J., Testing for serial correlation in least squares regression. II, Biometrika 38, 159 (1951).

M 13, 144 
Dvoretzky, A., Sequential decision problems for processes with continuous time parameter. Testing hypotheses, Ann. Math. Statist. 24, 254 (1953).

M 14, 997

-Dvoretzky, A., Sequential decision problems for processes with continuous time parameter. Probems of estimation, Ann. Math. Statist. 24, 403 (1953).

M 15, 242

Dvoretzky, A., On stochastic approximation, Proc. Third Berkeley Symp. Math. Stat. \& Prob. I, 39 (1956).

M 18, 946

Dvoretzky, A., Asymptotic minimax character of the sample distribution function and of the classical multinomial estimator, Ann. Math. Statist. 2\%, 642 (1956).

M 18, 772

Dwass, M., A note on simultaneous confidence intervals, Ann. Math. Statist. 26, 146 (1955).

M 16, 728

Dwyer, P. S., Grouping methods, Ann. Math. Statist. 13, 138 (1942).

M 4, 24

Dynkin, E. B., On sufficient and necessary statistics for families of probability distributions, Doklady Akad. Nauk SSSR \%5, 161 (1950). M 12, 427

Dykstra, O., A note on the rank analysis of incomplete block designs-applications beyond the scope of existing tables, Biometrics 12, 301 (1956).

M 18, 633

Eckler, A. R., Rotation sampling, Ann. Math. Statist. 26, 664 (1955).

M 1\%, 503

Edgett, G. L., Multiple regression with missing observations among the independent variables, J. Amer. Statist. Assoc. 51, 122 (1956). M 17,981

van Eeden, C., Methods for comparing, testing and estimating unknown probabilities, Statistica, Rijswijk $\boldsymbol{\gamma}, 141$ (1953).

M 15, 886

van Eeden, C., A test against trend for a number of probabilities, Statistica, Neerlandica 9, 131 (1955).

M 1\%, 505

van Eeden, C., A sequential test with three possible decisions for comparing two unknown probabilities, based on groups of observations, Rev. Inst. Internat. Statist. 23, 20 (1955).

M 18, 243

-van Eeden, C., Guide to Wilcoxon's test (continuation). Exact treatment in the case of like observations, Math. Centrum Amsterdam Statist. Rap. S 176(M 65 A) (1955).

M 18, 682

$\checkmark$ van Eeden, C., A test for the equality of probilities against a class of specified alternative hypotheses, including trend. I, II, Nederl. Akad. Wetensch. Proc. Ser. A $\mathbf{5 8}$ (1955). $\quad$ M 17, 56

van Eeden, C., Maximum likelihood estimation of ordered probabilities, Math. Centrum Amsterdam Statist. Afdeling. Rep. S 188 (VP 5) 8 pp. (1956).

M 1\%, 640

van Eeden, C., Maximum likelihood estimation of ordered probabilities. II, Math. Centrum Amsterdam Statist. Afdeling. Rep. S 196 (VP ) 12 pp. (1956).

M 1\%, 982

$\checkmark$ van Eeden, C., General theorems on Wilcoxon's test for symmetry, Math. Centrum Amsterdam Statist. Rap. S 209 (VP 10) (1956). M 18, 682

-van Eeden, C., (See A. Benard) Math. Centrum Amsterdam Stat. Rap. S 208 (M $\%$ (1956).
Egudin, G. I., On an effective method of calculation of the mathematical expectations of central sample moments, C. R. Doklady Acad. Sci. URSS 53, 487 (1946).

$M \mathbf{8 , 4 7 6}$

Egudin, G. I., On the stability of some very general classes of statistics, Doklady Akad. Nauk SSSR 5\%, 115 (1947).

M 9, 195

Ehrenberg, A. S. C., Estimation of heterogeneous error variances, Nature 166, 608 (1950).

M 12, 428

Ehrenberg, A. S. C., The unbiased estimation of heterogeneous error variances, Biometrika $\mathbf{3} \%, 347$ (1950).

M 12, 346

Ehrenfeld, S., On the efficiency of experimental designs, Ann. Math. Statist. 26, 247 (1955).

M 1\%, 56

Eisenhart, C., A note on a priori information, Ann. Math. Statist. 10, 390 (1939).

M 1, 152

Eisenhart, C., The assumptions underlying the analysis of variance, Biometrics 3, 1 (1947)

M 8, 593

-Eisenhart, C., Selected Techniques of Scientific and Industrial Research and Production and Management Engineering, by the Statistical Research Group, Columbia University, (McGraw Hill Book Co., Inc., New York, 1947.) M 9, 365

Elfving, G., The asymptotical distribution of range in samples from a normal population, Biometrika 34, 111 (1947).

M 8, 395

Elfving, G., A simple method of deducing certain distributions connected with multivariate sampling Skand. Aktuarietidskr. 30, 56 (1947). M 9, 48

Elfving, G., Geometric allocation theory, Skand. Aktuarietidskr. 3\%, 170 (1955) M 1\%, 640

Elfving, G., Über optimale Allokation, Bericht $\ddot{u}$ Tagung Wahrsch. ü Math. Stat., Berlin, Oktober 1954, pp. 89-95 (Verlag der Wissenschaften, Berlin, 1956).

M 18, 425

Elfving, G., Selection of nonrepeatable observations for estimation, Proc. Third Berkeley Symp. Math. Stat. \& Prob. I, 69 (1956).

M 18, 946

Elfving, G., An expansion principle for distribution, functions with application to Student's statistic Ann. Acad. Fenn. Ser. A. I., 204, 8 pp. (1955).

M 17,981

El Shanawany, M. R., An illustration of the accuracy of the $\chi^{2}$ approximation, Biometrika $\mathbf{2 8 ,} 179$ (1936).

$\mathrm{Z} \mathrm{14,} 30$

Epstein, B., On the statistics of sensitivity data, Ann. Math. Statist. 15, 90 (1944). M 5, 209

-Epstein, B., Some theorems relevant to life testing from an exponential distribution, Ann. Math. Statist. 25, 373 (1954). M 15, 810

Epstein, B., Truncated life tests in the exponential case, Ann. Math. Statist. 25, 555 (1954).

M 16, 272

Epstein, B., Sequential life tests in the exponential case, Ann. Math. Statist. 26, 82 (1955). M 16, 728

Epstein, B., Simple estimators of the parameters of exponential distributions when samples are consored, Ann. Inst. Statist. Math., Tokyo 8, 15 (1956).

M 18, 344 
Epstein, B., A sequential two sample life test, $J$. Franklin Inst. $\mathbf{2 6 0 ,} 25$ (1955).

M 16, 1133

Ewing, G. M., (See M. Ayer) Ann. Math. Statist. 26, 641 (1955).

Eyraud, H., Les lois d'erreurs dans deux dimensions, Ann. Univ. Lyon. (A), ק, 19 (1939). M 8, 282

Fabián, V., Structural relation, Czechoslovak Math. J. 4, 354 (1954).

M 16, 842

-Fay, L. C., (See P. O. Johnson) Psychometrika 15, 349 (1950)

Federer, W. T., Testing proportionality of covariance matrices, Ann. Math. Statist. 22, 102 (1951).

M 1\%, 622

Féraud, L., Critères statistiques applicables à un petit nombre d'observations, $C$. R. Sèances Soc. Phys. Hist. Nat. Genève 59, 116 (1942).

M $\%, 212$

Féraud, L., Statistique mathématique: Distributions de produits intérieurs, $C$. R. Séances Soc. Phys. Hist. Nat. Genève 60, 196 (1943). M $\%, 212$

Fernández, O., Contribution to the study of Pearson's $\chi^{2}$, Revista Math. Hist. Amer. 6, 66 (1946).

M 8, 161

$\checkmark$ Ferris, C. D., Operating characteristics for the common statistical tests of significance, Ann. Math. Statist. 1\%, 178 (1946).

M 8, 43

Fertig, J. W., On a method of testing the hypothesis that an observed sample of $n$ variables and of size $N$ has been drawn from a specified population of the same number of variables, Ann. Math. Statist. \%, 113 (1936).

Z 15, 221

Fertig, J. W., A test of a sample variance based on both tail ends of the distribution, Ann Math. Statist. 8, 193 (1937)

Z 18, 266

Festinger, L., An exact test of significance for means of samples drawn from populations with an exponential frequency distribution, Psychometrika 8, 153 (1943).

M 5, 43

Festinger, L., A statistical test for means of samples from skew populations, Psychometrika 8, 205 (1943).

M 5, 128

Fieller, E. C., A numerical test of the adequacy of A. T. McKay's approximation, J. Roy. Statist. Soc. 95, 699 (1932).

Z 5, 303

Fieller, E. C., The distribution of the index in a normal bivariate population, Biometrika $\mathbf{2 4}, 428$ (1932).

Z 6, 21

- Fieller, E. C., Sampling with control variables, Biometrika 41, 494 (1954).

M 16, 603

Finch, D. J., The effect of non-normality on the z-test, when used to compare the variances in two populations, Biometrika 3\%, 186 (1950). M 1\%, 38

de Finetti, B., Rôle et domaine d'application du théorème de Bayes selon les différents points de vue sur les probabilités, Cong. Internat. Philos. des Sciences IV, 67-82 (Hermann \& Cie, Paris 1951).

M 13, 851

de Finetti, B., Recent suggestions for the reconciliation of theories of probability, Proc. Second Berkeley Symp. Math. Stat. \& Prob., pp. 217-225 (1951).

M 13, 851

Finney, D. J., The distribution of the ratio of estimates of the two variances in a sample from a normal bi-variate population, Biometrika $\mathbf{3 0}$, 190 (1938).

Z 19, 35

Finney, D. J., The joint distribution of variance ratios based on a common error mean square, Ann. Eugenics 11, 136 (1941).

M 3, 172

Finney, D. J., The frequency distribution of deviates from means and regression lines in samples from a multivariate normal population, Ann. Math. Statist. 1\%, 344 (1946).

M 8, 161

Finney, D. J., The Fisher-Yates test of significance in $2 \times 2$ contingency tables, Biometrika $\mathbf{3 5}, 145$ (1948).

M 10, 52

Finney, D. J., The truncated binomial distribution, Ann. Eugenics 14, 319 (1949).

M 11, 42

Finney, D.J., On a method of estimating frequencies, Biometrika 36, 233 (1949).

M 11, 529

Finney, D. J., The estimation of the parameters of tolerance distributions, Biometrika 36, 239 (1949).

M 11, 448

Fisher, R. A., On the mathematical foundations of theoretical statistics, Roy. Soc. London, Phil. Trans. A 2\%2, 309 (1922).

Fisher, R. A., The concepts of inverse probability and fiducial probability referring to unknown parameters, Proc. Roy. Soc. London A 139, 343 (1933).

Z 6, 174

Fisher, R. A., The logic of inductive inference, J. Roy. Statist. Soc. 98, 39 (1935). $\quad$ Z 11, 32

Fisher, R. A., The mathematical distributions used in the common tests of significance, Econometrica $\mathbf{3}$, 353 (1935).

Z 1\%, 217

Fisher, R. A., Uncertain inference, Proc. Amer.

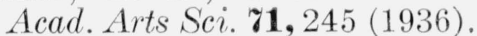

7. 15, 363

Fisher, R. A., The comparison of samples with possibly unequal variances, Ann. Eugenics 9, 174 (1939).

Z 2\%, 63

Fisher, R. A., 'The sampling distribution of some statistics obtained from non-linear equations, Ann. Eugenics 9, 238 (1939).

M 1, 248

Fisher, R. A., A note on fiducial infererce, Ann. Math. Statist. 10, 383 (1939).

M 1, 153

Fisher, R. A., On the similarity of the distributions found for the test of significance in harmonic analysis, and in Steven's problem in geometrical probability, Ann. Eugenics 10, 14 (1940).

M 1, 347

Fisher, R. A., The asymptotic approach to Behren's integral with further tables for the $d$ test of significance, Ann. Eugenics 11, 141 (1941).

M 3, 175

Fisher, R. A., The negative binomial distribution, Ann. Eugenics 11, 182 (1941).

M 4, 26

Fisher, R. A., The likelihood solution of a problem in compounded probabilities, Ann. Eugenics 11, 306 (1942).

M 4, 26

Fisher, R. A., The logical inversion of the notion of the random variable, Sankhyā \%, 129 (1945).

M \%, 318

Fisher, R. A., Conclusions fiduciaries, Ann. Inst. $H$. Poincaré 10, 191 (1948).

M 10, 312

Fisher, R. A., Contributions to Mathamatical Statistics, (John Wiley \& Sons, Inc., New York, 1950).

M 1\%, 427 
Fisher, R. A., Note on the efficient fitting of the negative binomial, Biometrics 9, 197 (1953).

M 14, 1104

Fisher, R. A., Statistical methods and scientific induction, J. Roy. Statist. Soc. Ser. B 17, 69 (1955).

M 1\%, 868

Fog, D., The geometrical method in the theory of sampling, Biometrika 35, 46 (1948).

M 9, 600

Fox, M., Charts of the power of the F-test, Ann. Math. Statist. 2\%, 484 (1956).

M 18, 426

- Francis, M. G. (See C. Chandra Sekar) Sankhyā 5, 165 (1941).

Francis, V. J., On the distribution of the sum of $n$ sample values drawn from a truncated rormal population, Suppl. J. Roy. Statist. Soc. 8, 223 (1946).

M 9, 47

- Frankel, L. R. (See H. Hotelling), Ann. Math. Statist. 9, 87 (1938).

$\checkmark$ Frankel, A. (See S. Kullback) Ann. Math. Statist. 11, 209 (1940).

- Frankel, L. R. (See J. S. Stock) Ann. Math. Statist. 10, 288 (1939).

Fraser, D. A. S., Note on the $\chi^{2}$ smooth test, Biometrika 3\%, 447 (1950).

M 1\%, 345

Fraser, D. A. S., Normal samples with linear constraints and given variances, Canadian J. Math. 3, 363 (1951).

M 13, 53

Fraser, D. A. S., Sufficient statistics and selection depending on the parameter, Ann. Math. Statist. 23, 417 (1952).

M 14, 297

- Fraser, D. A. S., Bhattacharyya bounds without regularity assumptions, Ann. Math. Statist. 23, 629 (1952).

M 14, 1102

Fraser, D. A. S., The Behrens-Fisher problem for regression coefficients, Ann. Math. Statist. 24, 390 (1953).

M 15, 142

Fraser, D. A. S., A vector form of the Wald-Wolfowitz-Hoeffding theorem, Ann. Math. Statist. 2\%, 540 (1956).

M 17, 1219

Fraser, D. A. S., Sufficient statistics with nuisance parameters, Ann. Math. Statist. 2\%, 838 (1956).

M 18, 243

Fréchet, M., Sur les précisions comparées de la moyenne et de la médiane, Aktuár. Védy 5, 29 (1935).

$\mathrm{Z} \mathbf{1 1}, 126$

Fréchet, M., Sur une limitation très générale de la dispersion de la médiane, J. Soc. Statist. Paris 81, 67 (1940).

M 10, 722

Fréchet, M., Fondements des méthodes statistiques d'estimation, Portugaliae Math. 5, 137 (1946).

M 8, 161

Fréchet, M., Rapport sur une enquête internationale relative á l'estimation statistique des paramètres, Inter. Statist. Instit. Proc. Vol. III, 363 (1947).

M 13, 570

Fréchet, M., Les valeurs typiques d'ordre nul ou infini d'un nombre aléatoire, Rev. Inst. Internat. Statistique 16, 1 (1948).

M 11, 40

Fréchet, M., Sur l'estimation statistique, Ann. Soc. Polon. Math. 21, 207 (1949).

M 11, 42

Freire, R., L'estimation des paramètres des fonctions d'Engel, Publ. Inst. Statist. Univ. Paris 2, 19 (1953).
Freund, J. E., Some methods of estimating the parameters of discrete heterogeneous populatioms, J. Roy. Statist. Soc. B 18, 222 (1956). M 18, 606

Freund, J. E., Some results on restricted occupancy theory, Ann. Math. Statist. 27, 537 (1956).

M 1\%, 1221

Friede, G., Pascalische Verteilungen, Confidenceund Fiduzialschluss, Mitteilungsblatt Math. Statist. 2, 171 (1950).

M 12, 509

Fry, T. C., Consistency of independent countings as a criterion for completeness, J. Math. Physics, Mass. Inst. Tech. 15, 211 (1936).

Z 16, 129

Fry, T. C., The $\chi^{2}$-test of significance. J. Amer. Statist. Assoc. 33, 513 (1938).

Z 19, 319

Ganguli, M., A method of estimating variance of sample grand-mean and zone variances in unequal nested sampling, Science and Culture 6, 724 (1941).

M 5, 43

Gani, J., Some theorems and sufficiency conditions for the maximum-likehood estimator of an unknown parameter in a simple Markov chain, Biometrika 4\%, 342 (1955).

M 1\%, 640

Gårding, L., The distributions of the first and second order moments, the partial correlation coefficients and the multiple correlation coefficient in samples from a normal multivariate population, Skand. Aktuarietidskr. 24, 185 (1941). M \%, 212

Gartšteĭn, B. N., On certain limit laws for the range, Doklady Akad. Nauk. SSSR 60, 1119 (1948)'

M 10, 51

Garwood, F., Fiducial limits for the Poisson distribution, Biometrika 28, 437 (1936).

Z 15, 262

de la Garza, A., Spacing of information in polynomial regression, Ann. Math. Statist. 25, 123 (1954).

M 15, 725

de la Garza., Quadratic extrapolation and a related test of hypotheses, J. Amer. Statist. Assoc. 51, $644(1956)$.

M 18, 833

Gayen, A. K., (See C. Bose) Sankhyā 8, 73 (1946).

Gayen, A. K., The distribution of "Student's" $t$ in random samples of any size drawn from nonnormal universes, Biometrika 36, 353 (1949).

M 11, 447

Gayen, A. K., The distribution of the variance ratio in random samples of any size drawn from nonnormal universes, Biometrika 37, 236 (1950).

M 12, 345

Gayen, A. K., Significance of difference between the means of two non-normal samples, Biometrika 37, 399 (1950).

M 12, 345

Gayen, A. K., The frequency distribution of the product-moment correlation coefficient in random samples of any size drawn from non-normal universes, Biometrika 38, 219 (1951). M 13, 53

Geary, R. C., The ratio of the mean deviation to the standard deviation as a test of normality, Biometrika 2\%, 310 (1935).

Z 13, 29

Geary, R. C., Moments of the ratio of the mean deviation to the standard deviation for normal samples, Biometrika 28, 295 (1936). Z 15, 407

Geary, R. C., Tests for normality. (Cambridge Univ. Press, London, 1938). Z 19, 74

Geary, R. C., The estimation of many parameters, J. Roy. Statist. Soc. 105, 213 (1942). M 4, 165 
Geary, R. C., Relations between statistics: the general and the sampling problem when the samples are large, Proc. Roy. Irish Acad. Sect. A 49, 177 (1944).

M 6, 10

Geary, R. C., Comparison of the concepts of efficiency and closeness for consistent estimates of a parameter, Biometrika 33, 123 (1944).

M 6, 10

Geary, R. C., The frequency distribution of $\sqrt{b_{1}}$ for samples of all sizes drawn at random from a normal population, Biometrika 34, 68 (1947).

M 8, 394

-Geary, R. C., On the computation of universal moments of tests of statistical normality derived from samples drawn at random from a normal universe. Application to the calculation of the seventh moment of $b_{2}$, Biometrika 34, 98 (1947).

M 8, 395

Geary, R. C., Testing for normality, Biometrika 34, 209 (1947)

M 9, 364

Geary, R. C., Non-linear functional relationship between two variables when one variable is controlled, J. Amer. Statist. Assoc. 48, 94 (1953).

M 14, 776

Gebelein, H., Verfahren zur Beurteilung einer sehr geringen Korrelation zwischen zwei statistischen Merkmalsreihen, Z. Angew. Math. Mech. 2\%, 286 (1942).

M 6, 6

Geidel, H., Zur Anwendung von Gleitmittelwertverfahren bei der Auswertung von Feldversuchen, Mitt. Math. Sem. Giessen Beiheft 2, 86 pp. (1956).

M 18. 772

Geiringer, H., Observations of analysis of variance theory, Ann. Math. Statist. 13, 350 (1942).

M 4, 106

Geiringer, H., A new explanation of nonnormal dispersion in the Lexis theory, Econometrica 10, 53 (1942).

M 3, 173

Geiringer, H., Einige Probleme Mendelscher Genetik, Z. Angew. Math. Mech. 33, 130 (1953).

M 15, 455

$\checkmark$ Gel'fand, I. M., On the general definition of the amount of information, Dokl. Akad. Nauk SSSR 111, 745 (1956).

M 18, 859

George, A., On the problem of interval estimation, Sankhyā 6, 111 (1942).

M 6, 10

Geppert, M. P., U̇ber den Vergleich zweier beobachteter Häufigkeiten, Deutsche Math. y, 553 (1944).

M 8, 393

Geppert, M. P., Mutungsgrenzen und Mutungswahrscheinlichkeit, Z. Angew. Math. Mech. 25, 253 (1947).

М 9, 295

Geppert, M. P., Maximum-likelihood-Schätzung und Rückschlussverteilung, Z. Angew. Math. 28, 85 (1948)

M $\mathbf{9 ,} 602$

Gervaise, A. M., Risque d'erreur dans un test d'hypothèse appliqué à un paramètre aléatoire, moyenne de $k$ paramètres indépendants lorsque la taille de l'échantillon varie avec $k, C$. R. Acad. Sci. Paris, 24\%, 729 (1956).

M 18, 641

Ghizzetti, A., Sul problema del collaudo di partite di numerosi oggetti, Consiglio Naz. Ricerche. Pubbl. Ist. Appl. Calcolo No. 164, 19 pp. (1945).

M 10, 52
Ghosh, B., On the construction of some natural fields, Science and Culture 9, 213 (1943).

M $\boldsymbol{g}, 462$

Ghosh, M. N., On the problem of similar regions, Sankhyā 8, 329 (1948).

M 10, 135

Ghosh, M. N., Simultaneous tests of linear hypotheses, Biometrika 4\%, 441 (1955).

M 1\%, 640

Ghosh, M. N., Strong convergence of Robbins and Monro and Kiefer and Wolfowitz processes, Bull. Calcutta Math. Soc. 48, 25 (1956).

M 18, 773

Ghurye, S. G., On the use of Student's $t$-test in an asymmetrical population, Biometrika 36, 426 (1949).

M 11, 447

Ghurye, S. G., Transformations of a binomial variate for the analysis of variance, J. Indian Soc. Agric. Statistics \%, 94 (1949).

M 11, 528

Ghurye, S. G., Two-stage procedures for estimating the difference between means, Biometrika 41, 146 (1954).

M 15, 972

Gibson, W. A., An extension of Anderson's solution for the latent structure equations, Psychometrika 20, 69 (1955).

M 1\%, 756

Giesekus, H., Die Anwendung der statistischen Prüfverfahren auf Reihen mit Erhaltungsneigung und kontinuierliche Gesamtheiten, Mitteilungsblatt Math. Statist. 5, 103 (1953).

M 15, 240

Gihman, I. I., Some remarks on A. N. Kolmogorov's criterion of fit, Doklady Akad. Nauk SSSR 91, 715 (1953).

M 15, 452

Gihman, I. I., On some limit theorems for conditional distributions and on problems of mathematical statistics connected with them, Ukrain Mat. Žurnal 5, 413 (1953). M 15, 722

Gilbert, N. E. G., Likelihood function for capturerecapture samples, Biometrika 43, 488 (1956).

M 18, 426

Gildemeister, M., Die Zulässigkeit des $\chi^{2}$-Kriteriums für kleine Versuchszahlen, Ber. Verh. Sächs. Akad. Wiss. Leipzig Math.-Nat Kl. 95, 145 (1943). M 8, 394

Gillis, P. P., (See C. Dresselaers) Acad. Roy. Belgique Bull. Cl. Sci. 3\%, 449 (1951).

Gini, C., The means of samples, Internat. Statist. Institute Proc. III, 258 (1947). $\quad$ M 13, 570

Gini, C., Le medie dei campioni, Metron 15, 13 (1949).

M 11, 446

Girault, M., Sur la notion de facteur commun en analyse factorielle générale, $C$. R. Acad. Sci. Paris 22\%, 499 (1948).

M 10, 136

Girshick, M. A., On the sampling theory of roots of determinantal equations, Ann. Math. Statist. 10, 203 (1939).

M 1, 22

Girshick, M. A., Bayes and minimax estimates for quadratic loss functions, Proc. Second Berkeley Symp. Math. Stat. \& Prob., pp. 53-73 (1951).

M 13, 571

Girshick, M. A., A Bayes approach to a quality control model, Ann. Math. Statist. 23, 114 (1952).

M 13, 854

$\checkmark$ Girshick, M. A., Estimates of bounded relative error in particle counting, Ann Math. Statist. 26, 276 (1955). 
Gjeddebaek, N. F., Contribution to the study of grouped observations. Application of the method of maximum likelihood in case of normally distributed observations, Skand. Aktuarietidskr. 32, 135 (1949).

M 11, 446

-Gnedenko, B. V., On the maximum discrepancy between two empirical distributions, Doklady Akad. Nauk SSSR 80, 525 (1951).

M 13, 570

Godambe, V. P., On two-stage sampling, J. Roy. Statist. Soc. Ser. B 13, 216 (1951). M 14, 298

Godambe, V. P., A unified theory of sampling from finite populations, J. Roy. Statist. Soc. Ser. B 1\%, 269 (1955).

M 1\%, 982

Godwin, H. J., On the distribution of the estimate of mean deviation obtained from samples from a normal population, Biometrika 33, 254 (1945).

M 8, 42

Godwin, H. J., A further note on the mean deviation, Biometrika 35, 304 (1948).

M 10, 387

Godwin, H. J., A note on Kac's derivation of the distribution of the mean deviation, Ann. Math. Statist. 20, 127 (1949).

M 10, 466

Godwin, H. J., On the estimation of dispersion by linear systematic statistics, Biometrika 36, 92 (1949).

M 11, 673

Goffman, C., Note on the variation of means, Ann. Math. Statist. 24, 307 (1953).

M 14, 888

-Goldberg, H., Approximate formulas for the percentage points and normalization of $t$ and $\chi^{2}$, Ann. Math. Statist. 1\%, 216 (1946).

M 8, 42

Good, I. J., Probability and the Weighing of Evidence, (Charles Griffin \& Co., London, 1950). M 12, 837

Good, I. J., The population frequencies of species and the estimation of population parameters, Biometrika 40, 237 (1953).

M 15, 809

Good, I. J., The likelihood ratio test for Markoff chains, Biometrika 42, 531 (1955). M 17, 381

Good, I. J., On the weighted combination of significance tests, J. Roy. Statist. Soc. Ser. B 1\%, 264 (1955).

M 1\%, 870

Good, I. J., On the estimations of small frequencies in contingency tables, J. Roy. Statist. Soc. 18, 113 (1956).

M 18, 956

Good, I. J., The number of new species, and the increase in population coverage, when a sample is increased, Biometrika 43, 45 (1956). M 1\%, 982

Goodman, L. A., On the estimation of the number of classes in a population, Ann. Math. Statist. 20, 572 (1949)

M 11, 260

Goodman, L. A., On the analysis of samples from $k$ lists, Ann. Math. Statist. 23, 632 (1952). M 14,390

Goodman, L. A., A simple method for improving some estimators, Ann. Math. Statist. P4, 114 (1953).

M 14, 888

Gordon, R. D., The estimation of a quotient when the denominator is normally distributed, Ann. Math. Statist. 12, 115 (1941).

M 3,8

Graybill, F. A., On quadratic estimates of variance components, Ann. Math. Statist. 25, 367 (1954).

M 15, 810

-Graybill, F. A., A note on uniformly best unbiased estimators for variance components, J. Amer. Statist. Assoc. 51, 266 (1956).
Green, J. R., A confidence interval for variance components, Ann. Math. Statist. 25, 671 (1954).

M 16, 841

$\checkmark$ Greenberg, B. G. (See A. E. Sarhan), Ann. Math. Statist. 2\%, 427 (1956).

Greenhood, E. R., A Detailed Proof of the Chi-Square Test of Goodness of Fit (Harvard University Press, Cambridge, Mass., 1940).

M 1, 346

Grenander, U., Stochastic processes and statistical inference, Ark. Mat. 1, 195 (1950). $\quad$ M 12, 511

Grenander, U., On the estimation of regression coefficients in the case of an autocorrelated disturbance, Ann. Math. Statist. 25, 252 (1954).

M 15, 973

- Grenander, U., Regression analysis of time series with stationary residuals, Proc. Nat. Acad. Sci. USA 40, 812 (1954).

M 15, 974

Gronow, D. G. C., Test for the significance of the difference between means in two normal populations having unequal variances, Biometrika 38, 252 (1951).

M 13, 143

Grubbs, F. E. (See C. D. Ferris), Ann. Math. Statist. 1\%, 178 (1946).

$\checkmark$ Grubbs, F. E. (See A. P. Morse), Ann. Math. Statist. 18, 194 (1947).

Grundy, P. M., The fitting of grouped truncated and grouped censored normal distributions, Biometrika 39, 252 (1952).

M 14, 487

Grundy, P. M., A method of sampling with probability exactly proportional to size, J. Roy. Statist. Soc. B 16, 236 (1954).

M 16, 1037

Grundy, P. M., Economic choice of the amount of experimentation, J. Roy. Statist. Soc. B 18, 32 (1956)

M 18, 244

Grundy, P. M., Fiducial distributions and prior distributions: an example in which the former cannot be associated with the latter, J. Roy Statist. Soc. $B \mathbf{1 8}, 217$ (1956).

M 18, 682

Guest, P. G.. Estimation of the error at a point on a least-squares curve, Australian J. Sci. Research Ser. A 3, 173 (1950).

M 12, 513

Guest, P. G., The estimation of standard error from successive finite differences, J. Roy. Statist. Soc. $B$ 13, 233 (1951).

M 53, 64

Guiraum, Martin, A., Modification of Lawley's test for a small sample, Las Ciencias 18, 753 (1953).

M 1\%, 983

Gulliksen, H., Regression tests for several samples. Psychometrika 15, 91 (1950).

M 1\%, 193

Gumbel, E. J., La précision de la moyenne arithmétique et de la médiane, Aktuar. Vedy 6, 145 (1937).

$\mathrm{Z} \mathbf{1 8}, 77$

Gumbel, E. J., La probabilité des hypothèses, $C . R$. Acad. Sci. Paris $\mathbf{2 0 9}, 645$ (1939). $\quad$ M 1, 152

Gumbel, E. J., Simple tests for given hypotheses, Biometrika 32, 317 (1942).

M 4, 26

Gumbel, E. J., On the reliability of the classical chisquare test, Ann. Math, Statist. 14, 253 (1943).

M 6, 9

Gumbel, E. J., Déterimination commune des constantes dans les distributions des plus grandes valeurs, C. R. Acad. Sci. Paris 222, 34 (1946).

M $\%, 464$ 
Gumbel, E. J., Statistical theory of extreme values and some practical applications. A series of lectures, (Nat. Bur. Stds. Appl. Math. Series 33, USGPO, Washington, 1954).

M 15, 811

Gumbel, E. J., Statistische Theorie der Ermüdungserscheinungen bei Metallen, Mitteilungsbl. Math. Statist. 8, 97 (1956).

M 18, 833

Gumbel, E. J., On the asymptotic covariance of the sample mean and standard deviation, Metron 18, 113 (1956).

M 18, 606

Gurland, J., (See E. W. Barankin) Univ. California Publ. Statist. 1, 89 (1951).

Gurland, J., On regularity conditions for maximum likelihood estimators, Skand. Aktuarietidskr. 3\%, 71 (1954).

M 16, 729

Gurland, J., On Wallis' formula, Amer. Math. Monthly 63, 643 (1956).

M 18, 500

Gurney, M., (See T. Dalenius) Skand. Aktuarietidskr. 34, 133 (1951).

Guttman, L., A note on the derivation of formulae for multiple and partial correlation, Ann. Math. Statist. 9, 305 (1938).

Z 20,39

Guttman, I., (See D. A. S. Fraser) Ann. Math. Statist. 83, 629 (1952).

Hájek, J., Linear estimation of the mean value of a stationary random process with convex correlation function, Czechoslovak Math. J. 6, 94 (1956).

M 18, 241

- Hald, A., Some applications of methods of transformation in the normal distribution theory, (Den Danske Aktuarforening pp. 52-65, Copenhagen, 1943).

M 8, 42

Hald, A., Maximum likelihood estimation of the parameters of a normal distribution which is truncated at a known point, Skand, Aktuarietidskr. 32, 119 (1949).

M 1\%, 193

- Hald, A., (See N. Arley). Mat. Tidsskr. B 1950, 86 (1950).

Haldane, J. B. S., A note on inverse probability, Proc. Cambridge Philos. Soc. 28, 55 (1932).

Z 3, 356

Haldane, J. B. S., The approximate normalization of a class of frequency distributions, Biometrika 29, 392 (1938).

Z 18, 157

Haldane, J. B. S., The mean and variance of $\chi^{2}$, when used as a test of homogeneity, when expectations are small, Biometrika $\mathbf{3 1}, 346$ (1940).

M 1, 346

Haldane, J. B. S., The cumulants and moments of the binomial distribution, and the cumulants of $\chi^{2}$ for a $(n \times 2)$-fold table, Biometrika 31, 392 (1940). M 1, 346

Haldane, J. B. S., The fitting of binomial distributions, Ann. Eugenics 11, 179 (1941).

M 4, 26

Haldane, J. B. S., The cumulants of the distribution of Fisher's " $u_{11}$ " and " $u_{31}$ " scores used in the detection and estimation of linkage in man, Ann. Eugenics 13, 122 (1946).

M 8, 162

Haldane, J. B. S., Moments of the distributions of powers and products of normal variates, Biometrika 32, 226 (1942).

M 4, 20

Haldane, J. B. S., The cumulants of the distribution of the square of a variate, Biometrika 3\%, 199 (1941).

M 3, 170
Haldane, J. B. S., The precision of observed values of small frequencies, Biometrika 35, 297 (1948).

M 10, 554

Haldane, J. B. S., A note on non-normal correlation, Biometrika 36, 467 (1949).

M 11, 733

Haldane, J. B. S., The estimation of two parameters from a sample, Sankhyā 1\%, 313 (1953).

M 15, 726

Haldane, J. B. S., The rapid calculation of $\chi^{2}$ as a test of homogeneity from a $2 \times n$ table, Biometrika 4\%, 519 (1955).

M 1\%, 169

Haldane, J. B. S., The sampling distribution of a maximum-likelihood estimate, Biometrika 43, 96 (1956).

M 1\%, 981

Halmos, P. R., The theory of unbiased estimation, Ann. Math. Statist. 1\%, 34 (1946). M $\%, 463$

$\checkmark$ Halmos, P. R., Application of the Radon-Nikodym theorem to the theory of sufficient statistics, Ann. Math. Statist. 20, 225 (1949).

M 11, 42

Halphen, E., Quelques remarques sur le problème de l'estimation, Colloq. Internat. Centre Nat. Rech. Sci. Paris 13, 87 (1949).

M 11, 448

Halperin, M., Maximum likelihood estimation in truncated samples, Ann. Math. Statist. 23, 226 (1952).

M 14, 65

Hamaker, H. C., Random frequencies, an expedient for the construction of artificial samples of large size, Statistica, Rijswijk $\boldsymbol{2} 129$ (1948).

M 11, 191

Hamaker, H. C., Random sampling frequencies; an implement for rapidly constructing largesize artificial samples, Nederl. Akad. Wetensch. Proc. 52, 432 (1949).

M 11, 191

Hammersley, J. M., The unbiassed estimate and standard error of the interclass variance, Metron 15, 189 (1949).

M 11, 446

Hammersley, J. M., On estimating restricted parameters, J. Roy. Statist. Soc. Ser. B 12, 192 (1950).

M 1\% 725

- Hammersley, J. M., The estimation of location and scale parameters from grouped data, Biometrika 41, 296 (1954).

M 16, 602

- Hammersley, J. M., Sampling from an isotropic Gaussian process, Proc. Cambridge Philos. Soc. 51, 652 (1955).

M 18, 170

- Hammersley, J. M., General principles of antithetic variates, Proc. Cambridge Philos. Soc. 5?, 476 (1956).

M 18, 344

Hannan, E. J., The asymptotic powers of certain tests based on multiple correlations, J. Roy. Statist. Soc. B 18, 227 (1956).

M 18, 682

Hannan, E. J. An exact test for correlation between times series, Biometrika 4\%, 316 (1955). M 1\%, 381

- Hansen, M. H., On the theory of sampling from finite populations, Ann. Math. Statist. 14, 333 (1943).

M 5, 210

- Hansen, M. H., On the determination of optimum probabilities in sampling, Ann. Math. Statist. 20, 426 (1949).

M 11, 42

- Hansen, M. H., Sample survey methods and theory. Vol. I. Methods and applications, (John Wiley \& Sons, N. Y., 1953). 
-Hansen, M. H., Sample survey methods and theory. Vol. II. Theory, (John Wiley \& Sons, N.Y., 1953).

M 15, 332

Hart, B. I., Significance levels for the ratio of the mean square successive difference to the variance, Ann. Math. Statist. 13, 445 (1942). M 4, 165

Hartley, H. O., Studentization and large-sample theory, J. Roy. Statist. Soc. Suppl. 5, 80 (1938).

$\mathrm{Z}$ 19, 74

Hartley, H. O., Testing the homogeneity of a set of variances, Biometrika 31, 249 (1940). M 1, 346

Hartley, H. O., The range in random samples, Biometrika 32, 334 (1942). M 4, 21

Hartley, H. O., Studentization or the elimination of the standard deviation of the parent population from the random sample-distribution of statistics, Biometrika 33, 173 (1944).

M 6, 10

Hartley, H. O., Note on the calculation of the distribution of the estimate of mean deviation in normal samples, Biometrika 33, 257 (1945). M 8, 42

$\checkmark$ Hartley, H. O., Tables for testing the homogeneity of a set of estimated variances, Biometrika 33, 296 (1946).

M 8, 42

Hartley, H. O., Tests of significance in harmonic analysis, Biometrika 36, 194 (1949). M 11, 529

Hartley, H. O., The maximum $F$-ratio as a shortcut test for heterogeneity of variance, Biometrika $\mathbf{3 \%}, 308$ (1950).

M 12, 345

-Hartley, H. O., (See E. C. Fieller) Biometrika 41, 494 (1954).

-Hastay, M. W., (See C. Eisenhart) (McGraw Hill Book Co., Inc, New York, 1947).

Hayashi, C., Multidimensional quantification. I, Proc. Japan Acad. 30, 61 (1954). $\quad$ M 16, 381

Healy, M. J. R., A significance test for the difference in efficiency between two predictors, $J$. Roy. Statist. Soc. Ser. B 1\%, 266 (1955). $\quad$ M 1\%, 869

-Healy, M. J. R., (See P. M. Grundy) J. Roy. Statist. Soc. 18, 32 (1956).

Healy, W. C., Two-sample procedures in simultaneous estimation, Ann. Math. Statist. 2\%, 687 (1956). M 18, 344

Hemelrijk, J., Construction of a confidence region for a line, Nederl. Akad. Wetensch. Proc. 52, 995 (1949).

M 11, 529

-Hemelrijk, J., The use of unilateral and bilateral critical regions in the testing of hypotheses, Statistica, Rijswijk 4, 54 (1950).

M 12, 192

-Hemelrijk, J., (See C. van Eeden) Nederl. Akad. Wetensch. Proc. Ser. A 58, (1955).

Hemelrijk, J., Exemple d'application des méthodes non paramétriques et un nouveau test pour l' egalité de plusieurs probabilités, Colloq. Statist. Bruxelles, p. 93 (Georges Thone, Liège, 1955).

M 1\%, 381

Henderson, C. R., Estimation of variance and covariance components, Biometrics 9, 226 (1953).

M 14, 1105

Hendricks, W. A., The sampling distribution of the coefficient of variation, Ann. Math. Statist. \%, 129 (1936).

Z 15, 310

Hildreth, C., Point estimates of ordinates of concave functions, J. Amer. Statist. Assoc. 49, 598 (1954).
Hirschfeld, H. O., The distribution of the ratio of covariance estimates in two samples drawn from normal bivariate populations, Biometrika 29, 65 (1937)

Z 17, 126

Hitchcock, H. P., The estimation of the probable error from successive and independent variances, Ballistic Research Lab. Aberdeen Proving Ground, Md., Rep. 193, (1940).

M 12, 37

Hodges, J. L., The choice of inspection stringency in acceptance sampling by attributes, Univ. California Publ. Statist. 1, 1 (1949). M 12, 429

- Hodges, J. L., Some problems in minimax point estimation, Ann. Math. Statist. 21, 182 (1950).

M 12, 36

Hodges, J. L., Sone applications of the CramérRao inequality, Proc. Second Berkeley Symp. Math. Stat. \& Prob., pp. 13-22 (1951). M 13, 479

-Hodges, J. L., Testing the approximate validity of statistical hypotheses, J. Roy. Statist. Soc. Ser. B 16, 261 (1954).

M 16, 1039

Hodges, J. L., A bivariate sign test, Ann. Math. Statist. 26, 523 (1955). M 17, 56

Hodges, J. L., Two approximations to the RobbinsMonro process, Proc. Third Berkeley Symp. Math. Stat. \& Prob. I, 95 (1956).

M 18, 947

Hoeffding, W., A class of statistics with asymptotically normal distribution, Ann. Math. Statist. 19, 293 (1948).

M 10, 134

Hoeffding, W., The efficiency of tests, Ann. Math. Statist. 26, 52 (1955). M 16, 1133

Hoeffding, W., On the distribution of the number of successes in independent trials, Ann. Math. Statist. 2\%, 713 (1956).

M 18, 240

Hoel, P. G., On indices of dispersion, Ann. Math. Statist. 14, 155 (1943).

M 4, 280

Hoel, P. G., The accuracy of sampling methods in ecology, Ann. Math. Statist. 14, 289 (1943).

M 6, 162

Hoel, P. G., On statistical coefficients of likeness, Univ. Cal. Publ. Math. 2, 1 (1944). M 6, 6

Hoel, P. G., Testing the homogeneity of Poisson frequencies, Ann. Math. Statist. 16, 362 (1945).

M $\boldsymbol{\gamma}, 464$

Hoel, P. G., Discriminating between binomial distributions, Ann. Math. Statist. 18, 556 (1947).

M 9, 295

Hoel, P. G., On the uniqueness of similar regions, Ann. Math. Statist. 19, 66 (1948). M 10, 135

$\checkmark$ Hoel, P. G., A solution to the problem of optimum classification, Ann. Math. Statist. 20, 433 (1949).

M 11, 191

Hoel, P. G., Conditional expectation and the efficiency of estimates, Ann. Math. Statist. 22, 299 (1951).

M 13, 143

Hoel, P. G., Confidence regions for linear regression, Proc. Second Berkeley Symp. Math. Stat. \& Prob., pp. 75-81 (1951).

M 13, 481

Hoel, P. G., On a property of the sequential $t$-test, Skand. Aktuarietidskr. 3\%, 19 (1954). M 16, 604

Hogg, R. V., On the distribution of the likelihood ratio, Ann. Math. Statist. 27, 529 (1956). M 18, 78

Hojo, T., Distribution of the median, quartiles, and interquartile distance in samples from a normal population, Biometrika $\mathbf{2 3 ,} 315$ (1931). $\quad$ Z 4, 359 
Hojo, T., A further note on the relation between the median and the quartiles in small samples from a normal population, Biometrika 25, 79 (1933).

Z 7,25

Hooke, R., Symmetric functions of a two-way array. Ann. Math. Statist. 2\%, 55 (1956). M 1\%, 868

Hooke, R., Some applications of bipolykays to the estimation of variance components and their moments, Ann. Math. Statist. 2\%, 80 (1956).

M 1\%, 868

Horvitz, D. G., A generalization of sampling without replacement from a finite universe, J. Amer. Statist. Assoc. 4\%, 663 (1952). M 14, 777

- Hotelling, H., The transformation of statistics to simplify their distribution, Ann. Math. Statist. 9, 87 (1938).

$\mathrm{Z} \mathrm{19,} 227$

Hotelling, H., The selection of variates for use in prediction with some comments on the general problem of nuisance parameters, Ann. Math. Statist. 11, 271 (1940).

M 2, 111

Hotelling, H., A generalized $T$ test and measure of multivariate dispersion, Proc. Second Berkeley Symp. Math. Stat. \& Prob., pp. 23-41 (1951).

M 13, 479

-Hotelling, H., (See J. T. Chu) Ann. Math. Statist. 26, 593 (1955).

Hsu, P. L., On the best unbiased quadratic estimate of the variance, Statist. Res. Mem., Univ. London 2, 91 (1938).

Z 20, 149

Hsu, P. L., Contribution to the theory of "Student's" $t$-test as applied to the problem of two samples, Statist. Res. Mem, Univ. London 2, 1 (1938).

Z 20, 149

Hsu, P. L., Notes on Hotelling's generalized T, Ann. Math. Statist. 9, 231 (1938).

Z 20, 148

Hsu, P. L., A new proof of the joint product moment distribution, Proc. Cambridge Philos. Soc. 35, 336 (1939).

Z 21, 42

Hsu, P. L., On generalized analysis of variance. I, Biometrika 31, 221 (1940).

M 2, 111

- Hsu, C. T., The derivation of the fifth and sixth moments of the distribution of $b_{2}$ in samples from a normal population, Biometrika 31, 238 (1940).

M 1, 346

Hsu, C. T., On samples from a normal bivariate population, Ann. Math. Statist. 11, 410 (1940).

M 2,236

Hsu, P. L., On the limiting distribution of roots of a determinantal equation, J. London Math. Soc. 16, 183 (1941).

M 3, 174

Hsu, P. L., On the problem of rank and the limiting distribution of Fisher's test function, Ann. Eugenics 11, 39 (1941).

M 3, 8

Hsu, P. L., Analysis of variance from the power function standpoint, Biometrika 32, 62 (1941).

M 2, 236

Hsu, C. T., Samples from two bivariate normal populations, Ann. Math. Statist. 12, 279 (1941).

M 3, 174

Hsu, L. C., Some combinatorial formulas on mathematical expectation, Ann. Math. Statist. 16, 369 (1945).
Hsu, P. L., On the power functions of the $E^{2}$-test and the $T^{2}$-test, Ann. Math. Statist. 16, 278 (1945)

M $\boldsymbol{g}, 212$

Hsu, L. C., Some combinatorial formulas with applications to probable values of a polynomial-product and to differences of zero, Ann. Math. Statist. 15, 399 (1944).

M 6, 234

Hsu, P. L., On the asymptotic distributions of certain statistics used in testing the independence between successive observations from a normal population, Ann. Math. Statist. 17, 350 (1946). M 8, 161

Hsu, P. L., The limiting distribution of functions of sample means and application to testing hypotheses, Proc. Berkeley Symp. Math. Stat. \& Prob., pp. 359-402 (1949).

M 10, 387

-Hudimoto, H., (See K. Matusita) Ann. Inst. Statist. Math. Tokyo. 6, 133 (1954).

Hughes, H.M., Estimation of the variance of the bivariate normal distribution, Univ. California Publ. Statist. 1, 37 (1949).

M 12, 346

Huitson, A., A method of assigning confidence limits to linear combinations of variances, Biometrika 4\%, 471 (1955).

M 17, 279

-Hunter, J. S., (See G. E. P. Box) Biometrika 41, 190 (1954).

Huntsberger, D. V., A generalization of a preliminary testing procedure for pooling data, Ann. Math. Statist. 26, 734 (1955).

M 17, 504

Huron, R., Loi multinomiale et test du $\chi^{2}, C$. R. Acad. Sci. Paris 240, 2047 (1955). M 17, 56

$\checkmark$ Hurwitz, W. N., (See M. H. Hansen) Ann. Math. Statist. 14, 333 (1943).

-Hurwitz, W. N., (See M. H. Hansen) Ann. Math. Statist. 20, 426 (1949).

-Hurwitz, W. N., (See M. H. Hansen) (John Wiley \& Sons, N.Y., 1953).

Hussain, Q. M., A note on interaction, Sankhyā 6, 321 (1943).

M 5, 126

Huzurbazar, V. S., The likelihood equation, consistency and the maxima of the likelihood function, Ann. Eugenics 14, 185 (1948). M 10, 388

Huzurbazar, V. S., Inverse probability and sufficient statistics, Proc. Cambridge Philos. Soc. 45, 225 (1949).

M 10, 466

Huzurbazar, V. S., On a property of distributions admitting sufficient statistics, Biometrika 36, 71 (1949).

M 11, 529

Huzurbazar, V. S., Probability distributions and orthogonal parameters, Proc. Cambridge Philos. Soc. 46, 281 (1950).

M 11, 608

Huzurbazar, V. S., Confidence intervals for the parameter of a distribution admitting a sufficient statistic when the range depends on the parameter, J. Roy. Statist. Soc. Ser. B 1\%, 86 (1955).

M 1\%, 503

Hyrenius, H., Sampling distributions from a compound normal parent population, Skand. Aktuarietidskr. 32, 180 (1949). $\quad$ M 11, 446

Iegudin, G., Parameters of distribution of a random variable invariant under translations, and algebraic semiinvariants, C.R. Doklady Acad. Sci. USSR 48, 615 (1945). 
Ihm, P., Ein Kriterium für zwei Typen zweidimensionaler Normalverteilungen, Mitteilungsbl. Math. Statist. 7, 46 (1955).

M 16, 1039

-Ikeda, N., (See T. Seguchi) Mem. Fac. Sci. Kyūsyū Unir. A 8, 187 (1954).

Ikeda, S., On the estimation of the quality of a group of lots by the single sampling inspection in destructive case, Osaka Math. J. \%, 131 (1955).

M 1\%, 639

-Ikeda, N., (See Y. Washio) Bull. Math. Statist. 6, 69 (1956).

Irwin, J. O., Mathematical theorems involved in the analysis of variance, J. Roy. Statist. Soc. 94, 284 (1931).

$\mathrm{Z} 2,200$

Irwin, J. O., The frequency distribution of the difference between two independent variates following the same Poisson distribution, J. Roy. Statist. Soc. 100, 415 (1937).

$\mathrm{Z} \mathbf{1 \%}, 77$

Irwin, J. O., On the distribution of a weighted estimate of variance and on analysis of variance in certain cases of unequal weighting, J. Roy. Statist. Soc. 105, 115 (1942).

M 4, 106

- Irwin, J. O., Sampling moments of moments for a finite population, Ann. Eugenics 1\%, 138 (1944).

M 6, 162

Irwin, J. O., A note on the subdivision of $\chi^{2}$ into components, Biometrika 36, 130 (1949).

M 11, 528

Irwin, J. O., A unified derivation of some well-known frequency distributions of interest in biometry and statistics, J. Roy. Statist. Soc. A 118, 389 (1955).

M 1\%, 380

Isaacson, S. L., On the theory of unbiased tests of simple statistical hypotheses specifying the values of two or more parameters, Ann. Math. Statist. 22, 217 (1951).

M 12, 842

Isida, M. D., A remark on the linear regression estimate, Ann. Inst. Statist. Math. Tokyo 4, 7 (1952).

M 14, 487

Isserlis, L., On the moment distributions of moments in the case of samples drawn from a limited universe, Proc. Roy. Soc. London A 132, 586 (1931).

$\mathrm{Z} \boldsymbol{2}, 279$

Itô, K., On Student's test, Proc. Imp. Acad. Tokyo 20, 694 (1944).

M $\boldsymbol{y}, 318$

Izaki, M., Convergence of integral and its applications, Bull. Math. Statist. 5, 31 (1952). M 14, 888

Jackson, D., Mathematical principles in the theory of small samples, Amer. Math. Monthly 42, 344 (1935).

Z 11, 409

$\checkmark$ Jackson, J. E., Extended tables for use with the "G" test for means, J. Amer. Statist. Assoc. 50, 416 (1955).

M 16, 1038

Jackson, R. W. B., Tests of statistical hypotheses in the case when the set of alternatives is discontinuous, illustrated on some genetical problems, Statist. Res. Mem. Univ. London 1, 138 (1936).

Z 14, 122

James, A. T., Normal multivariate analysis and the orthogonal group, Ann. Math. Statist. 25, 40 (1954).

M 15, 726
James, G. S., Tests of linear hypotheses in univariate and multivariate analysis when the ratios of the population variances are unknown, Biometrika 41, 19 (1954).

M 16, 842

James, G. S., On the accuracy of weighted means and ratios, Biometrika 43, 304 (1956) M 18, 426

-James, G. S., (See W. H. Trickett) Biometrika 43, 203 (1956).

Janardana Aiyer, S. On the arithmetic and the geometric means from a type III population, Math. Student 13, 11 (1945).

M $\boldsymbol{\%}, 212$

Jeeves, T. A., Identification and estimation of linear manifolds in n-dimensions, Ann. Math. Statist. 25, 714 (1954).

M 16, 604

Jeffreys, H., On the prior probability in the theory of sampling, Proc. Cambridge Philos. Soc. 29, 83 (1933).

Z 6, 69

Jeffreys, H., Some tests of significance, treated by the theory of probability, Proc. Cambridge Philos. Soc. 31, 203 (1935).

Z 11, 316

Jeffreys, H., Further significance tests, Proc. Cambridge Philos. Soc. 32, 416 (1936).

$\mathrm{Z}$ 15, 33

Jeffreys, H., On the relation between direct and inverse methods in statistics, Proc. Roy. Soc. London A 160, 325 (1937).

Z 16, 412

Jeffreys, H., The tests for sampling differences and contingency, Proc. Roy. Soc. London A 162, 479 (1937).

Z 1\%, 316

Jeffreys, H., Significance tests for continuous departures from suggested distributions of chance, Proc. Roy. Soc. London A 164, 307 (1938).

Z 18, 157

Jeffreys, H., Significance tests when several degrees of freedom arise simultaneously, Proc. Roy Soc. London A 165, 161 (1938).

Z 18, 414

Jeffreys, H., The comparison of series of measures on different hypotheses concerning by standard errors. Proc. Roy. Soc. London A 16\%, 367 (1938).

Z 19, 318

Jeffreys, H., The posterior probability distributions of the ordinary and intraclass correlation coefficients, Proc. Roy. Soc. London A 16\%, 464 (1938).

Z 19, 317

Jeffreys, H., The use of minimum $\chi^{2}$ as an approximation to the method of maximum likelihood, Proc. Cambridge Philos. Soc. 34, 156 (1938).

Z 18, 321

Jeffreys, H., Note on the Behrens-Fisher formula, Ann. Eugenics 10, 48 (1940). M 1, 347

Jeffreys, H., Some applications of the method of minimum $\chi^{\prime 2}$, Ann. Eugenics 11, 108 (1941)

M 3, 175

Jeffreys, H., On the significance tests for the introduction of new functions to represent measures, Proc. Roy. Soc. London Ser. A 180, 256 (1942).

M 4, 107

Jeffreys, H., An invariant form for the prior probability in estimation problems, Proc. Roy. Soc. London Ser. A 186. 4.5.3 (1946)。

M 8. 163

Jenkins G. M. Tests of hypotheses in the linear autoregressive model. I. Null hypotheses distributions in the Yule scheme, Biometrika 41, 405 (1954). 
Jenkins, G. M. Tests of hypotheses in the linear autoregressive model. II. Null distributions for higher order schemes: non-null distributions, Biometrika 43, 186 (1956).

M 18, 79

Jensen, A., A short remark on the theory of random sampling and the theory of variance, Skand. Aktuarietidskr. 35, 195 (1953).

M 14, 777

Johnson, E., Estimates of parameters by means of least squares, Ann. Math. Statist. 11, 453 (1940).

M 2,233

Johnson, N. L., Parabolic test for linkage, Ann. Math. Statist. 11, 227 (1940).

M 2,112

$\checkmark$ Johnson, N. L., (See F. N. David) Biometrika 35, 182 (1948).

$\checkmark$ Johnson, N. L., (See F. N. David), Biometrika 37, 42 (1950).

Johnson, N. L., On the comparison of estimators, Biometrika 3\%, 281 (1950).

M 13, 259

Johnson, N. L., Estimators of the probability of the zero class in Poisson and certain related populations, Ann. Math. Statist. 22, 94 (1951).

M 12, 622

-Johnson, N. L., (See F. N. David), Ann. Math. Statist. 22, 382 (1951).

४Johnson, N. L., (See F. N. David), Biometrika 38, 43 (1951).

$\checkmark$ Johnson, N. L. (See F. N. David), Biometrics 8, 275 (1952).

-Johnson, N. L. (See F. N. David), Ann. Math. Statist. 23, 594 (1952).

- Johnson, P. O., The Johnson-Neyman technique, its theory and application, Psychometrika 15, 349 (1950).

M 12, 510

-Johnson, R. B. (See G. E. Albert), Ann. Math. Statist. 22, 596 (1951).

Jones, A. E., Systematic sampling of continuous parameter populations, Biometrika 35, 283 (1948).

M 10, 388

Jones, H. L., Approximating the mode from weighted sample values, J. Amer. Statist. Assoc. 48, 113 (1953).

M 15, 240

Jordan, K., Statistical inference, Magyar Tud. Akad. Mat. Fiz. Oszt. Közleményei 1, 218 (1951).

M 14, 65

Jowett, G. H., Sampling properties of local statistics in stationary stochastic series, Biometrika $\mathbf{4 2}, 160$ (1955).

M 16, 1134

Jowett, G. H., The comparison of means of sets of observations from sections of independent stochastic series, J. Roy. Statist. Soc. Ser. B 17, 208 (1955).

M 1\%, 869

Jung, J., On linear estimates defined by a continuous weight function. Ark. Mat. 3, 199 (1956).

M 1\%, 981

- Junge, C. O. (See D. G. Chapman), Ann. Math. Statist. 27, 375 (1956).

Jurgensen, C. E., Table for determining phi coefficients, Psychometrika 12, 17 (1947). M 8, 477

Kac, M., On the characteristic functions of the distributions of estimates of various deviations in samples from a normal population, Ann. Math. Statist. 19, 257 (1948).
- Kac, M., On tests of normality and other tests of goodness of fit based on distance methods, Ann. Math. Statist. 26, 189 (1955).

M 18, 55

Kallianpur, G., A note on the Robbins-Monro stochastic approximation method, Ann. Math. Statist. 25, 386 (1954).

M 15, 973

-Kallianpur, G., On Fisher's lower bound to asymptotic variance of a consistent estimate, Sankhyā 15, 331 (1955). M 1\%,757

Kaloujnine, L., Quelques idées au sujet du mémoire de M. G. Neymann "L'estimation statistique traitée comme un problème classique de probabilitié," Publ. Math. Debrecen 1, 101 (1949).

M 12, 36

Kamat, A. R., Some properties of estimates for the standard deviation based on deviations from the mean and variate differences, J. Roy. Statist. Soc. Ser. B 15, 233 (1953).

M 15, 726

Kamat, A. R., Distribution theory of two estimates for standard deviation based on second variate differences, Biometrika 41, 1 (1954). M 15,971

Kamat, A. R., Moments of the mean deviation, Biometrika 41, 541 (1954).

M 16, 381

Kanô, S., On the prediction problem of a stationary stochastic process, Mem. Fac. Sci. Kyūsyū Univ. A 6, 173 (1952).

M 14, 889

Katz, L., On the relative efficiencies of BAN estimates, Ann. Math. Statist. 21, 398 (1950).

M 12, 116

Kawata, T., The distribution of grouped moments in large samples, Proc. Imp. Acad. Tokyo 20, 337 (1944)

M $\boldsymbol{\%}, 317$

- Kawata, T., On the characterisation of the normal population by the independence of the sample mean and the sample variance, J. Math. Soc. Japan 1, 111 (1949).

M 11, 188

Kazami, A., Asymptotic properties of the estimates of an unknown parameter in stationary Markoff process, Ann. Inst. Statist. Math. Tokyo 4, 1 (1952).

M 14, 569

Keeping, E. S., Note on a point in the theory of sampling, Amer. Math. Monthly 42, 161 (1935).

Z 11, 126

Keeping, E. S., Note on Wald's method of fitting a straight line when both variables are subject to error, Biometrics 12, 445 (1956).

M 18, 602

Kellerer, H., Eine Verallgemeinerung des einfachen Urnenmodells und ihre Anwendung in der Stichprobentheorie, Allg. Statist. Arch. 39, 221 (1955).

M 1\%, 757

Kempthorne, O., Comments on the note "On a theorem concerning sampling," J. Roy. Statist. Soc. 10\%, 58 (1944).

M 6, 162

Kendall, M. G., Some properties of $k$-statistics, Ann. Eugenics 10, 106 (1940).

M 1, 347

Kendall, M. G., Proof of Fisher's rules for ascertaining the sampling semi-invariants of $k$-statistics, Ann. Eugenics 10, 215 (1940).

M 2, 110

Kendall, M. G., The derivation of multivariate sampling formulae from univariate formulae by symbolic operation, Ann. Eugenics 10, 392 (1940).

M 2,235 
Kendall, M. G., On the method of maximum likelihood, J. Roy. Statist. Soc. 103, 388 (1940).

$\mathrm{M} 2,235$

Kendall, M. G., On seminvariant statistics, Ann. Eugenics 11, 300 (1942).

M 4, 104

$\checkmark$ Kendall, M. G., (See J. O. Irwin), Ann. Eugenics 12, 138 (1944).

Kendall, M. G., The Advanced Theory of Statistics, (Vol. II, Charles Griffin Co., London, W.C.2, 1946).

M 8, 473

- Kendall, D. G., (See M. S. Bartlett) Suppl. J. Roy. Statist. Soc. 8, 128 (1946).

Kendall, M. G., Continuation of Dr. Jones's paper, Biometrika 35, 291 (1948).

M 10, 388

Kendall, M. G., Regression, structure and functional relationship. I, Biometrika 38, 11 (1951).

M 13, 144

Kendall, M. G.. (See J. Durbin) Biometrika 38, $150(1951)$.

Kenney, J. F., The regression systems of two sums having random elements in common, Ann. Math. Statist. 10, 70 (1939).

Z 20, 244

Kenney, J. F., A note on certain formulas used in sampling theory, Amer. Math. Monthly 45, 456 (1938).

Z 19, 358

-Kent, R. H., (See J. von Neumann) Ann. Math. Statist. 12, 153 (1941).

Kerrich, J. E., Least squares, and a generalisation of the "Student"-Fisher theorem, Skand. Aktuarietidskr. 20, 244 (1937).

$\mathrm{Z} \mathbf{1 8}, 35$

Kiefer, J., Stochastic estimation of the maximum of a regression function, Ann. Math. Statist. 23, 462 (1952).

M 14, 299

Kiefer, J., Sequential minimax estimation for the rectangular distribution with unknown range, $A n n$. Math. Statist. 23, 586 (1952).

M 14, 487

Kiefer, J., On minimum variance estimators, Ann. Math. Statist. 23, 627 (1952).

M 15, 241

- Kiefer, J., (See A. Dvoretzky) Ann. Math. Statist. 24, 254 (1953).

$\checkmark$ Kiefer, J., (See A. Dvoretzky) Ann. Math. Statist. 24, 403 (1953).

Kiefer, J., Sequential minimax search for a maximum, Proc. Amer. Math. Soc. 4, 502 (1953).

Kiefer, J., (See M. Kac) Ann. Math Statist 1103 189 (1955).

- Kiefer, J., Sequential tests of hypotheses about the mean occurrence time of a continuous parameter Poisson process, Naval Res. Logist. Quart. 3, 205 (1956)

M 18, 833

-Kiefer, J., (See A. Dvoretzky) Ann. Math. Statist. 2\%, 642 (1956).

Kimball, A. W., On dependent tests of significance in the analysis of variance, Ann. Math. Statist. 22, 600 (1951).

M 13, 368

Kimball, B. F., Sufficient statistical estimation functions for the parameters of the distribution of maximum values, Ann. Math. Statist. 1\%, 299 (1946).

M 8, 475

Kimball, B. F., An approximation to the sampling variance of an estimated maximum value of given frequency based on fit of doubly exponential distribution of maximum values, Ann. Math. Statist. 20, 110 (1949).

M 10, 466

Kimball, B. F., The bias in certain estimates of the parameters of the extreme-value distribution, Ann. Math. Statist. 28, 758 (1956). $\quad$ M 18, 159

King, E. P., The operating characteristic of the control chart for sample means, Ann. Math. Statist. 23, 384 (1952).

M 14, 297

Kingston, J., A Teoria da Inducão Estatística. (The Theory of Statistical Induction), (Instit. Brasil. Geog. e Estatíst. Rio de Janeiro, 1945).

Kitabatake, S., (See Kitabatake, S., (See H. Sugiyama) Math. Japon 3, $152(1955)$.

Kitagawa, T., Successive process of statistical inferences, I, Mem. Fac. Sci. Kyūsyū Univ. A 5, 139 (1950).

M 13, 854

Kitagawa, T., Successive process of statistical inferences. II, Mem. Fac. Sci. Kyūsyū Univ. A 6, 55 (1951).

M 14, 390

Kitagawa, T., Successive process of statistical inferences. III, Mem. Fac. Sci. Kyūsyū Univ. A 6, 131 (1952).

M 14, 997

Kitagawa, T. Successive process of statistical inferences. IV, Bull. Math. Statist. 5, 35 (1952).

M 14, 997

Kitagawa, T., Successive process of statistical inferences. V, Mem. Fac. Sci. Kyūsyū Univ. A \%, 81 (1953).

M 15, 544

Kitagawa, T., Successive process of statistical inferences. VI, Mem. Fac. Sci. Kyūsyū Univ. A 8, 1 (1953).

M 15, 545

Kitagawa, T., Sampling from processes depending upon a continuous parameter, Mem. Fac. Sci. Kyūsyū Univ. A 5, 181 (1950).

M 13, 570

- Kitagawa, T., On the determination of sample size from the two sample theoretical formulation, Bull. Math. Statist. 5, 35 (1953).

M 15, 141

Kitagawa, T., Some contributions to the design of sample surveys, Sankhyā 14, 317 (1955).

M 16, 1132

Kitagawa, T., Some contributions to the design of sample surveys, Sankhya 1\%, 1 (1956). M 18, 833

- Kitahara, T., (See 'T. Kitagawa) Bull. Math. Statist. 5, 35 (1953).

Klerk-Grobben, G., A test for comparing two small unknown probabilities, using samples of equal size, and its power, Statistica, den Haag 8, 7 (1954).

M 16, 499

-Klerk-Grobben, G., Confidence regions for the standard deviation of a normally distributed variate based on the mean range of a number of samples, Statistica, Neerlandica 10, 99 (1956).

M 18, 344

van Klinken, J., Survey of testing and estimation methods with respect to the Poisson distribution, Math. Centrum Amsterdam Statist. Afdeling $\mathbf{S} \mathbf{1 3 3}$ (1954).

M 16, 383

K. N. M., A note on correlation between two unbiased estimators, Calcutta Statist. Assoc. Bull. 4, 72 (1952).

M 14, 190 
Koeppler, H., Das Wahrscheinlichkeitsgesetz zweier wahrer einander zugeordneten Fehler und einige mit diesem zusammenhängende Betrachtungen, Metron 12, 35 (1936).

$\mathrm{Z} \mathbf{1 5}, 118$

\Kogo, K. (See J. Ogawa) Osaka Math. J. \%, 15 (1955).

Kolmogoroff, A., Confidence limits for an unknown distribution function, Ann. Math. Statist. 12, 461 (1941).

$\mathrm{M} \mathrm{4,25}$

Kolmogoroff, A., Sur l'estimation statistique des parametrès de la loi de Gauss, Bull. Acad. Sci. URSS Sér. Math. 6, 3 (1942).

M 4, 221

Kolmogorov, A. N., On the proof of the method of least squares, Uspehi Matem. Nauk 1, 57 (1946).

M 8, 523

Kolmogoroff, A. N., Unbiased estimates, Amer. Math. Soc. Translation No. 98, (1953). M 15, 452

-Kolmogorov, A. N., (See I. M. Gel'fand) Dokl. Akad. Nauk SSSR 111, 745 (1956).

Kolodziejczyk, S., On an important class of statistical hypotheses, Biometrika $\mathbf{2 r}, 161$ (1935).

Z 11, 220

Kolodziejezyk, S., Sur l'erreur de la seconde catégorie dans le problème de M. Student, C.R. Acad. Sci. Paris 19\%, 814 (1933).

Z 8, 25

Konijn, H. S. Some estimates which minimize the least upper bound of a probability together with the cost of observation, Ann. Inst. Statist. Math. Tokyo \%, 143 (1956).

M 18, 425

Koopmans, T. C., Statistical Inference in Dynamic Economic Models (Cowles Commission Monograph No. 10, J. Wiley \& Sons. N.Y., 1950). M 12, 431

Korolyuk, V. S. (See B. V. Gnedenko), Doklady Akad. Nauk SSSR 80, 525 (1951).

Kosambi, D. D.. A bivariate extension of Fisher's z test, Current Sci. 10, 191 (1941).

M 3, 175

Kosambi, D. D., A test of significance for multiple observations, Current Sci. 11, 271 (1942).

M 4, 107

Kosambi, D. D., An extension of the least-squares method for statistical estimation, Ann. Eugenics 13, 257 (1947).

M 9, 49

Kosambi, D. D., Characteristic properties of series distributions, Proc. Nat. Inst. Sci. India 15, 109 (1949).

M 11, 42

Koshal, R. S., Maximal likelihood and minimal $\chi^{2}$ in relation to frequency curves, Ann. Eugenics $\mathbf{9 , 2} 209$ (1939).

M 1, 249

Kozelka, R. M. Approximate upper percentage points for extreme values in multinomial sampling, Ann. Math. Statist. 2\%, 507 (1956).

M 1\%, 1222

Kózniewska, I., Comparison of the efficiency of drawing lots with and without returning them, when the variance of the general population is unknown, Zastos. Mat. 2, 297 (1955).

M 18, 159

Kraft, C., Some conditions for consistency and uniform consistency of statistical procedures, Univ. California Publ. Statist. 2, 125 (1955). M 1\%, 505

Kraft, C., A remark on the roots of the maximum likelihood equation, Ann. Math. Statist. 2\%, 1174 (1956).

M 18, 772

Krishna, P. V. The theory of probability distributions of points on a line, J. Indian Soc. Agric. Statistics 1, 173 (1948).
Krishna, P. V., The first and second moments of some probability distributions arising from points on a lattice and their application, Biometrika $\mathbf{3 6}$, 135 (1949).

M 11, 607

Krishna, P. V., Difference equations of momentgenerating functions for some probability distributions, Nature 165, 370 (1950).

M 11, 446

Krishna, P. V., The theory of probability distributions of points on a lattice, Ann. Math. Statist. 21, 198 (1950).

M 11, 732

Krishna, P. V., Further contributions to the theorv of probability distributions of points on a line. I, J. Indian Soc. Agric. Statistics \$, 141 (1950).

M 12, 271

Krishna, P. V., Problem of distance in sampling, Bull. Inst. Internat. Statist. $\mathbf{2 3 ,} 113$ (1951).

M 16, 1037

Krishna Sastry, K. V., On a certain distribution in the theory of sampling, Proc. Nat. Inst. Sci. India 12, 427 (1946).

M 9, 364

Krishna Sastry, K. V., On a Bessel function of the second kind and Wilks' Z-distribution, Proc. Indian Acad. Sci. Sect. A 28, 532 (1948).

M 10, 387

Kruskal, W., Helmert's distribution, Amer. Math. Monthly 53, 435 (1946).

M 8, 161

-Kruskal, W. H., (See H. T. David) Ann. Math. Statist. 2\%, 797 (1956).

Krylov, V., The serial samples, Acta Univ. Asiae Mediae (Ser $V$-a) 25, 24 pp. (1939). M 8, 594

Krysicki, W. On the combined problem of Bayes and Bernoulli, Zastos. Mat. 2, 172 (1955).

M 16, 940

Kudô, A., Note on the estimation of the mean value of the stochastic process, Bull. Math. Statist. 5, $53(1953)$

M 15, 142

Kudô, A., On the testing of outlying observations, Sankhyā 1\%, 67 (1956).

M 18, 833

Kudô, A., On the confidence interval of the extreme value of a second sample from a normal universe, Bull. Math. Statist. 6, 51 (1956).

M 18, 772

Kudō, H., On a formulation of classical problems of statistics, Nat. Sci. Rep. Ochanomizu Univ. 1, 9 (1951).

M 14, 996

Kudō, H., A remark on the efficient estimation, Nat. Sci. Rep. Ochanomizu Univ. 2, 18 (1951).

M 14, 996

Kudō, H., Dependent experiments and sufficient statistics, Nat. Sci. Rep. Ochanomizu Univ. 4, 151 (1954).

M 16, 730

$\checkmark$ Kudō, T., Analyses of bimodal distributions. (On the decomposition of a bimodal distribution into two normal curves), J. Gakugei Tokushima U. Nat. Sci. Math. 6, 75 (1955).

M 1\%, 1102

Kullback, S., An application of characteristic functions to the distribution problem of statistics, Ann. Math. Statist. 5, 263 (1934).

$\mathrm{Z} \mathbf{1 1}, 32$

Kullback, S., A note on the distribution of a certain partial belonging coefficient, Metron 12, 65 (1935).

Z 13, 175

Kullback, S., On samples from a multivariate normal population, Ann. Math. Statist. 6, 202 (1935). 
Kullback, S., The distribution laws of the difference and quotient of variables independently distributed in Pearson type III laws, Ann. Math. Statist. \%, 51 (1936).

Z 14, 73

Kullback, S., On certain distribution theorems of statistics, Bull. Amer. Math. Soc. 42, 407 (1936).

$\mathrm{Z} \mathrm{14,} 320$

Kullback, S., A note on Neyman's theory of statistical estimation, Ann. Math. Statist. 10, 388 (1939).

M 1, 152

- Kullback, S., A simple sampling experiment on confidence intervals, Ann. Math. Statist. 11, 209 (1940).

M 1, 347

-Kullback, S., On information and sufficiency, Ann. Math. Statist. 22, 79 (1951).

M 12, 623

Kullback, S., An application of information theory to multivariate analysis. II, Ann. Math. Statist. $2 \%$, 122 (1956).

M 1\%. 982

Lal, D. N., On the test of a hypothesis concerning two independent frequency distributions, J. Indian Soc. Agric. Statistics 4, 72 (1952).

M 14, 298

-Lamotte, M., Sur certains problèmes d'estimation dans les cas de double échantillonnage, Biometrics \%, 275 (1951).

M 13, 571

Lancaster, H. O., A reconciliation of $\chi^{2}$, considered from metrical and enumerative aspects, Sankhya 13, 1 (1953).

M 15, 972

Lange, O., Statistical estimation of parameters in Markov processes, Colloq. Math. 3, 147 (1955).

M 16, 1039

Latscha, R., Tests of significance in a $2 \times 2$ contingency table: Extension of Finney's table, Biometrika 40, 74 (1953).

M 14, 1104

Lawley, D. N., A generalization of Fisher's z test, Biometrika 30, 180 (1938).

Z 19, 129

Lawley, D. N., A correction to "A generalization of Fisher's z test," Biometrika 30, 467 (1939).

Z 20, 243

LLawley, D. N., (See C. T. Hsu) Biometrika 31, 238 (1940).

Lawley, D. N., Tests of significance for the latent roots of covariance and correlation matrices, Biometrika 43, 128 (1956).

M 1\%, 1220

Lawley, D. N., A general method for approximating to the distribution of likelihood ratio criteria, Biometrika 43, 295 (1956).

M 18, 521

Lecam, L., On some asymptotic properties of maximum likelihood estimates and related Bayes' estimates, Univ. California Publ. Statist. 1, 277 (1953).

M 14, 998

-Lecam, L., (See C. Kraft), Ann. Math. Statist. 27, 1174 (1956).

Lecam, L., On the asymptotic theory of estimation and testing hypotheses, Proc. Third Berkeley Symp. Math. Stat. \& Prob. I, 129 (1956).

M 18, 947

$\checkmark$ Leech, J. W., (See R. O. Davies), Proc. Cambridge Philos. Soc. 50, 575 (1954).

Lehmann, E., Une propriété optimale de certains ensembles critiques du type $A, C$. R. Acad. Sci. Paris 223, 567 (1946).

M 8, 283

Lehmann, E. L., On families of admissible tests, Ann. Math. Statist. 18, 97 (1947).

M 9, 151
Lehmann, E. L., On optimum tests of composite hypotheses with one constraint, Ann. Math. Statist. 18, 473 (1947). M 9, 454

$\checkmark$ Lehmann, E. L., On the problem of similar regions, Proc. Nat. Acad. Sci. USA 33, 382 (1947).

M 9, 365

Lehmann, E. L., Most powerful tests of composite hypotheses. I. Normal distributions, Ann. Math. Statist. 19, 495 (1948).

M 10, 723

Lehmann, E. L., Some comments on large sample tests, Proc. Berkeley Symp. Math. Stat. \& Prob., pp. 451-457 (1949).

M 10, 388

Lehmann, E. L., (See J. L. Hodges), Ann. Math. Statist. 21, 182 (1950).

-Lehmann, E. L., Completeness, similar regions, and unbiased estimation. I, Sankhyā 10, 305 (1950).

M 12, 511

Lehmann, E. L., Some principles of the theory of testing hypotheses, Ann. Math. Statist. 21, 1 (1950).

M 11, 528

Lehmann, E. L., A general concept of unbiasedness, Ann. Math. Statist. 22, 587 (1951). M 13, 854

Lehmann, E. L., (See J. L. Hodges), Proc. Second Berkeley Symp. Math. Stat. \& Prob., pp. 13-22 (1951).

Lehmann, E. L., On the existence of least favorable distributions, Ann. Math. Statist. 23, 408 (1952).

M 14, 298

Lehmann, E. L., Testing multiparameter hypotheses, Ann. Math. Statist. 23, 541 (1952).

M 14, 666

-Lehmann, E. L., The admissibility of certain invariant statistical tests involving a translation parameter, Ann. Math. Statist. 24, 473 (1953).

M 15, 46

-Lehmann, E. L., (See H. Chernoff) Ann. Math. Statist. 25, 579 (1954).

-Lehmann, E. L., (See J. L. Hodges), J. Roy. Statist. Soc. Ser. B 16, 261 (1954).

-Lehmann, E. L., Completeness, similar regions, and unbiased estimation, II, Sankhya 15, 219 (1955).

M 1\%, 279

-Lehmann, E. L., (See J. L. Hodges), Proc. Third Berkeley Symp. Math. Stat. \& Prob. I, 95 (1956).

M 18, 947

Lehmer, E., Inverse tables of probabilities of errors of the second kind, Ann. Math. Statist. 15, 388 (1944).

M 6, 161

Leibler, R. A., (See S. Kullback), Ann. Math. Statist. 22, 79 (1951).

Leipnik, R. B., Distribution of the serial correlation coefficient in a circularly correlated universe, $A n n$. Math. Statist. 18, 80 (1947).

M 8, 476

Lengyel, B. A., On testing the hypothesis that two samples have been drawn from a common normal population, Ann. Math. Statist. 10, 365 (1939).

M 1, 153

Lev, J., The point biserial coefficient of correlation, Ann. Math. Statist. 20, 125 (1949).

M 10, 465

Levine, H., (See H. Goldberg), Ann. Math. Statist. 1\%, 216 (1946).

-Levine, H., (See L. A. Aroian) J. Amer. Statist. Assoc. 45, 520 (1950). 
Levinsky, V., On the frequency constants of the sum of the several populations, Acta Univ. Asiae Mediae Ser. V-a, 26, (1939). $\quad$ M 8, 474

Lévy, P., Sur la détermination expérimentale de la loi des erreurs, Enseignement Math. 38, 227 (1942).

M 4, 103

Lieberman, G. J., A note on Dodge's continuous inspection plan, Ann. Math. Statist. 24, 480 (1953).

M 15, 240

-Lieberman, G. J., Sampling plans for inspection by variables, J. Amer. Statist. Assoc. 50, 457 (1955).

M 16, 1133

-Lieberman, G. J., Multi-level continuous sampling plans, Ann. Math. Statist. 26, 686 (1955).

M 18, 757

Lindblom, S. G., On the connection between tests of significance for correlation coefficients and for differences between means, Skand. Aktuarietidskr. 29, 12 (1946).

M 8, 42

Linder, A., Statistische Methoden für Naturwissenschafter, Mediziner und Ingenieure, (Verlag Birkhäuser, Basel, 1945).

M $\%, 316$

Lindlev, D. V., Grouping corrections and maximum likelihood equations, Proc. Cambridge Philos. Soc. 46, 106 (1950).

M 11, 258

Lindley, D. V., Estimation of a functional relationship, Biometrika 40, 47 (1953).

M 14, 1104

Lindley, D. V.. Statistical inference, J. Roy. Statist. Soc. Ser. B 15, 30 (1953).

M 15, 242

Linnik, Y. V., On a question of the statistics of dependent events, Izvestiya Akad. Nauk SSSR Ser. Mat. 14, 501 (1950).

M 12, 512

-Littauer, S. B., (See P. Peach) Ann. Math. Statist. 17, 81 (1946).

Lomnicki, Z. A.. 'The standard error of Gini's mean difference, Ann. Math. Statist. 23, 635 (1952).

M 53, 389

Lord, E., The use of range in place of standard deviation in the t-test, Biometrika 34, 41 (1947).

M 8, 394

Lord, E., Power of the modified $t$-test ( $u$-test) based on range, Biometrika 3\%, 64 (1950). M 12, 117

Lord, F. M., Sampling fluctuations resulting from the sampling of test items, Psychometrika 20, 1 (1955).

M 16, 841

Lorenz, P., Drei mathematisch-statistische Arbeiten, Wiss. Z. Humboldt Univ. Berlin Math.-Nat. Reihe 3, 349 (1954).

M 16, 940

Lukacs, E., Characterization of populations by properties of suitable statistics, Proc. Third Berkeley Symp. Math. Stat. \& Prob. II, 195 (1956).

M 18, 942

-Lukaszewicz, J., On measuring by comparison, Zastos. Mat. 2, 225 (1955).

M 1\%, 757

Luvsanceren, Š., Maximum likelihood estimates and confidence regions for unknown parameters of a stationary Gaussian process of Markov type, Doklady Akad. Nauk SSSR 98, 723 (1954).

M 16, 385

Lyapunov, A. A., On choosing from a finite number of distribution laws, Uspehi Matem. Nauk 6, 178 (1951).

M 12, 842
-Madow, L. H., (See W. G. Madow) Ann. Math. Statist. 15, 1 (1944).

Madow, L. H., Systematic sampling and its relation to other sampling designs, J. Amer. Statist. Assoc. 41, 204 (1946).

M $\%, 465$

Madow, W. G., Contributions to the theory of multivariate statistical analysis, Trans. Amer. Math. Soc. 44, 454 (1938).

$\mathrm{Z} \mathbf{2 0}, 40$

Madow, W. G., Note on tests of departure from normality, J. Amer. Statist. Assoc. 35, 515 (1940).

M 2,111

- Madow, W. G., On the theory of systematic sampling, Ann. Math. Statist. 15, 1 (1944).

M 5, 210

Madow, W. G., On a source of downward bias in the analysis of variance and covariance, Ann. Math. Statist. 19, 351 (1948).

M 10, 722

Madow, W. G., On the limiting distributions of estimates based on samples from finite universes, Ann. Math. Statist. 19, 535 (1948). M 11, 554

Madow, W. G., On the theory of systematic sampling, Ann. Math. Statist. 20, 333 (1949). M 11, 261

- Madow, W. G.. (See M. H. Hansen) (John Wiley \& Sons, N.Y., 1953)

Mahalanobis, P. C.. Mathematics and statistics. Sample surveys, Science and Culture Suppl. \%, 1 (1942).

M 5, 130

Malmquist, K. G., On some formulas for the computation of space densities, Ark. Mat. Astr. Fys. No. 8 29B, (1943).

M 6, 235

Maniya, G. M., Practical application of the estimate of the maximum of bilateral deviations of an empirical distribution curve in a given interval of growth of a theoretical law, Soobšceniya Akad. Nauk Gruzin. SSR 14, 521 (1953). M 15, 809

-Mann, H. B., On the choice of the number of class intervals in the application of the chi square test, Ann. Math. Statist. 13, 306 (1942). M 4, 105

- Mann, H. B., On stochastic limit and order relationships, Ann. Math. Statist. 14, 217 (1943).

M 5, 125

Mann, H. B., Note on a paper by C. W. Cotterman and L. H. Snvder, Ann. Math. Statist. 16, 311 (1945)

M $\boldsymbol{\gamma}, 213$

Mann, H. B., The estimation of parameters in certain stochastic processes, Sankhyā 11, 97 (1951).

M 13, 667

Mann, H. B., On the estimation of parameters determining the mean value function of a stochastic process, Sankhyā 12, 117 (1952). M 15, 242

Marakathavalli, N., Unbiased test for a specified value of the parameter in the non-central $F$ distribution, Sankhyā 15, 321 (1955). M 1\%, 170

Maritz, J. S., Estimation of the correlation coefficient in the case of a bivariate normal population when one of the variables is dichotomized, Psychometrika 18, 97 (1953).

M 14, 996

Massey, F. J., A note on the estimation of a distribution function by confidence limits, Ann. Math. Statist. 21, 116 (1950).

M 11, 446

Masuyama, M., The misclassification in the sampling inspection, Rep. Statist. Appl. Res. Union Jap. Sci. Eng. 1, 7 (1952). 
Masuyama, M., A graphical method of estimating parameters in Kapteyn distributions, Rep. Statist. Appl. Res. Union. Jap. Sci. Eng. 1, 32 (1952).

M 14, 487

Masuyama, M., Graphical method of statistical inference. V. On a gamma distribution and related problems, Rep. Statist. Appl. Res. Union Jap. Sci. Eng. 3, 3 (1953).

M 16, 154

Masuyama, M., Mathematical note on area sampling, Sankhyā 13, 241 (1954).

M 15, 810

Masuyama, M., On the error in crop cutting experiment due to the bias on the border of grid. (Application of integral geometry to areal sampling problems. IV.), Sankhyā 14, 181 (1954).

M 16, 727

Masuyama, M., Graphical method of statistical inference, (Maruzen Co., Ltd., Tokyo, 1954).

M 16, 499

Masuyama, M., On a fundamental formula in bulk sampling from the viewpoint of integral geometry, Rep. Statist. Appl. Res. Un. Jap. Sci. Engrs. 4, 85 (1956).

M 18, 425

Matschinski, M., Sur les compositions applicables à l'estimation de la probabilité d'une hypothèse, C.R. Acad. Sci. Paris \$36, 1849 (1953).M 14, 889

- Matsumura, N., (See T. Kudō), J. Gakugei Tokushima U. Nat. Sci. Math. 6, 75 (1955).

Matthai, A., Estimation of parameters from incomplete data with application to design of sample surveys, Sankhyā 11, 145 (1951).

M 13, 571

Matusita, K., Note on the independence of certain statistics, Ann. Inst. Statist. Math. Tokyo 1, 79 (1949).

M 11, 260

Matusita, K., A remark to the Wald's theory of statistical inference, Ann. Inst. Statist. Math. Tokyo 1, 141 (1950).

M 12, 37

Matusita, K., A remark to "On the estimation by the minimum distance method," Ann. Inst. Statist. Math. Tokyo 6, 124 (1954).

M 15, 973

- Matusita, K., On testing statistical hypotheses, Ann. Inst. Statist. Math. Tokyo 6, 133 (1954).

M 16, 728

Mauchly, J. W., Significance test for sphericity of a normal $n$-variate distribution, Ann. Math. Statist. 11, 204 (1940).

M 1, 348

- Mauldon, J. G., (See J. M. Hammersley) Proc. Cambridge Philos. Soc. 52, 476 (1956).

McCarthy, M. D., On the application of the z-test to randomized blocks, Ann. Math. Statist. 10, 337 (1939).

M 1, 154

McKay, A. T., Distribution of the coefficient of variation and the entended " $t$ " distribution, $J$. Roy. Statist. Soc. 95, 695 (1932).

Z 5, 302

McKay, A. T., The distribution of the difference between the extreme observation and the sample mean in samples of $n$ from a normal universe, Biometrika 2\%, 466 (1935).

$\mathrm{Z} \mathbf{1 3}, 30$

McMillan, B., On two problems of sampling, Ann. of Math. 42, 437 (1941).

M 3, 1

- Medgyessy, P., Mathematical investigation of chemical countercurrent distribution, in case of non-complete diffusion, Magyar Tud. Akad. Alkalm. Mat. Int. Közl. 3, 81 (1955).
- Mendonca, P., (See de Varennes) Portugaliae Math. 3, 234 (1942).

Méric, J., Test progressif de l'hypothèse que le paramètre d'une loi binomiale est voisin d'une valeur donnée, C.R. Acad. Sci. Paris 23\%, 1390 (1953).

M 15, 727

Méric, J., Etude de la formule de Walker donnant le fonction "O.C." du test binomial de Wald, C.R. Acad. Sci. Paris 239, 1117 (1954). $\quad$ M 16, 383

Méric, J., Ajustement des constantes d'un test binomial de Wald permettant d'obtenir les expressions exactes de ses caractéristiques, C.R. Acad. Sci. Paris 238, 2142 (1954).

M 16, 272

- Merrington, M., (See H. O. Hartley) Biometrika 33, 296 (1946).

$\checkmark$ Merrington, M., (See E. S. Pearson) Biometrika 35, 331 (1948).

Midzuno, H., On certain groups of inequalities. Confidence intervals for the mean, Ann. Inst. Statist. Math. Tokyo 2, 21 (1950).

M 12, 509

Midzuno, H., An outline of the theory of sampling systems, Ann. Inst. Statist. Math. Tokyo 1, 149 (1950).

M 12, 36

Midzuno, H., On the sampling system with probability proportionate to sum of sizes, Ann. Inst. Statist. Math. Tokyo 3, 99 (1952). M 14, 390 Milicer-Gruzewska, H., The precision of the weighted average, Ann. Math. Statist. 4, 196 (1933).

Z 8, 123

v. Mises, R., On the correct use of Bayes' formula, Ann. Math. Statist. 13, 156 (1942). M 4, 27

v. Mises, R., On the problem of testing hypotheses, Ann. Math. Statist. 14, 238 (1943). M 5, 44

v. Mises, R., On the asymptotic distribution of differentiable statistical functions, Ann. Math. Statist. 18, 309 (1947).

M 9, 194

v. Mises, R., Théorie et application des fonctions statistiques, Univ. Roma. 1st. Naz. Alta Mat. Rend. Mat. e Appl. 11, 374 (1952). $\quad$ M 15, 637

Mitra, S. K., A note on minimum variance in unbiased estimation, Sankhyā 14, 53 (1954). M 16, 383

Miyasawa, K., Minimax estimations, Bull. Math. Statist. 5, 59 (1952).

M 14, 666

Miyasawa, K., On the minimax point estimations, Bull. Math. Statist. 5, 1 (1953).

M 16, 1134

Miyasawa, K., Most stringent tests and invariant tests, Mem. Fac. Sci. Kyūsyū Univ. A 8, 57 (1953).

M 15, 810

Mohnsame, M., Processus stochastiques et interprétation géométrique des équations de M. Matschinski, C. R. Acad. Sci. Paris 236, 1851 (1953).

M 14, 889

Mokashi, V. K., Efficiency of stratification in subsampling designs for the ratio method of estimation, J. Indian Soc. Agri. Statist. 6, 77 (1954). M 17, 869

Molina, E. C., Some fundamental curves for the solution of sampling problems, Ann. Math. Statist. 1\%, 325 (1946).

M 8, 161

Mood, A. M., Note on the L test for many samples, Ann. Math. Statist. 10, 187 (1939). Z Z3, 149

Mood, A. M., On the joint distribution of the medians in samples from a multivariate population, Ann. Math. Statist. 12, 268 (1941).

M 3, 172 
Mood, A. M., On the dependence of sampling inspection plans upon population distributions, Ann. Math. Statist. 14, 415 (1943).

M 5, 210

Mood, A. M.. Tests of independence in contingency tables as unconditional tests, Ann. Math. Statist. 20, 114 (1949).

M 10, 466

Mood, A. M., Introduction to the theory of statistics, (McGraw Hill Book Co., Inc., N.Y., 1950).

M 11, 445

Moore, P. G., A sequential test for randomness, Biometrika 40, 111 (1953).

M 14, 1104

Moore, P. G., The mean successive difference in samples from an exponential population, Trabajos Estadist. 6, 133 (1955).

M 1\%, 869

Moore, P. G., The estimation of the mean of a censored normal distribution by ordered variables, Biometrika 43, 482 (1956).

M 18, 772

Moran, P. A. P., Rank correlation and productmoment correlation, Biometrika 35, 203 (1948).

М 9, 601

Moran, P. A. P., The distribution of the multiple correlation coefficient, Proc. Cambridge Philos. Soc. 46, 521 (1950).

M 11, 732

Moran, P. A. P., Estimation methods for evolutive processes, J. Roy. Statist. Soc. Ser. B 13, 141 (1951).

M 13, 667

-Moran, P. A. P., (See L. N. Chown) Biometrika 38, 464 (1951).

Moran, P. A. P., The random division of an interval. II, J. Roy. Statist. Soc. Ser. B 13, 147 (1951).

M 13, 667

Moran, P. A. P., The estimation of the parameters of a birth and death process, J. Roy. Statist. Soc. Ser. B 15, 241 (1953).

M 15, 545

Moran, P. A. P., A test of significance for an unidentifiable relation, J. Roy. Statist. Soc. Ser. B 18, 61 (1956).

M 18, 426

Morgan, W. A., A test for the significance of the difference between the two variances in a sample from a normal bivariate population, Biometrika 31, 13 (1939).

M 1, 64

Moriguti, S., Confidence limits for a variance component, Rep. Statist. Appl. Res. Union Jap. Sci. Engrs. 3, 29 (1954).

M 16, 384

Moriguti, S., Optimality of orthogonal designs, Rep. Statist. Appl. Res. Union Jap. Sci. Engrs. 3, 75 (1954).

M 16, 842

Moriguti, S., Efficiency of a sampling inspection plan, Rep. Statist. Appl. Res. Union Jap. Sci. Engrs. 4, 71 (1956).

M 18, 426

-Morimoto, H., (See Y. Washio) Bull. Math. Statist. 6, 69 (1956).

Morrell, A. J. H., Note on Wilson and Hilferty's approximation to the $\chi^{2}$-distribution, J. Roy. Statist. Soc. 10\%, 59 (1944).

M 6, 234

- Morse, A. P., The estimation of dispersion from differences, Ann. Math. Statist. 18, 194 (1947).

M 9, 48

-Morton, K. W., (See J. M. Hammersley) Biometrika 41, 296 (1954).

Mosak, J. L., The least-squares standard error of the coefficient of elasticity of demand, J. Amer. Statis. Assoc. 34, 353 (1939).

Z 21, 147
Münzner, H., Das Fehlergesetz des mittleren Fehlers und seine Anwendung, Bl. Versich.-Math. 2, 237 (1932).

$\mathrm{Z} \quad \mathbf{4}, 67$

Murakami, M., Some considerations on the ratio and regression estimates, Bull. Math. Statist. 4, 39 (1950).

M 14, 190

Murty, V. N., A note on Bhattacharyya bounds for the negative binomial distribution, Ann. Math. Statist. 2\%, 1182 (1956).

M 18, 772

Nabeya, S., Note on the moments of the transformed correlation, Ann. Inst. Statist. Math., Tokyo 3, 1 (1951).

M 13, 478

Nagler, H., On the best unbiased quadratic estimate of the variance, Biometrika 3\%, 444 (1950).

M 12, 346

Nair, A. N. K., Distribution of Student's " $t$ " and the correlation coefficient in samples from non-normal populations, Sankhyā 5, 383 (1941). M 4, 164

Nair, K. R., The application of the technique of analysis of covariance to field experiments with several missing or mixed-up plots, Sankhyā 4, 581 (1940).

M 4, 108

Nair, K. R., A note on the method of "fitting of constants" for analysis of non-orthogonal data arranged in a double classification, Sankhya $\mathbf{5}$, 317 (1941).

M 4, 108

Nair, K. R., The recovery of inter-block information in incomplete block designs, Sankhy ā 6, 383 (1944). M 6, 11

Nair, K. R., Certain symmetrical properties of unbiased estimates of variance and covariance, $J$. Indian Soc. Agric. Statistics 1, 162 (1948).

M 11, 448

Nair, K. R., The Studentized form of the extreme mean square test in the analysis of variance, Biometrika 35, 16 (1948).

M 9, 601

Nair, U. S., The standard error of Gini's mean difference, Biometrika 28, 428 (1936). Z Z 15, 311

- Nair, U. S., (See D. J. Bishop), J. Roy. Statist. Soc. Suppl, 6, 89 (1939).

Nair, U. S., The application of the moment function in the study of distribution laws in statistics, Biometrika 30, 274 (1939).

Z 20, 148

Nair, U. S., Probability statements regarding the ratio of standard deviations and correlation coefficient in a bivariate normal population, Sankhyā 5, 151 (1941). M 4, 164 Nair, U. S., A comparison of tests for the significance of the difference between two variances, Sankhyā 5, 157 (1941).

M 4, 222

Nanda, D. N., Distribution of a root of a determinantal equation, Ann. Math. Statist. 19, 47 (1948).

M 9, 453

Nanda, D. N., Limiting distribution of a root of a determinantal equation, Ann. Math. Statist. 19, 340 (1948).

M 10, 135

Nanda, D. N., Distribution of the sum of roots of a determinantal equation under a certain condition, Ann. Math. Statist. 21, 432 (1950). M 12, 192

Nandi, H. K., Note on tests applied to samples from normal bivariate population, Science and Culture 12, 249 (1946).
M 8, 283 
Nandi, H. K., On the power function of Studentised $D^{2}$-statistic, Bull. Calcutta Math. Soc. 38, 79 (1946).

M 8, 394

Nandi, H. K., On the average power of test criteria, Sankhyā 8, 67 (1946).

M 8, 477

Nandi, H. K., A note on Student's $t$ for paired samples, Bull. Calcutta Math. Soc. 39, 61 (1947).

M 10, 51

Nandi, H. K., A note on conditional tests of significance, Bull. Calcutta Math. Soc. 41, 121 (1949).

M 11, 530

Nandi, H. K., On Type $B_{1}$ and Type $B$ regions, Sankhyā 11, 13 (1951).

M 13, 54

Nandi, H. K., On analysis of variance test, Calcutta Statist. Assoc. Bull. 3, 103 (1951). M 13, 143

Nandi, H. K., Joint tests of several hypotheses, Calcutta Statist. Assoc. Bull. 6, 17 (1955).

M 1\%, 280

Narain, R. D., Frequency distribution of $\chi^{2}$-constituents under a linear constraint, Proc. Benares Math. Soc. 8, 33 (1946).

M 10, 553

Narain, R. D., A new approach to sampling distributions of the multivariate normal theory. I, $J$. Indian Soc. Agric. Statistics 1, 59 (1948). M 10, 387

Narain, R. D., A new approach to sampling distributions of the multivariate normal theory. II, J. Indian Soc. Agric. Statistics 1, 137 (1948).

M 11, 607

Narain, R. D., On the distribution of estimated error components in analysis of variance and covariance, J. Indian Soc. Agric. Statistics 1, 70 (1948).

M 10, 722

Narain, R. D., On the completely unbiassed character of tests of independence in multivariate normal systems, Ann. Math. Statist. 21, 293 (1950).

M 12, 37

Narain, R. D., On sampling without replacement with varying probabilities, J. Indian Soc. Agric. Statistics 3, 169 (1951).

M 13, 570

- Narain, R. D., (See P. V. Sukhatme) J. Indian Soc. Agric. Statistics 4, 42 (1952).

- Narain, R. D., (See D. P. Bhattacharyya) Sankhyā 5, 401 (1941).

Narumi, S., On the frequency distribution of the values of the mean, Tôhoku Math. J. 38, 50 (1933).

Z 8, 266

Nayer, P. P. N., An investigation into the application of Neyman and Pearson's $L_{1}$ test, with tables of percentage limits, Statist. Res. Mem. Univ. London 1, 38 (1936).

Z 14, 357

-Nelder, J. A., (See J. M. Hammersley) Proc. Cambridge Philos. Soc. 51, 652 (1955).

-von Neumann, J., The mean square successive difference, Ann. Math. Statist. 12, 153 (1941).

M 3, 7

von Neumann, J., Distribution of the ratio of the mean square successive difference to the variance. Ann. Math. Statist. 12, 367 (1941). M 4, 21

von Neumann, J., A further remark concerning the distribution of the ratio of the mean square successive difference to the variance, Ann. Math. Statist. 13, 86 (1942).

M 4, 22
- Neyman, J., On the problem of $k$ samples, Bull. Int. Acad. Polon. Sci. A 6, 460 (1931); see also, C.R. Soc. Sci. Varsovie 24, 122 (1932). $\quad$ Z 4, 157 - Neyman, J., Further notes on $\chi^{2}$ distribution, Biometrika 22, 298 (1931): see also, C. R. Soc. Sci. Varsovie 24, 108 (1932).

$\mathrm{Z} \mathbf{5}, 212$

- Neyman, J., On the problem of the most efficient tests of statistical hypotheses, Philos. Trans. Roy. Soc. London A 231, 289 (1933).

Z 6, 268

- Neyman, J., The testing of statistical hypotheses in relation to probabilities a priori, Proc. Cambridge Philos. Soc. 29, 492 (1933).

Z 8, 24

Neyman, J., On the two different aspects of the representative method: The method of stratified sampling and the method of purposive selection, J. Roy. Statist. Soc. 9\%, 558 (1934).

$\mathrm{Z} \mathrm{10,72}$

Neyman, J., On the problem of confidence intervals, Ann. Math. Statist. 6, 111 (1935).

Z 12, 363

Neyman, J., Su un teorema concernente le cosiddette statistiche sufficienti, Giorn. 1st. Ital. Attuari 6, 320 (1935).

Z 13, 174

Neyman, J., Sur la vérification des hypothèses statistiques composées, Bull. Soc. Math. France 63, 246 (1935).

$\mathrm{Z}$ 13, 409

Neyman, J., Contributions to the theory of testing statistical hypothesis. I. Unbiased critical regions of type $A$ and type $A_{1}$, Statist. Res. Mem. Univ. London 1, 1 (1936).

Z 14, 321

Neyman, J., Sufficient statistics and uniformly most powerful tests of statistical hypotheses, Statist. Res. Mem. Univ. London 1, 113 (1936).

$\mathrm{Z} \mathrm{14,} 357$

- Neyman, J., Errors of the second kind in testing "Students" hypothesis, J. Amer. Statist. Assoc. 31, 318 (1936).

Z 14, 358

Neyman, J., La vérification de l'hypothèse concernant la loi de probabilité d'une variable aléatoire, C. R. Acad. Sci. Paris 203, 1047 (1936). Z 15, 262

Neyman, J. Outline of a theory of statistical estimation based on the classical theory of probability, Philos. Trans. Roy. Soc. London A $\mathbf{2 3 6 ,} 333$ (1937).

Z 1\%, 124

Neyman, J., "Smooth test" for goodness of fit, Skand. Aktuarietidskr 20, 149 (1937). Z Z 18, 34

Neyman, J., Tests of statistical hypotheses which are unbiased in the limit, Ann. Math. Statist. 9, 69 (1938).

Z 19, 227

Neyman, J., Contribution to the theory of sampling human populations, J. Amer. Statist. Assoc. 33, 101 (1938).

Z 18, 226

Neyman, J., On statistics the distribution of which is independent of the parameters involved in the original probability law of the observed variables, Statist. Res. Mem. Univ. London 2, 58 (1938).

Z $\mathbf{2 1}, 42$

Neyman, J., Conceptious diverses, Actual. Sci. et Industr. 739, (Herman \& Cie, Paris 1938). Z 22, 243

- Neyman, J., Contributions to the theory of testing. statistical hypotheses, Statist. Res. Mem. Univ. London 2, 25 (1938). 
Neyman, J., Lectures and conferences on mathematical statistics. Revised and supplemented by W. Edwards Deming, (Graduate School, U.S. Dept. Agriculture, Washington, D.C., 1938;2d ed. 1952).

Z 18, 265 and M 14, 664

Neyman, J., On one fundamental problem of the mathematical statistics, Acta Univ. Asiae Mediae Ser. V-a, Fasc. 29. (1939).

M 8, 524

Neyman, J., On a statistical problem arising in routine analyses and in sampling inspections of mass production, Ann. Math. Statist. 12, 46 (1941).

M 3, 9

Neyman, J., Fiducial argument and the theory of confidence intervals, Biometrika 32, 128 (1941).

M 3, 175

Neyman, J., Basic ideas and some recent results of the theory of testing statistical hypotheses, J. Roy. Statist. Soc. 105, 292 (1942).

M 5, 44

Neyman, J., Raisonnement inductif ou comportement inductif? Les conceptions modernes de la statistique mathématique, Intern. Stat. Inst. Proc. III, 423 (1947).

M 13, 664

- Neyman, J., Consistent estimates based on partially consistent observations, Econometrica 16, 1 (1948).

M 9, 600

Neyman, J., Contribution to the theory of the $\chi^{2}$ test, Proc. Berkeley Symp. Math. Stat. \& Prob., pp. 239-273 (1949).

M 10, 388

Neyman, J., First course in probability and statistics, (Henry Holt \& Co., N.Y., 1950).

M 12, 270

- Neyman, J., On certain methods of estimating the linear structural relation, Ann. Math. Statist. 22, 352 (1951).

M 13, 259

Neyman, J., Existence of consistent estimates of the directional parameter in a linear structural relation between two variables, Ann. Math. Statist. 22, 497 (1951). M 13, 481

Neyman, J., Foundation of the general theory of statistical estimation, Cong. Int. Phil. des. Sci., Paris IV, 83, (1951).

M 13, 762

Neyman, J., Sur une famille de tests asymptotiques des hypothèses statistiques composées, Trabajos Estadist. 5, 161 (1954).

M 16, 729

Nicholson, C., A geometrical analysis of the frequency distribution of the ratio between two variables, Biometrika 32, 16 (1941). $\quad$ M 2,231

Nicholson, W. L., A computing formula for the power of the analysis of variance test, $A n n$. Math. Statist. 25, 607 (1954).

M 16, 272

Noether, G. E., On a connection between confidence and tolerance intervals, Ann. Math. Statist. 22, 603 (1951).

M 13, 667

Noether, G. E., On a theorem of Pitman, Ann. Math. Statist. 26, 64 (1955).

M 16, 1133

Noether, G. E., Two sequential tests against trend, J. Amer. Statist. Assoc. 51, 440 (1956). M 18, 345

- Nomachi, Y., (See T. Kitagawa) Bull. Math. Statist. 5, 35 (1953).

Nordbotten, S., On the determination of an optimal sample size, Skand. Aktuarietidskr. 3\%, 60 (1954).

M 16, 729

Norris, N., Some efficient measures of relative dispersion, Ann. Math. Statist. 9, 214 (1938).
Norris, N., The standard errors of the geometric and harmonic means and their application to index numbers, Ann. Math. Statist. 11, 445 (1940).

M 2,228

Nybölle, H. C., On the statistical distinction between sets of two-dimensional observations, Skand. Aktuarietidskr. 19, 1 (1936).

Z 14, 269

Oboukhoff, A. M., Sur la corrélation normale des vecteurs, Bull. Acad. Sci. USSR, Ser. Math. 3, 339 (1938).

$\mathrm{Z} \mathrm{19,} 228$

Obukhov, V. M., Applicability of test figures, Akad. Nauk. SSSR Prikl. Mat. Meh. 11, 485 (1947).

M 9, 602

Oderfeld, J., On the dual aspect of sampling plans, Colloquium Math. 2, 89 (1951).

M 13, 142

Oderfeld, J., On sampling inspection with a twosided criterion, Zastos. Mat. 2,210 (1955). M 1\%, 53

Odone, V., Il collaudo di prodotti in serie ed il calcolo delle probabilità, Atti Accad. Sci. Torino Cl. Sci. Fis. Mat. Nat. \%', 407 (1942).

M $\%, 464$

Ogawa, J., On the independence of bilinear and quadratic forms of a random sample from a normal population, Ann. Inst. Statist. Math. Tokyo 1, 83 (1949). M 11, 260

Ogawa, J., Note on the Markoff's theorem on least squares, Osaka Math. J. 2, 145 (1950). M 12, 513

Ogawa, J., On the independence of quadratic forms in a non-central normal system, Osaka Math. J. ק, 151 (1950).

M 12, 509

Ogawa, J., On a confidence interval of the ratio of population means of a bivariate normal distribution, Proc. Japan Acad. 2\%, 313 (1951).

M 13, 962

- Ogawa, J., On the correlation of efficient estimates of unknown parameters, Osaka Math. J. $;, 15$ (1955).

M 1\%, 54

Okamoto, M., Unbiasedness in the test of goodness of fit, Osaka Math. J. 4, 211 (1952). M 14, 666

Okamoto, M., Some combinatorial tests of goodness of fit, Osaka Math. J. 4, 215 (1952). M 14, 666

Olds, E. G., A note on the problem of estimation, Amer. Math. Monthly 44, 92 (1937). Z Z 16, 129

Olds, E. G., On a method of sampling, Ann. Math. Statist. 11, 355 (1940).

M 2,112

Olds, E. G., (See N. C. Severo), Ann. Math. Statist. 2\%, 670 (1956).

Olekiewicz, M., On the efficiency of biased estimates, Ann. Univ. Mariae Curie-Sklodowska Sect. A 3, 103 (1949).

M 12, 36

Olekiewicz, M., Determining number of independent observations $n^{\prime}$, equivalent to $n$ observations that are not independently obtained, Ann. Univ. Mariae Curie-Sklodowska Sect. A 4, 105 (1950).

M 13, 259

Olekiewicz, M., On certain improved estimates of the mean, Ann. Univ. Mariae Curie-Sklodowska Sect. A 5, 139 (1953).

M 15, 46

Olshevsky, L., Two properties of sufficient statistics, Ann. Math. Statist. 11, 104 (1940).

M 1, 249

O'Toole, A. L., On a best value of $R$ in samples of $R$ from a finite population of $N$, Ann. Math. Statist. 5, 146 (1934). 
Ottestad, P., On the test of the hypothesis that the probability of an event is contained within given limits, Skand. Aktuarietidskr. 34, 197 (1951).

M 13, 854

Owen, A. R. G., Ancillary statistics and fiducial distributions, Sankhyā 9, 1 (1948). M 10, 723

Owen, D. B., A double sample test procedure, Ann. Math. Statist. 24, 449 (1953).

$\mathrm{M} \mathrm{15,} 46$

Ozols, V., Generalization of the theorem of GnedenkoKoroluk to three samples in the case of two onesided boundaries, Latvijas PSR Zinātnu Akad. Vēstis 10, 141 (1956).

M 18, 833

Page, E. S., An improvement to Wald's approximation for some properties of sequential tests, J. Roy. Statist. Soc. Ser. B 16, 136 (1954).

M 16, 498

Page, E. S., A test for a change in a parameter occurring at an unknown point, Biometrika 4\%, 523 (1955).

M 1\%, 280

Pateman, J. E., The application of sampling methods to analogue integrators, Elliott J. 1, 110 (1953).

M 14, 909

Patnaik, P. B., The power function of the test for the difference between two proportions in a $2 \times 2$ table, Biometrika 35, 157 (1948).

M 9, 603

Patnaik, P. B., The non-central $\chi^{2}$-and $F$-distributions and their applications, Biometrika 36, 202 (1949).

M 11, 608

Patnaik, P. B., The use of mean range as an estimator of variance in statistical tests, Biometrika 3\%, 78 (1950).

M 12, 116

Patnaik, P. B., A test of significance of the standardised mean, Bull. Inst. Internat. Statist. 23, 163 (1951)

M 16, 1133

Patnaik, P. B., A test of significance of a difference between two sample proportions when the proportions are very small, Sankhya 14, 187 (1954).

M 16, 727

Patnaik, P. B., Hypotheses concerning the means of observations in normal samples, Sankhya $\mathbf{1 5}$, 343 (1955).

M 1\%, 872

Paulson, E., On certain likelihood-ratio tests associated with the exponential distribution, $A n n$. Math. Statist. 12, 301 (1941).

M 3, 174

Paulson, E., An approximate normalization of the analysis of variance distribution, Ann. Math. Statist. 13, 233 (1942).

M 4, 23

Paulson, E., A note on the estimation of some mean values for a bivariate distribution, Ann. Math. Statist. 13, 440 (1942).

M 4, 280

Paulson, E., A multiple decision procedure for certain problems in the analysis of variance, $A n n$. Math. Statist. 20, 95 (1949).

M 10, 467

- Peach, P., A note on sampling inspection, Ann. Math. Statist. 1\%, 81 (1946).

M $\%, 464$

Pearson, E. S., The analysis of variance in cases of non-normal variation, Biometrika 23, 114 (1931).

Z 3, 356

- Pearson, E. S., (See J. Neyman), Bull. Int. Acad. Polon. Sci. A 6, 460 (1931).

-Pearson, E. S., (See J. Neyman), Biometrika 22, 298 (1931).
Pearson, E. S., The percentage limits for the distribution of range in samples from a normal population. $\quad(n \leq 100)$, Biometrika 24, 404 (1932).

Z 5, 368

Pearson, E. S., Comparison of A. 'T. McKay's approximation with experimental sampling results, J. Roy. Statist. Soc. 95, 703 (1932). Z 5, 303

Pearson, E. S., (See J. Neyman), C. R. Soc. Sci. Varsovie 24, 108 (1932).

- Pearson, E. S., (See J. Neyman), C. R. Soc. Sci. Varsovie 24, 122 (1932).

- Pearson, E. S., Methods of statistical analysis appropriate for $k$ samples of two variables, Biometrika 25, 353 (1933).

Z 8, 123

-Pearson, E. S., (See J. Neyman), Proc. Cambridge Philos. Soc. 29, 492 (1933).

- Pearson, E. S., (See J. Neyman), Philos. Trans. Roy. Soc. London A R31, 289 (1933).

- Pearson, E. S., The efficiency of statistical tools and a criterion for the rejection of outlying observations, Biometrika 28, 308 (1936). Z 15, 262

$\checkmark$ Pearson, E. S. (See J. Neyman), Statist. Res. Mem. Univ. London 1, 1 (1936).

-Pearson, E. S. (See J. Neyman), Statist. Res. Mem. Univ. London 1, 113 (1936).

Pearson, E. S. Karl Pearson, an appreciation of some aspects of his life and work. (University Press at Cambridge; Macmillan Co., N.Y., 1938).

$\mathrm{Z} \mathbf{2 1}, 423$

Pearson, E. S. (See R. C. Geary). (Cambridge Univ. Press, London, 1938).

Pearson, E. S., The probability integral transformation for testing goodness of fit and combining independent tests of significance, Biometrika $\mathbf{3 0}$, 134 (1938).

Z 19, 128

Pearson, E. S., "Student" as a statistician, Biometrika 30, 210 (1939).

$\mathrm{Z} \mathbf{2 0}, 40$

Pearson, E. S., Note on Professor Pitman's contribution to the theory of estimation, Biometrika 30, 471 (1939).

Z 20, 149

Pearson, E. S., A note on further properties of statistical tests, Biometrika 32, 59 (1941). M 2,236

Pearson, E. S., Notes on testing statistical hypotheses, Biometrika 32, 311 (1942).

M 4, 26

Pearson, E. S., The probability integral of the mean deviation, Biometrika 33, 252 (1945). M 8, 42

-Pearson, E. S. (See H. O. Hartley), Biometrika 33, 296 (1946).

Pearson, E. S., The choice of statistical tests illustrated on the interpretation of data classed in a $2 \times 2$ table, Biometrika 34, 139 (1947). $\quad$ M 8, 395

Pearson, E. S., Note on Professor Haldane's paper regarding the treatment of rare events, Biometrika 35, 301 (1948).

M 10, 554

Pearson, E. S., $2 \times 2$ tables; the power function of the test on a randomized experiment, Biometrika 35, 331 (1948).

M 10, 388

Pearson, E. S., Some notes on the use of range, Biometrika 3\%, 88 (1950).

M 12, 116

Pearson, E. S., Statistical concepts in their relation to reality, J. Roy. Statist. Soc. Ser. B 1\%, 204 (1955).

M 1\%, 868 
Pearson, E. S., Some aspects of the geometry of statistics. The use of visual presentation in understanding the theory and application of mathematical statistics, J. Roy. Statist. Soc. Ser. A 119, 125 (1956).

M 18, 606

-Pearson, K., Further applications in statistics of the $T_{m}(x)$ Bessel function, Biometrika 24, 293 (1932).

$\mathrm{Z}$ 6, 22

- Pearson, K., Experimental discussion of the $\left(x^{2}, P\right)$ test for goodness of fit, Biometrika 24, 351 (1932).

Z 5, 368

Pearson, K., On the probability that two independent distributions of frequency are really samples from the same parent population, Biometrika $\mathbf{2 4}, 457$ (1932).

Z 6, 21

Pearson, K., On the application of the double Bessel function $\Omega \tau_{1}, \tau_{2}(x)$ to statistical problems, Biometrika 25, 158 (1933).

Z 8,71

Pearson, K., On a method of determining whether a sample of size $n$ supposed to have been drawn from a parent population having a known probability integral has probably been drawn at random, Biometrika 25, 379 (1933).

Z 8, 123

Pearson, K., Thoughts suggested by the papers of Messrs. Welch and Kolodziejczyk (Biometrika, Vol. XXVII, pp. 145-190), Biometrika 2\%, 227 (1935).

Z 11, 220

Pearson, K., Method of moments and method of maximum likelihood, Biometrika 28, 34 (1936).

Z 14, 29

Peek, R. L., Test of an observed difference in the frequency of two results, J. Amer. Statist. Assoc. 32, 532 (1937).

Z 1\%, 273

Peiser, A. M., Asymptotic formulas for significance levels of certain distributions, Ann. Math. Statist. 14, 56 (1943). M 4, 222

Peiser, A. M., Correction to "Asymptotic formulas for significance levels of certain distributions," Ann. Math. Statist. 20, 128 (1949).

M 10, 467

Perks, W., Some observations of inverse probability including a new difference rule, J. Inst. Actuar. 83, 285 (1947).

М 9, 599

Peterson, R. P. (See P. G. Hoel) Ann. Math. Statist. 20, 433 (1949).

Peterson, R. P., Uniformly best constant risk and minimax point estimates, J. Res. Nat. Bur. Standards 48, 49 (1952).

M 13, 854

Peterson, R. P., Constant risk minimax point estimates, Univ. Washington Publ. Math. 3, 77 (1952).

M 14, 298

Peterson, R. P., The determination of classes of constant risk estimates, Univ. Washington Publ. Math. 3, 85 (1952).

M 14, 298

Peterson, R. P., Density unbiased point estimates, Ann. Math. Statist. 25, 398 (1954).

M 15, 973

Petrov, A. A., Test of the hypothesis of the normality of distributions in small samples, Doklady

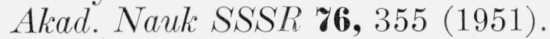

M 12, 622

Picard, H. C., The relation between the true distribution, the error distribution and the observable distribution, Statistica, Leiden 3, 101 (1949).

M 11, 258
Pierce, J. A., A study of a universe of $n$ finite populations with application to moment-function adjustments for grouped data, Ann. Math. Statist. 11, 311 (1940).

M 2, 109

Pillai, K. C. S., Confidence interval for the correlation coefficient, Sankhyā $\boldsymbol{\gamma}, 415$ (1946). M 8, 283 Pillai, K. C. S., Some new test criteria in multivariate analysis, Ann. Math. Statist. 26, 117 (1955).

M 16, 728

Pitcher, T. S., Sets of measures not admitting necessity and sufficient statistics or subfields, Ann. Math. Statist. 28, 267 (1957). $\quad$ M 18, 833

Pitman, E. J. G., Sufficient statistics and intrinsic accuracy, Proc. Cambridge Philos. Soc. 32, 567 (1936).

Z 15, 362

Pitman, E. J. G., The "closest" estimates of statistical parameters, Proc. Cambridge Philos. Soc. 33, 212 (1937).

Z 16, 364

Pitman, E. J. G., Significance tests which may be applied to samples from any populations, J. Roy. Statist. Soc. Suppl. 4, 119 (1937). Z 19, 35

Pitman, E. J. G., Significance tests which may be applied to samples from any populations. II. The correlation coefficient test, J. Roy. Statist. Soc. Suppl. 4, 225 (1937).

$\mathrm{Z}$ 19, 35

Pitman, E. J. G., Significance tests which may be applied to samples from any populations. III. The analysis of variance test, Biometrika $\mathbf{2 9}, 322$ (1938).

Z 18, 226

Pitman, E. J. G., A note on normal correlation, Biometrika 31, 9 (1939).

M 1, 63

Pitman, E. J. G., Tests of hypotheses concerning location and scale parameters, Biometrika 31, 200 (1939).

M 1, 63

Pitman, E. J. G., The estimation of the location and scale parameters of a continuous population of any given form, Biometrika 30, 391 (1939). Z 20, 149

Pitt, H. R., On the theory of statistical procedures, Proc. Cambridge Philos. Soc. 45, 354 (1949).

M 10, 723

Plackett, R. L., Limits of the ratio of mean range to standard deviation, Biometrika 34, 120 (1947).

M 8, 395

Plackett, R. L., An exact test for the equality of variances, Biometrika 34, 311 (1947). M 9, 453

Pollard, H. S., On the relative stability of the median and arithmetic mean, with particular reference to certain frequency distributions which can be dissected into normal distributions, $A n n$. Math. Statist. 5, 227 (1934).

Z 10, 174

Pomerantzewa, E., On the significance of a mean in small samples with the new tables of $T$, the inverse function of the "students" integral, J. Geophys, Moskau 6, 34 (1936).

Z 13, 314

Pompilj, G., Teorie statistiche della significatività e conformità dei risultati sperimentali agli schemi teorici, Statistica, Milano 8, 7 (1948). M 11, 445

Pompilj, G., Sulla significatività delle costanti statistiche, Boll. Un. Mat. Ital. 4, 112 (1949).

M 11, 260

Pompilj, G., Sulle medie combinatorie potenziate dei campioni, Rend. Sem. Mat. Univ. Padova 18, 181 (1949).

M 11, 260 
-Poti, S., (See C. Rao) Sankhyā \%, 439 (1946).

- Pozner, A. N., (See J. E. Freund) Ann. Math. Statist. 2\%, 537 (1956).

-Primakoff, H., (See M. Annis) Rev. Modern Physics 25, 818 (1953).

$\checkmark$ Prins, H. J., (See G. Klerk-Grobben) Statistica, den Haag 8, 7 (1954).

-Prins, H. J., (See J. van Klinken) Math. Centrum Amsterdam Statist. Afdeling Rep. S 133 (1954).

$\checkmark$ Prins, H. J., (See R. Doornbos) Math. Centrum Amsterdam Statist. Afdeling Rep. 187 (1956).

-Proehl, E. A., (See J. W. Fertig), Ann. Math. Statist. 8, 193 (1937).

- Przyborowski, J., Sur les erreurs de la première et de la seconde catégorie dans la vérification des hypothèses concernant la loi de poisson, $C . R$. Acad. Sci., Paris 200, 1460 (1935). Z 11, 262

-Przyborowski, J., Homogeneity of results in testing samples from Poisson series with an application to testing clover seed for dodder, Biometrika 31, 313 (1940).

M 1, 346

Putter, J., Sur une méthode de double échantillonnage pour estimer la moyenne d'une population laplacienne stratifiée, Rev. Inst. Internat. Statistique 19, 231 (1951).

M 16, 384

Quenouille, M. H., Notes on bias in estimation, Biometrika 43, 353 (1956).

M 18,344

Quensel, C., The distributions of the second moment and of the correlation coefficient in samples from populations of type $A$, Lunds Univ. Arsskr., N.F. 34, 1 (1938). . Z 18, 320

Quensel, C., An extension of the validity of "Student"-Fisher's law of distribution, Skand. Aktuarietidskr. 26, 210 (1943).

M $\boldsymbol{\%}, 212$

Quensel, C., The validity of the z-criterion when the variates are taken from different normal populations, Skand. Aktuarietidskr. 30, 44 (1947).

M 9, 151

Råde, L., A note on a modified $t$-test, Skand. Aktuarietidskr. 3\%, 65 (1954).

M 16, 604

$\checkmark$ Rafferty, J. A. (See D. F. Votaw), Psychometrika 15, 339 (1950).

Rajalakshman, D. V., On the extreme values of samples taken from a rectangular population, Math. Student 9, 103 (1941).

M 4, 21

Rajski, C., Comparing general populations on the basis of Bayes' rule, Zastos. Mat. 1, 330 (1954).

M 16, 1039

Rajski, C., On the verification of hypotheses concerning two populations consisting of items marked by attributes, Zastos. Mat. 2, 179 (1955).

M 16, 941

Ramachandran, K. V., On the simultaneous analysis of variance test, Ann. Math. Statist. 2\%, 521 (1956).

M 18, 77

Ramachandran, K. V., Contributions to simultaneous confidence interval estimation, Biometrics 12, 51 (1956).

M 1\%, 1102

Rao, C., Generalisation of Markoff's theorem and tests of linear hypotheses, Sankhy $\bar{a} \boldsymbol{\gamma}$, (1945).

M $\boldsymbol{\gamma}, 132$
Rao, C., Markoff's theorem with linear restrictions on parameters, Sankhyā', 16 (1945).

M \%, 132

Rao, C., Studentised tests of linear hypotheses, Science and Culture 11, 202 (1945). M \%,213

Rao, C., Information and the accuracy attainable in the estimation of statistical parameters, Bull. Calcutta Math. Soc. 3\%, 81 (1945).

M \%, 464

Rao, C., On the linear combination of observations and the general theory of least squares, Sankhya y, 237 (1946).

M 8, 41

Rao, C., On locally most powerful tests when alternatives are one sided, Sankhyā \%, 439 (1916).

M 8, 163

Rao, C. R., On the mean conserving property, Proc. Indian Acad. Sci. (A) 23, 165 (1946).

M 8, 40

Rao, C., Minimum variance and the estimation of several parameters, Proc. Cambridge Philos. Soc. 43, 280 (1947).

M 8, 478

Rao, C., Large sample tests of statistical hypotheses concerning several parameters with applications to problems of estimation, Proc. Cambridge Philos. Soc. 44, 50 (1948).

M 9, 454

Rao, C., Tests of significance in multivariate analysis, Biometrika 35, 58 (1948).

M 9, 602

Rao, C., Sufficient statistics and minimum variance estimates, Proc. Cambridge Philos. Soc. 45, 213 (1949).

M 10, 466

Rao, C., Representation of ' $p$ ' dimensional date in lower dimensions, Sankhyā 9, 248 (1949). M 11, 259

Rao, C., On a transformation useful in multivariate computations, Sankhyā 9,251 (1949). M 11,259

Rao, C., A note on unbiased and minimum variance estimates, Calcutta Statist. Assoc. Bull. 3, 36 (1950).

M 12, 427

Rao, C., On statistics with uniformly minimum variance, Science and Culture 1\%, 483 (1952).

M 13, 962

Rao, C., Some theorems on minimum variance estimation, Sankhyā 12, 27 (1952). M 14, 1103

Rao, C., Minimum variance estimation in distributions admitting ancillary statistics, Sankhyā 12, 53 (1952).

M 14, 1103

Rao, C. R., Advanced statistical methods in biometric research (John Wiley \& Sons, Inc., N.Y., 1952).

M 14, 388

Rao, C. R., Estimation and tests of significance in factor analysis, Psychometrika 20, 93 (1955).

M 1\%, 55

Rao, C. R., (See G. Kallianpur) Sankhyā 15, 331 (1955).

$\checkmark$ Rao, C. R., Some small sample tests of significance for a Poisson distribution, Biometrics 12, 264 (1956).

M 18, 425

Rao, K. S., A simple method of deriving best critical regions similar to the sample space in tests of an important class of composite hypotheses, Biometrika 40, 231 (1953).

M 14, 1104

$\checkmark$ Rasch, G., (See A. Hald) (Den Danske Aktuarforening, pp. 52-65, Copenhagen, 1943).

Rasch, G., A vectorial $t$-test in the theory of normal multivariate distributions, Mat. Tidsskr. B 1950, $76(1950)$. 
Rees, D. H., (See P. M. Grundy) J. Roy. Statist. Soc. 18, 32 (1956).

- Reid, W. T., (See M. Ayer) Ann. Math. Statist. 26, 641 (1955).

Reiersøl, O., Diferencialaj ekvacioj de specimenaraj distribuoj. (Differential equations of sampling distributions), (University Institute of Economics, Oslo, 1950).

M 13, 480

Reiersöl, O., Transformation from probability density to characteristic function by means of differential equations, and the inverse transformation, Portugaliae Math. 10, 71 (1951).

M 13, 480

Reiter, S., Estimates of bounded relative error for the ratio of variances of normal distributions, J. Amer. Statist. Assoc. 51, 481 (1956). M 18, 607

Rényi, A., Eine neve Methode in der Theorie der geordneten Stichproben, Bericht über die Math.Tagung, pp. 203-212 (Verlag Wissenschaften, Berlin, 1953).

M 16, 603

- Resnikoff, G. J., (See G. J. Lieberman) J. Amer. Statist. Assoc. 50, 457 (1955).

Richardson, J. T., A table of Lagrangian coefficients for logarithmic interpolation of standard statistical tables to obtain other probability levels, Suppl. J. Roy. Statist. Soc. 8, 212 (1946). M 9, 48

Richter, H., Zur Gaussischen Verteilung im ndimensionalen Raume, Z. Angew. Math. Mech. 29, 161 (1949).

M 11, 258

Richter, H., Über die Testärke des Fisherschen Testes, Z. Angew. Math. Mech. 30, 197 (1950).

M 1\%, 271

Ricker, W. E., The concept of confidence on fiducial limits applied to the Poisson frequency distribution, J. Amer. Statist. Assoc. 3\%, 349 (1937).

Z 16, 313

Rider, P. R., A note on small sample theory, $J$. Amer. Statist. Assoc. 26, 172 (1931). Z \%, 200

Rider, P., Certain moment functions for Fisher's $K$-statistics in samples from a finite population, Acta Univ. Asiae Mediae Ser. V-a 30, (1939).

M 8, 476

Rietz, H. L., Comments on applications of recently developed theory of small samples, J. Amer. Statist. Assoc. 26, 1950 (1931).

Z\%, 199

Rietz, H. L., On the frequency distribution of certain ratios, Ann. Math. Statist. \%, 145 (1936).

Z 15, 311

Rietz, H. L., Some topics in sampling theory, Bull. Amer. Math. Soc. 43, 209 (1937). Z 16, 314

Rietz, H. L., On a recent advance in statistical inference, Amer. Math. Monthly 45, 149 (1938).

Z 18, 226

Rietz, H. L., On the distribution of the "student" ratio for small samples from certain non-normal populations, Ann. Math. Statist. 10, 265 (1939).

M 1, 23

Rijkoort, P. J., A generalisation of Wilcoxon's test, Nederl. Akad. Wetensch. Proc. Ser. A 55, 394 (1952).

M 14, 391

Rios Garcia, S., (See F. Azorín Poh) Instituto Nacional de Estadistica, Madrid, (1950).

Ríos, S., Introducción a los metodos de la estadistica. $\boldsymbol{2}^{a}$ parte, (Madrid, 1954).

M 16, 726
Robbins, H., The distribution of a definite quadratic form, Ann. Math. Statist. 19, 266 (1948).

M 9, 601

Robbins, H., 'The distribution of Student's $t$ when the population means are unequal, Ann. Math. Statist. 19, 406 (1948). M 10, 134

-Robbins, H., (See R. R. Bahadur) Ann. Math. Statist. 21, 469 (1950).

Robbins, H. (See D. G. Chapman), Ann. Math. Statist. 22, 581 (1951).

- Robbins, H. (See S. G. Ghurye), Biometrika 41, 146 (1954).

Robbins, H., An empirical Bayes approach to statistics, Proc. Third Berkeley Symp. Math. Stat. \& Prob. 1, 157 (1956).

M 18, 947

Romanovski, V. I., On inductive conclusions in statistics, C. R. Acad. Sci. URSS 2\%, 419 (1940).

M \%, 112

Romanovskií, V. I., Evaluation of a plan of statistical quality testing, Akad. Nauk Uzbek. SSR Trudy Inst. Mat. Meh. 15, 11 (1955).

M 1\%, 757

Romanovskií, V. I., On a statistical criterion of D. I Mendeleev, Akad. Nauk Uabek. SSR Trudy Inst. Mat. Meh. 15, 31 (1955).

M 1\%, 757

Romanovski, V. I., Analytical inequalities and statistical tests, Bull. Acad. Sci. URSS, Sér. Math. 4, 457 (1938).

Z 19, 356

Romanovsky, W., Sur certains théorèmes concernant la méthode des moindres carrés, C. R. Acad. Sci. URSS 51, 263 (1946).

M 8, 54

Ronge, F., Die Verhältnisschätzung (ratio estimate) nach der Methode des "Veränderungsfaktors" und der "additiven Veränderung'sgrösse," Mitteilungsbl. Mat. Statist. 6, 221 (1954). M 16,604

Rosenblatt, J. R. (See W. Hoeffding), Ann. Math. Statist. 26, 52 (1955).

Rosenblatt, M., Limit theorems associated with variants of the von Mises statistic, Ann. Math. Statist. R3, 617 (1952).

M 14, 665

-Rosenblatt, M. (See V. Grenander), Proc. Nat. Acad. Sci. USA 40, 812 (1954).

Rosenblatt, M., On the estimation of regression coefficients of a vector-valued time series with a stationary residual, Ann. Math. Statist. 2\%, 99 (1956).

M 1\%, 871

-Ross, E. L., (See J. E. Jackson), J. Amer. Statist. Assoc. 50, 416 (1955).

$\checkmark$ Roy, S. N., The use and distribution of the Studentized $D^{2}$ - statistic when the variances and covariances are based on $k$ samples, Sankhy $\bar{a}$ 4, 535 (1940).

M 4, 105

$\checkmark$ Roy, S. N., On hierarchical sampling, hierarchical variances and their connexion with other aspects of statistical theory, Science and Culture 6, 189 (1940).

M 5, 43

Roy, S. N., The sampling distribution of $p$-statistics and certain allied statistics of the non-null hypothesis, Sankhyā 6, 15 (1942).

M 4, 106

Roy, S. N., The individual sampling distribution of the maximum, the minimum and any intermediate of the $p$-statistics on the null-hypothesis, Sankhya \%, 133 (1945). 
Roy, S. N., Multivariate analysis of variance: the sampling distribution of the numerically largest of the $p$-statistics on the non-null hypothesis, Sankhyā 8, 15 (1946).

M 8, 475

Roy, S. N., A note on multivariate analysis of variance when the number of variates is greater than the number of linear hypotheses per character, Sankhyā 8, 53 (1946).

M 8, 475

Roy, S. N., Notes on testing of composite hypotheses, Sankhya 8, 257 (1947).

M 9, 454

Roy, S. N., Notes on testing of composite hypotheses. II, Sankhyā 9, 19 (1948).

M 11, 42

- Roy, S. N., On the construction of an unbiassed and most powerful critical region out of any given statistic, Calcutta Statist. Assoc. Bull. 1, 177 (1948).

M 11, 608

Roy, S. N., Univariate and multivariate analysis as problems in testing of composite hypotheses. I, Sankhyā 10, 29 (1950).

M 12, 37

Roy, S. N., On a property of Bayes solutions in the Neyman-Pearson set-up, Calcutta Statist. Assoc. Bull. 4, 67 (1952).

M 14, 190

Roy, S. N., On some aspects of statistical inference, Proc. Internat. Cong. Math. 1, 555 (1952).

M 13, 366

Roy, S. N., On a heuristic method of test construction and its use in multivariate analysis, Ann. Math. Statist. 24, 220 (1953).

M 15, 241

$\checkmark$ Roy, S. N., Simultaneous confidence interval estimation, Ann. Math. Statist. 24, 513 (1953).

M 15, 726

Roy, S. N., Some further results in simultaneous confidence interval estimation, Ann. Math. Statist. 25, 752 (1954).

M 16, 382

Roy, S. N., A note on "Some further results in simultaneous confidence interval estimation," $A n n$. Math. Statist. 2\%, 856 (1956).

M 18, 772

Ruben, H., On the moments of the range and product moments of extreme order statistics in normal samples, Biometrika 43, 458 (1956). M 18, 607

-Rubin, H., (See T. W. Anderson), Ann. Math. Statist. 21, 570 (1950).

$\checkmark$ Rubin, H., (See M. A. Girshick), Ann. Math. Statist. 23, 114 (1952).

Rubin, H., Uniform convergence of random functions with applications to statistics, Ann. Math. Statist. 2\%, 200 (1956).

$M \mathbf{1 7}, 869$

-Rubin, H., (See M. A. Girshick), Ann. Math. Statist. 26, 276 (1955).

$\checkmark$ Rubin, H., (See H. Chernoff), Proc. Third Berkeley Symp. Math. Stat. \& Prob. I, 19 (1956).

Rushton, S., On a sequential $t$-test, Biometrika $\mathbf{3 \%}$, 326 (1950).

M 13, 367

Rushton, S., On a two-sided sequential $t$-test, Biometrika 39, 302 (1952).

M 14, 665

Sakaguchi, M., Notes on statistical applications of the information theory, Rep. Statist. Appl. Res. Union Jap. Sci. Eng. 1, 27 (1952). M 14, 996

Sakaguchi, M., Notes on statistical applications of information theory. II, Rep. Statist. Appl. Res. Un. Jap. Sci. Engrs. 4, 57 (1955).
Sakaguchi, M., On minimax tests of hypotheses, Rep. Statist. Appl. Res. Un. Jap. Sci. Engrs. 3, 130 (1955).

M 16, 1039

Sakamoto, H., On the distributions of the product and the quotient of the independent and uniformly distributed random variables, Tôkoku Math. J. 49, 243 (1943).

M 8, 523

Sakamoto, H., On the criteria of the independence and the degrees of freedom of statistics and their applications to the analysis of variance, Ann. Inst. Statist. Math. Tokyo 1, 109 (1949).

M 11, 260

- Sakamoto, H. (See T. Kawata) J. Math. Soc. Japan 1, 111 (1949).

MR 11, 188

Salvemini, T., Sui momenti di una variabile casuale somma di variabili dipendenti, Accad. Sci. Fis. e Mat. Napoli, Rend. \%, 40 (1937). Z 18, 156

- Sandberg, H. D. (See G. Klerk-Grobben) Statistica, Neerlandica 10, 99 (1956).

Sandelius, M., Unbiased estimation based on inverse hypergeometric sampling, Kungl. Lantbrukshögskolans Annaler 18, 123 (1951).

M 14, 65

Sandelius, M., Truncated inverse binomial sampling, Skand. Aktuarietidskr. 34, 41(1951). M 14, 665

Sandelius, M., A confidence interval for the smallest proportion of a binomial population, $J$. Roy. Statist. Soc. Ser. B 14, 115 (1952).

M 14, 488

Sandelius, M., Some unbiased estimates for a type of two-phase sampling, Kungl. Lantbrukshögskolans Annaler 19, 113 (1953).

M 15, 142

Sankara Pillai, K., A note on Poisson distribution, Proc. Indian Acad. Sci. Sect. A 18, 179 (1943).

M 5, 128

Sarhan, A. E., Estimation of the mean and standard deviation by order statistics, III, Ann. Math. Statist. 26, 576 (1955).

M 1\%, 504

- Sarhan, A. E., Estimation of location and scale parameters by order statistics from singly and doubly censored samples, Ann. Math. Statist. 2\%, 427 (1956).

M 18, 238

Sarkadi, K., On the rule of dualism concerning the Bayes' probability limits of the fraction defective, Magyar Tud. Akad. Alkalm. Mat. Int. Közl. $\boldsymbol{2}, 275$ (1954).

M 16, 384

Sarkadi, K., On the a priori beta distribution of fraction defective, Magyar Tud. Akad. Alkalm. Mat. Int. Közl. R, 287 (1954).

M 16, 384

Sastry, N. S. R., The range of samples taken from a rectangular population, $J$. Indian Math. Soc. 1, 228 (1935).

Z 13, 30

Sato, R., Mathematical Statistics (Baifûkan, Tokyo, 1948).

Ḿ 13, 366

Sato, R., The $r$ tests relating to the regression, $A n n$. Inst. Statist. Math. Tokyo 3, 45 (1951).

M 13, 571

Satterthwaite, F. E. Synthesis of variance, Psychometrika 6, 309 (1941).

M 3, 172

Satterthwaite, F. E., A generalized analysis of variance, Ann. Math. Statist. 13, 34 (1942).

M 4, 24

Satterthwaite, F. E., Linear restrictions on chisquare, Ann. Math. Statist. 13, 326 (1942).

M 4, 104 
- Savage, L. J. (See P. R. Halmos), Ann. Math. Statist. 20, 225 (1949).

- Savage, L. J. (See M. A. Girshick), Proc. Second Berkeley Symp. Math. Stat. \& Prob., pp. 53-73 (1951).

Savur, S. R., The use of the median in tests of significance, Proc. Indian Acad. Sci. Sect. A 5, 564 (1937).

Z 1\%, 127

Sawkins, D. T., Remarks on goodness of fit of hypotheses and on Pearson's $\chi^{2}$ test, J. Proc. Roy. Soc. New South Wales 75, 85 (1941).

M 3, 175

Schäfer, W., Bayes-Funktion ohne Hypothese, Mitteilungsblatt Math. Statist. 5, 70 (1953).

M 14, 889

Schäfer, W., Das Mutungsproblem der BesetzungsVerteilung, Mitteilungsblatt Math. Statist. 6, 1 (1954).

M 15, 972

Scheffé, H., On the theory of testing composite hypotheses with one constraint, Ann. Math. Statist. 13, 280 (1942).

M 4, 107

Scheffé, H., On the ratio of the variances of two normal populations, Ann. Math. Statist. 13, 371 (1942).

M 4, 164

Scheffé, H., On solutions of the Behrens-Fisher problem, based on the $t$-distribution, Ann. Math. Statist. 14, 35 (1943).

M 4, 221

Scheffé, H., Note on the use of the tables of percentage points of the incomplete beta function to calculate small sample confidence intervals for a binomial $p$, Biometrika 33, 181 (1944). M 6, 9

Scheffé, H., A note on the Behrens-Fisher problem, Ann. Math. Statist. 15, 430 (1944).

M 6, 234

Scheffé, H., The relation of control charts to analysis of variance and chi-square tests, J. Amer. Statist. Assoc. 42, 425 (1947).

M 9, 48

- Scheffé, H., (See E. L. Lehmann) Proc. Nat. Acad. Sci. USA 33, 382 (1947).

- Scheffé, H., (See E. L. Lehmann) Sankhyā 10, $305,(1950)$.

- Scheffé, H., (See H. Chernoff) Ann. Math. Statist. 23, 213 (1952).

Scheffé, H., A method for judging all contrasts in the analysis of variance, Biometrika 40, 87 (1953).

M 15, 239

Scheffé, H., Statistical methods for evaluation of several sets of constants and several sources of variability, Chem. Engrg. Progress 50, 200 (1954).

M 16, 54

- Scheffé, H., (See E. L. Lehmann) Sankhyā 15, 219 (1955).

von Schelling, H., Zur Beurteilung einer alternativen Stichprobe von $n$ Beobachtungen, Deutsche Math. 5, 107 (1940).

M ?, 112

von Schelling, H., Statistische Schätzungen auf kombinatorischer Grundlage, Z. Angew. Math. Mech. 21, 52 (1941).

M 3, 7

Schilling, W., A frequency distribution represented as the sum of two Poisson distributions, J. Amer. Statist. Assoc. 42, 407 (1947).

M 9, 48

Schmetterer, L., Über ein Beispiel aus der Statistik, Z. Angew. Math. Mech. 32, 281 (1952).

M 14, 391
Schmetterer, L., Zur Bayesschen Regel, Statist. Vierteljschr. 5, 174 (1952).

M 14, 1102

Schmetterer, L. Bemerkungen zum Verfahren der stochastischen Iteration, Österreich. Ing.-Arch. $\boldsymbol{\%}$ 111 (1953).

M 14, 1103

Schmetterer, L., Sur l'approximation stochastique, Bull. Inst. Internat. Statist. 24, 203 (1954).

M 16, 941

Schmetterer, L., Zum Sequentialverfahren von Robbins und Monro, Monatsh. Math. 58, 33 (1954).

M 15, 809

Schutzenberger, M. P., Sur les rapports entre la quantité d'information au sens de Fisher et au sens de Wiener, C. R. Acad. Sci. Paris 232, 925 (1951).

M 12, 623

-Schutzenberger, M., (See M. Lamotte) Biometrics g, 275 (1951).

Schutzenberger, M. P., Contribution aux applications statistiques de la théorie de l'information, Publ. Inst. Statist. Univ. Paris 3, 3 (1954).

M 17, 1099

-Scott, E. L., (See J. Neyman) Econometrica 16, 1 (1948).

Scott, E. L., Note on consistent estimates of the linear structural relation between two variables, Ann. Math. Statist. 21, 284 (1950). M 11, 733

- Scott, E. L., (See J. Neyman) Ann. Math. Statist. 22, 352 (1951).

Seal, H. L., A note on the $\chi^{2}$ smooth test, Biometrika 35, 202 (1948).

M 11, 42

Seal, H. L., The estimation of mortality and other decremental probabilities, Skand. Aktuarietidskr. 3\%, 137 (1954).

M 1\%, 279

Seal, K. C., On errors of estimates in various types of double sampling procedure, Sankhya 11, 125 (1951).

M 13, 570

Seal, K. C., On certain extended cases of double sampling, Sankhyā 12, 357 (1953). M 15, 544

Seal, K. C., On minimum variance among certain linear functions of order statistics, Ann. Math. Statist. 27, 854 (1956).

M 18, 159

Seelbinder, B. M., On Stein's two-stage sampling scheme, Ann. Math. Statist. 24, 640 (1953).

M 15, 637

Segal, I. E., Fiducial distribution of several parameters with application to a normal system, Proc. Cambridge Philos. Soc. 34, 41 (1938).

Z 18, 157

-Seguchi, T., Note on the statistical inferences of certain continuous stochastic processes, Mem. Fac. Sci. Kyūsyū Univ. A 8, 187 (1954). M 16, 385

Sen, A. R., On the estimate of the variance in sampling with varying probabilities, J. Indian Soc. Agric. Statist. 5, 119 (1953).

M 16, 841

Sen, A. R., On the selection of $n$ primary sampling units from a stratum structure $(n \geq 2)$, Ann. Math. Statist. 26, 744 (1955).

M 1\%, 504

Seth, G. R., On the variance of estimates, Ann. Math. Statist. 20, 1 (1949).

M 10, 554

- Seth, G. R., (See P. U. Sukhatme) J. Indian Soc. Agric Statist. 4, 5 (1952). 
Sevast'yanov, B. A., The theory of branching random processes, Uspehi Matem. Nauk 6, 47 (1951).

M 13, 763

- Severo, N. C., A comparison of tests on the mean of a logarithmico-normal distribution with known variance, Ann. Math. Statist. 28, 670 (1956).

M 18. 426

Shafei, A. M. N., On the standard deviation of samples drawn from a type III distribution, Proc. Math. Phys. Soc. Egypt 1, 1 (1939).

M $\%, 212$

Shen, C. L., Fundamentals of the theory of inverse sampling, Ann. Math. Statist. 7, 62 (1936).

Z 15, 73

Shenton, L. R., Maximum likelihood and the efficiency of the method of moments, Biometrika $\mathbf{3 \%}$, 111 (1950).

M 12, 193

Shenton, L. R., Efficiency of the method of moments and the Gram-Charlier Type A distribution, Biometrika 38, 58 (1951).

M 13, 142

Shewhart, W. A., Random sampling, Amer. Math. Monthly 38, 245 (1931).

Z 1, 400

Shimada, S., Power of R-chart, Rep. Statist. Appl. Res. Union Jap. Sci. Eng. 3, 70 (1954).

M 16, 727

Shone K. J., Relations between the standard deviation and the distribution of range in non-normal populations, J. Roy. Statist. Soc. (B) 11, 85 (1949).

M 11, 260

Sichel, H. S., The estimation of the parameters of a negative binomial distribution with special reference to psychological data, Psychometrika 16, 107 (1951).

M 13, 53

Silberstein, L., On two accessories of three-dimensional colorimetry. I. The probable error of colorimetric tensor components as derived from a number of color matchings. II. The determination of the principal colorimetric axes at any point of the color threefold, J. Opt. Soc. Amer. 36, 464 (1946).

M 8, 44

Sillitto, G. P., Note on approximations to the power function of the " $2 \times 2$ comparative trial," Biometrika 36, 347 (1949).

M 11, 447

- Silverman, E., (See M. Aver) Ann. Math. Statist. 26, 641 (1955).

Simaika, J. B., On an optimum property of two important statistical tests, Biometrika $\mathbf{3 2}, 70$ (1941).

M 2, 236

Simon, H. A., Symmetric tests of the hypothesis that the mean of one normal population exceeds that of another, Ann. Math. Statist. 14, 149 (1943).

M 5, 128

Simonsen, W., On the distributions of certain functions of samples from a multivariate infinite population, Skand. Aktuarietidskr. 20, 200 (1937).

Z 17, 411

Simonsen, W., On distributions of functions of samples from a normally distributed infinite population, Skand. Aktuarietidskr. 27, 235 (1944).

M $\%, 212$

Simonsen, W., On distributions of functions of samples from a normally distributed infinite population. II, Skand. Aktuarietidskr. 28, 20 (1945).
Simpson, H., On a theorem concerning sampling, J. Roy. Statist. Soc. 106, 266 (1943). M 6, 9 Simpson, P. B., Note on the estimation of a bivariate distribution function, Ann. Math. Statist. 22, 476 (1951).

M 13, 142

- Singh, D., (See P. V. Krishna) Bull. Inst. Internat. Statist. 23, 113 (1951).

Singh, D., Problems in statistical hypotheses involving several parameters, J. Indian Soc. Agric. Statist. 5, 78 (1953).

M 16, 272

Singh, D., On efficiency of the sampling with varying probabilities without replacement, J. Indian Soc. Agric. Statist. 6, 48 (1954).

M 1\%, 869

Siraždinov, S. H., A simple statistical acceptance control, Akad. Nauk Uzbek. SSR. Trudy Inst Mat. Meh. 15, 41 (1955).

M 1\%, 757

- Sitgreaves, R., (See M. A. Girshick) Ann. Math. Statist. 26, 276 (1955).

Skellam, J. G., The frequency distribution of the difference between two Poisson variates belonging to different populations, J. Roy. Statist. Soc. 109, 296 (1946).

M 8, 592

Skellam, J. G., The distribution of the moment statistics of samples drawn without replacement from a finite population, J. Roy. Statist. Soc. Ser. $B$ 11, 291 (1949).

M 11, 607

Smirnoff, N., Sur les écarts de la courbe de distribution empirique, Rec. Math. 6, 3 (1939).

M 1, 246

Smirnoff, N., On the estimation of the discrepancy between empirical curves of distribution for two independent samples, Bull. Math. Univ. Moscou ?, 16 pp. (1939).

M 1, 345

Smirnov, N., Table for estimating the goodness of fit of empirical distributions, Ann. Math. Statist. 19, 279 (1948).

M 9, 599

Smirnov, N. V., On the Cramér-Mises criterion, Uspehi Matem. Nauk 4, 196 (1949). M 11, 261

Smirnov, N. V., On the construction of confidence regions for the density of distribution of random variables, Doklady Akad. Nauk SSSR \%4, 189 (1950).

M 12, 271

Smirnov, N. V., On the statistical estimation of transition probabilities in Markov chains, Vestnik Leningrad Univ. 10, 47 (1955).

M 18,757

Smith, H. F., Standard errors of means in sampling surveys with two-stage sampling, J. Roy. Statist. Soc. 110, 257 (1947).

M 9, 603

Smith, J. H., Estimation of linear functions of cell proportions, Ann. Math. Statist. 18, 231 (1947).

M 8, 593

Smith, W. L., (See D. R. Cox) Biometrika 41, 91 (1954).

-Smith, S. M., (See J. B. S. Haldane) Biometrika 43, 96 (1956).

- Sobel, M., (See B. Epstein) Ann. Math. Statist. 25, 373 (1954).

- Sobel, M., (See B. Epstein) Ann. Math. Statist. 26, 82 (1955).

Sobel, M., Statistical techniques for reducing the experiment time in reliability studies, Bell System Tech. J. 35, 179 (1956).
M 1\%, 640 
Solomon, L., Statistical estimation, J. Inst. Actuaries Students' Soc. '7, 144 (1948).

M 9, 366

-Solomon, H., (See G. J. Lieberman) Ann. Math. Statist. 26, 686 (1955).

Somerville, P. N., Some problems of optimum sampling, Biometrika 41, 420 (1954). M 16, 604

Starkey, D. M., A test of the significance of the difference between means of samples from two normal populations without assuming equal variances, Ann. Math. Statist. 9, 201 (1938).

Z 19, 358

Steffensen, J. F., Free functions and the "Student"Fisher theorem, Skand. Aktuarietidskr. 19, 108 (1936).

Z 14, 269

Steffensen, J. F., On the $\omega$ test of dependence between statistical variables, Skand. Aktuarietidskr. 24, 13 (1941).

M 3, 5

Stein, C., A two-sample test for a linear hypothesis whose power is independent of the variance, $A n n$. Math. Statist. 16, 243 (1945).

M $\boldsymbol{y}, 213$

-Stein, C., (See E. L. Lehmann) Ann. Math. Statist. 19, 495 (1948).

Stein, C., Unbiased estimates with minimum variance, Ann. Math. Statist. 21, 406 (1950).

M 12, 192

Stein, C. M., A property of some tests of composite hypotheses, Ann. Math. Statist. 22, 475 (1951).

M 13, 143

-Stein, C. M., (See E. L. Lehmann) Ann. Math. Statist. 24, 473 (1953).

- Stuart, A., (See D. R. Cox) Biometrika 4\%, 80 (1955).

Stein, C., The admissibility of Hotelling's 'T2-test, Ann. Math. Statist. 27, 616 (1956). M 18, 243

Stein, C., Inadmissibility of the usual estimator for the mean of a multivariate normal distribution, Proc. Third Berkeley Symp. Math. Stat. \& Prob. I, 197 (1956).

M 18, 948

Stein, C., Efficient nonparametric testing and estimation, Proc. Third Berkeley Symp. Math. Stat. \& Prob. I, 187 (1956).

M 18, 948

Steinhaus, H., Sur l'interprétation des résultats statistiques, Colloquium Math. 1, 232 (1948).

M 10, 312

Steinhaus, H., Elementary inequalities between the expected values of current estimates of variance, Colloquium Math. 1, 312 (1948).

M 10, 724

Steinhaus, H., Quality control by sampling (a plea for Bayes' rule), Colloquium Math. 2, 98 (1951).

M 13, 854

Steinhaus, H., The principles of statistical quality control, Zastosowania Mat. 1, 4 (1953). M 15, 47

- Steinhaus, H. (See J. Lukaszewicz) Zastosowania Mat. 2, 225 (1955).

Stene, S., A preliminary note on tests of significance and problems of goodness of fit, Norske Vid. Selsk., Forh. 11, 68 (1938).

$\mathrm{Z} \mathbf{2 0}, 40$

Sterne, T. E., Some remarks on confidence or fiducial limits, Biometrika 41, 275 (1954).

M 15, 971

Stevens, W. L., Solution to a geometrical problem in probability, Ann. Eugenics 9, 315 (1939).

M 1, 245
Stevens, W. L. Statistical estimation. Theory of the estimation of two or more parameters, illustrated by the problem of the estimation of the frequencies of the genes of blood groups, Revista Fac. Ci. Univ. Coimbra 12, 23, (1944).

W. M 8, 161

Stevens, W. L., Application of the $\chi^{2}$ test to the analysis of variance, Revista Fac. Ci. Univ. Coimbra 13, 4 (1945).

M 8, 161

Stevens, W. L., Fiducial limits of the parameter of a discontinuous distribution, Biometrika $\mathbf{3 \%}, 117$ (1950).

M 12, 37

Stevens, W. L., Asymptotic regression, Biometrics \%, 247 (1951).

M 13, 571

-Stock, J. S., The allocation of samplings among several strata, Ann. Math. Statist. 10, 288 (1939).

M 1, 23

Störmer, H., Anwendung des Stichprobenverfahrens beim Beurteilen von Fernsprechverkehrsmessungen, Arch. Elektr. Übertragung 8, 439 (1954).

M 16, 273

-Stouffer, S. A. (See K. Pearson) Biometrika 24, 293 (1932).

Strebel, K., Asymptotische Entwicklung einer Summe, die beim Problem der zwei Stichproben auftritt, Math. Ann. 12\%, 401 (1954). M 16, 55

Stuart, A., A simple presentation of optimum sampling results, J. Roy. Statist. Soc. $B \mathbf{1 6}$, 239 (1954).

M 16, 1037

Stuart, A., A test for homogeneity of the marginal distributions in a two-way classification, Biometrika 42, 412 (1955).

M 1\%, 280

Stuart, A., A paradox in statistical estimation, Biometrika 42, 527 (1955). M 1\%, 279

Student, The probable error of a mean, Biometrika 6, 1 (1908).

Student, "Student's" Collected Papers, (Edited by E. S. Pearson and John Wishart; Biometrika Office, University College, London, 1942).

M 5, 126

Subramanian, S., Compatibility of Fisher's tests for index number formulae, Math. Student 8, 124 (1940).

M 3, 9

Sugiyama, H., Some theory of control charts. I, Math. Japonicae 3, 13 (1953).

M 16, 153

Sugiyama, H., Some theory of control charts. II. (Summarized preliminary report), Math. Japonicae 3, 30 (1953).

M 16, 154

Sugivama, H., Some theory of control charts. III. (Summarized preliminary report), Math. Japonicae 3, 33 (1953).

M 16, 154

- Sugiyama, H., On a method of truncated lifetesting, Math. Japonicae 3, 152 (1955).

M 18, 241

Sukhatme, P. V., A contribution to the problem of two samples, Proc. Indian Acad. Sci. Sect. A $\mathbf{2}$, 584 (1935).

Z 13, 175

Sukhatme, P. V., On the analysis of $k$ samples from exponential populations with especial reference to the problem of random intervals, Statist. Res. Mem, Univ. London 1, 94 (1936).

Z 14, 269 
Sukhatme, P. V., The problem of $k$ samples for Poisson population, Proc. Nat. Inst. Sci. India 3, 297 (1937).

Z 1\%, 273

Sukhatme, P. V., On the distribution of $\chi^{2}$ in samples of the Poisson series, J. Roy. Statist. Soc. Suppl. 5, 75 (1938).

Z 18, 321

Sukhatme, P. V., Random association of points on a lattice, J. Indian Soc. Agric. Statistics 2, 60 (1949).

M 11, 674

Sukhatme, P. V., Non-sampling errors in surveys, J. Indian Soc. Agric. Statistics 4, 5 (1952).

M 14, 390

- Sukhatme, P. V., Sampling with replacement, J. Indian Soc. Agric. Statistics 4, 42 (1952).

M 14, 390

Sukhatme, P. V., Sampling theory of surveys with applications, (Iowa State College Press, Ames, Iowa, 1954).

M 16, 54

Sun, S. P., On the successive approximation to the distribution of the third moment about the mean of independent variates, Acad. Sinica Science Record 1, 351 (1945).

M 8, 282

Sundrum, R. M., On the relation between estimating: efficiency and the power of tests, Biometrika 41, 542 (1954).

M 16, 604

- Suzuki, Y., (See K. Matusita) Ann. Inst. Statist. Math. Tokyo 6, 133 (1954).

Suzuki, Y., Note on the Nevman-Pearson's fundamental lemma, Ann. Inst. Statist. Math. Tokyo 6, 197 (1955).

M 18, 639

Sverdrup, E., Derivation of the Wishart distribution of the second order sample moments by straightforward integration of a multiple integral, Skand. Aktuarietidskr. 30, 151 (1947).

M 9, 453

Sverdrup, E., Similarity, unbiassedness, minimaxibility and admissibility of statistical test procedures, Skand. Aktuarietidskr. 36, 64 (1953).

M 15, 453

Swan, A. W., Sampling schemes for qualitative inspection, Inst. Mech. Engrs. J. Proc. 152, 81 (1945).

M $\boldsymbol{\gamma}, 132$

Székely, G., Ein mit der Qualitätskontrolle zusammenhängender stochastischer Prozess, Magyar Tud. Akad. Alkalm. Mat. Int. Közl. 2, 217 (1954).

M 16, 384

Takacs, L., Anwendung wahrscheinlichkeitstheoretischer Methoden bei der Untersuchung gewisser meteoro-pathologischer Erscheinungen, Magyar Tud. Akad. Alkalm. Mat. Int. Közl. 3, 301 (1954).

M 1\%, 870

Takashima, H., Statistical inference for random processes, Sûgaku 4, 161 (1952).

M 14, 776

Tang, P. C., The power function of the analysis of variance tests with tables and illustrations of their use, Statist. Res. Mem. Univ. London 2, 126 (1938).

Z 20, 243

Tate, R. F., The theory of correlation between two continuous variables when one is dichotomized, Biometrika 42, 205 (1955).

M 1\%, 54

Taylor, E. K., Tables for the determination of the significance of skewness and of the significance of the difference in the skewness of two independent distributions, Psychometrika 12, 111 (1947).

M 8, 592

Taylor, W. F., Distance functions and regular best asymptotically normal estimates, Ann. Math. Statist. 24, 85 (1953).

M 14, 996

Teicher, H., Identification of a certain stochastic structure, Econometrica 24, 172 (1956).

M 1\%, 1219

Teodoresco, C. C., Sur la comparaison de deux séries de mesures, Bull. Math. Phys. Ecole Polytechn. Bucarest 4, 10 (1933).

Z 11, 126

Terpstra, T. J., A confidence interval for the probability that a normally distributed variable exceeds a given value, based on the mean and the mean range of a number of samples, Appl. Sci. Research (A) 3, 297 (1952).

M 14, 391

Tettamanti, K., (See P. Medgyessy) Magyar Tud. Akad. Alkalm. Mat. Int. Közl. 3, 81 (1955).

Theil, H., A rank- invariant method of linear and polynomial regression analysis. III, Indagationes Math. 12, 467 (1950).

M 12, 725

Theil, H., Estimation of parameters of econometric models, Bull. Inst. Internat. Statist. 24, 122 (1954).

M 16, 1040

-Thompson, C. M., (See S. S. Wilks), Biometrika 99, 124 (1937)

-Thompson, C. M., (See H. O. Hartley), Biometrika 33, 296 (1946).

- Thompson, D. J., (See D. G. Horvitz), J. Amer. Statist. Assoc. 4\%, 663 (1952).

Thompson, W. R., On a criterion for the rejection of observations and the distribution of the ratio of deviation to sample standard deviation, Ann. Math. Statist. 6, 214 (1935).

Z 12, 411

Thompson, W. R., On confidence ranges for the median and other expectation distributions for populations of unknown distribution form, $A n n$. Math. Statist. \%, 122 (1936).

Z 15, 310

Thompson, W. A., The relative size of the inter- and intra-block error in an incomplete block design, Biometrics 11, 406 (1955).

M 1\%,641

Thompson, W. A., The ratio of variances in a variance components model, Ann. Math. Statist. 26, $325(1955)$

M 16, 1132

Tiago de Oliveira, J., On the problem of statistical estimation, Anais Fac. Ci. Porto 35, 229 (1951).

M 13, 963

Tiago de Oliveira, J., A note on a special case of inverse binomial sampling, Univ. Lisboa Revista Fac. Ci. A. Ci. Mat. 2, 111 (1952).

M 14, 995

Tintner, G., The distribution of svmmetric quadratic forms in normal and independent variables, Iowa State Coll. J. Sci. 13, 231 (1939).

Z 22, 60

Tintner, G., A note on rank, multicollinearity and multiple regression, Ann. Math. Statist. 16, 304 (1945).

M $\boldsymbol{g}, 132$

Tintner, G., The distribution of the variances of variate differences in the circular case, Metron 1\%, 43 (1955).

M 16, 1132

Tippett, L. H. C., The control of industrial processes subject to trends in quality, Biometrika 33, 163 (1944). 
Tocher, K. D., Extension of the Nevman-Pearson theory of tests to discontinuous variates, Biometrika $\mathbf{3} \%, 130(1950)$.

M 1\%, 193

-Tokarska, B., (See J. Neyman), J. Amer. Statist. Assoc. 31, 318 (1936).

de Toledo Piza, A. P., Considerations on the geometric law, Trabajos Estadistica \%, 79 (1951).

M 13, 142

\Toulmin, G. H., (See I. J. Good), Biometrika 43, 45 (1956).

Treloar, A. E., Random Sampling Distributions, (Burgess Publishing Co., Minneapolis, Minn., 1942).

M 4, 220

-Trickett, W. H., On the comparison of two means: further discussion of iterative methods for calculating tables, Biometrika 41, 361 (1954)

M 16, 603

-Trickett, W. H., Further critical values for the twomeans problem, Biometrika 43, 203 (1956).

M 18, 1101

Truax, D. R., An optimum slippage test for the variances of $K$ normal distributions, Ann. Math. Statist. 24, 669 (1953)

M 15, 727

Truksa, L., The simultaneous distribution in samples of mean and standard deviation, and of mean and variance, Biometrika 31, 256 (1940).

M ?, 109

Tsao, C. K., A simple sequential procedure for testing statistical hypotheses, Ann. Math. Statist. 25, 687 (1954).

M 16, 383

Tsao, C. K., Rank sum tests of fit, Ann. Math. Statist. 26, 94 (1955).

M 16, 941

Tsao, F., Tests of statistical hypotheses in the case of unequal or disproportionate numbers of observations in the subclasses, Psychometrika $\%, 195$ (1942).

M 4, 26

Tsao, F., General solution of the analysis of variance and covariance in the case of unequal or disproportionate numbers of observations in the subclasses, Psychometrika 11, 107 (1946). M 8, 42

-Tuker, J. W., Approximation of the distribution of the product of beta variables by a single beta variable, Ann. Math. Statist. 1\%, 318 (1946).

M 8, 162

-Tukey, J. W., (See G. W. Brown), Ann. Math. Statist. 1\%, 1 (1946).

Tukey, J. W., Approximate weights, Ann. Math. Statist. 19, 91 (1948).

M 9, 453

Tukey, J. W., Sufficiency, truncation and selection, Ann. Math. Statist. 20, 309 (1949).

M 10, 723

Tukey, J. W., Comparing individual means in the analvsis of variance, Biometrics 5, 99 (1949).

M 11, 43

Tukey, J. W., Some sampling simplified, J. Amer. Statist. Assoc. 45, 501 (1950).

M 1\%, 725

Tukey, J. W., Keeping moment-like sampling computations simple, Ann. Math. Statist. \%\%, 37 (1956).

M 1\%, 868

Tukey, J. W., Variances of variance components. III. Third moments in a balanced single classification, Ann. Math. Statist. 28, 378 (1957).

M 18, 955
Tweedie, M. C. K., The regression of the sample variance on the sample mean, J. London Math. Soc. 21, 22 (1946).

M 8, 524

Tweedie, M. C. K., The estimation of parameters from sequentially sampled data on a discrete distribution, J. Roy. Statist. Soc. Ser. B 14, 238 (1952).

M 14, 777

Tweedie, M. C. K., Some statistical properties of inverse Gaussian distributions, Virginia J. Sci. \%, 160 (1956).

M 18, 956

Ura, S., A table of the power function of the analysis of variance tests, Rep. Statist. Appl. Res. Union Jap. Sci. Eng. 3, 23 (1954).

M 16, 53

Ura, S., On the power function of Welch's test procedure in the two sample problems, Rep. Statist. Appl. Res. Un. Jap. Sci. Engrs. 4, 1 (1955)

M 1\%, 758

Uranisi, H., On the statistical inferences in finite populations by two sample theory, Bull. Math. Statist. 5, 9 (1952).

M 14, 888

van Uven, M. J., Likelihood as conditioned probability, Nederl. Akad. Wetensch. Proc. 44, 947 (1941).

M $\%, 318$

- van der Vaart, H. R., Some remarks on the power function of Wilcoxon's test for the problem of two samples, Indagationes Math. 1\%, 146 (1950).

M 1\%, 38

- van der Vaart, H. R., Some remarks on the power function of Wilcoxon's test for the problem of two samples. II, Indagationes Math. 12, 159 (1950).

M 1\%, 38

- van der Vaart, H. R., (See J. Hemelrijk) Statistica (Rijswijk) 4, 54 (1950).

Vajani, L., I criteri di R. A. Fisher per la scelta di una buona stima ed il metodo della massima verosimiglianza, Statistica, Bologna 13, 311 (1953)

M 15, 452

Vajda, S., On the constituent items of the reduction and the remainder in the method of least squares, Ann. Math. Statist. 16, 381 (1945). M \%, 316 Vajda, S., Average sampling numbers from finite lots, Suppl. J. Roy. Statist. Soc. 8, 198 (1946).

M 8, 593

Vajda, S., An outline of the theory of the 'analysis of variance,' J. Inst. Actuaries Students Soc. $\%$, 235 (1948).

M 9, 602

Vajda, S., A note on the use of weighted orthogonal functions in statistical analysis, Proc. Cambridge Philos. Soc. 44, 588 (1948).

M 10, 50

Vajda, S., Analytical studies in stop-loss reinsurance. Skand, Aktuarietidskr. 38, 180 (1955). M 18, 343

Vali, M. A., On the sampling distribution of harmonic means, Bull. Calcutta Math. Soc. 34, 87 (1942).

M 4, 164

de Varennes, Orthogonality and analysis of variance, Portugaliae Math. 3, 234 (1942). M 4, 164

Vatnsdal, J. R., Minimal variance and its relation to efficient moment tests, Ann. Math. Statist. 1\%, 198 (1946).

M 8, 40 
- Villars, D. S., Some significance tests for normal bivariate distributions, Ann. Math. Statist. 14, 141 (1943).

M 44, 127

Ville, J-A., Sur la convergence de la médiane des $n$ premiers résultats d'une suite infinie d'épreuves indépendantes, C.R. Acad. Sci. Paris 203, 1309 (1936).

$\mathrm{Z} \mathbf{1 5}, 261$

Ville, J., Sur un critère d'indépendance, C.R. Acad. Sci. Paris 216, 552 (1943).

M 5, 206

Ville, J., Sur la transitivité d'une methode d'estimation, Ann. Univ. Lyon Sect. A (3) \%, 14 (1944).

M 8, 43

Ville, J., Sur la théorie invariante de l'estimation statistique, Bull. Sci. Math. 68, 95 (1944).

M $\boldsymbol{\%}, 132$

Ville, J. A., Leçons sur quelques aspects nouveaux de la théorie des probabilités, Ann. Inst. H. Poincaré 14, 61 (1954).

M 16, 838

Vincze, I., Die Wirkung der Fehler von Messergebnissen bei der Aufnahme eines Histogramms, Magyar Tud. Akad. Alkalm. Mat. Int. Közl. 2, 267 (1954).

M 16, 271

- Vincze, I., (See P. Medgyessy) Magyar Tud. Akad. Alkalm. Mat. Int. Közl. 3, 81 (1955).

Vogel, W., Asymptotische Eigenschaften von Maximum-Likelihood Schätzwerten bei einem stochastischen Prozess, Monatsh. Math. 60, 313 (1956).

M 18, 682

Votaw, D. F., Testing compound symmetry in a normal multivariate distribution, Ann. Math. Statist. 19, 447 (1948).

M 10, 387

- Votaw, D. F., Estimation of parameters in a truncated trivariate normal distribution, Psychometrika 15, 339 (1950).

M 13, 367

-Votaw, D. F., (See W. L. Deemer) Ann. Math. Statist. 26, 498 (1955).

-Wabeke, I. D., (See C. van Eeden) Math. Centrum Amsterdam Statist. Rap. S 1\%6, (M 65. A.) (1955).

van der Waerden, B. L., Vertrauensgrenzen für unbekannte Wahrscheinlichkeiten Ber. Verh. Sächs. Akad. Wiss. Leipzig 91, 213 (1939).

M 1, 249

van der Waerden, B. L., Biologische Konzentrationsauswertung, Ber. Verh. Sächs. Akad. Wiss. Leipzig 92, 41 (1940).

M 2,236

- van der Waerden, B. L., (See M. Gildemeister) Ber. Verh. Sächs. Akad. Wiss. Leipzig Math-Nat KL 95, 145 (1943).

van der Waerden, B. L., The computation of the $X$-distribution, Proc. Third Berkeley Symp. Math. Stat. \& Prob. 1, 207 (1956).

M 18, 948

Wagner, G., Folgetest fūr die Abnahmeprüfung von Mengen mit grossen und kleinen Stückzahlen, Mitteilungsblatt Math. Statist. 5, 89 (1953).

M 15, 638

Wald, A., Contributions to the theory of statistical estimation and testing hypotheses, Ann. Math. Statist. 10, 299 (1939).

M 1, 152

Wald, A., A note on the analysis of variance with unequal class frequencies, Ann. Math. Statist. 11, 96 (1940).
Wald, A., Asymptotically most powerful test of statistical hypotheses Ann. Math. Statist. 12, 1 (1941).

M 3, 8

$\checkmark$ Wald, A., Note on confidence limits for continuous distribution functions, Ann. Math. Statist. 12, 118 (1941).

M 3, 9

- Wald, A., On the distribution of Wilks' statistic for testing the independence of several groups of variates, Ann. Math. Statist. 1\%, 137 (1941). M 3, 9

Wald, A., On the analysis of variance in case of multiple classifications with unequal class frequencies, Ann. Math. Statist. 12, 346 (1941).

M 3, 174

Wald, A., Some examples of asymptotically most powerful tests, Ann. Math. Statist. 12, 396 (1941).

M 4, 25

Wald, A., On the Principles of Statistical Inference, (Notre Dame Math. Lectures, No. 1, University of Notre Dame, Ind., 1942).

M 4, 25

- Wald, A., (See H. B. Mann) Ann. Math. Statist. 13, 306 (1942).

Wald, A., Asymptotically shortest confidence intervals, Ann. Math. Statist. 13, 127 (1942). M 4, 25

Wald, A., On the power function of the analysis of variance test, Ann. Math. Statist. 13, 434 (1942).

M 5, 129

Wald, A., On the efficient design of statistical investigations, Ann. Math. Statist. 14, 134 (1943).

M 5, 129

Wald, A., (See H. B. Mann) Ann. Math. Statist. 14, 217 (1943).

Wald, A., Tests of statistical hypotheses concerning' several parameters when the number of observations is large, Trans. Amer. Math. Soc. 54, 426 (1943)

$\mathrm{M} \boldsymbol{\gamma}, 20$

Wald, A., On a statistical problem arising in the classification of an individual into one of two groups, Ann. Math. Statist. 15, 145 (1944). M 6, 9

Wald, A., Note on a lemma, Ann. Math. Statist. 15, 330 (1944).

M 6, 91

- Wald, A., Sampling inspection plans for continuous production which insure a prescribed limit on the outgoing quality, Ann. Math. Statist. 16, 30 (1945).

M $\boldsymbol{g}, 21$

Wald, A., Sequential tests of statistical hypotheses, Ann. Math. Statist, 16, 117 (1945). M g, 131

Wald, A., Some generalizations of the theory of cumulative sums of random variables, Ann. Math. Statist. 16, 287 (1945). M g, 209

Wald, A., Sequential method of sampling tor deciding. between two courses of action, J. Amer. Statist. Assoc. 40, 277 (1945).

M $\%, 132$

Wald, A., Statistical decision functions which minimize the maximum risk, Ann. of Math. 46, 265 (1945).

$\mathrm{M} \boldsymbol{\gamma}, 21$

Wald, A., Foundations of a general theory of sequential decision functions, Econometrica 15, 279 (1947).

M 9, 454

Wald, A., An essentially complete class of admissible decision functions, Ann. Math. Statist. 18, 549 (1947).

M 9, 364

Wald, A., A note on regression analysis, Ann. Math. Statist. 18, 586 (1947). 
Wald, A., Asymptotic properties of the maximum likelihood estimate of an unknown parameter of a discrete stochastic process, Ann. Math. Statist. 19, 40 (1948).

M 9, 454

Wald, A., Estimation of a parameter when the number of unknown parameters increases indefinitely with the number of observations, Ann. Math. Statist. 19, 220 (1948). M 10, 135

Wald, A., Note on the consistency of the maximum likelihood estimate, Ann. Math. Statist. 20, 595 (1949).

M 11, 261

-Wald, A., (See A. Berger) Ann. Math. Statist. 20, 104 (1949).

- Wald, A., Bayes solutions of sequential decision problems, Ann. Math. Statist. 21, 82 (1950).

M 11, 529

Wald, A., Statistical Decision Functions, John Wiley \& Sons, New York, 1950). M 12, 193

Wald, A., On the principles of statistical inference, Trabajos Estadistica 2, 113 (1951). $\quad$ M 13, 479

Wald, A., Asymptotic minimax solutions of sequential point estimation problems, Proc. Second Berkeley Symp. Math. Stat. \& Prob., pp. 1-11 (1951).

M 13, 367

Wald, A., (See G. B. Dantzig) Ann. Math. Statist. 22, 87 (1951).

Wald, A., Selected papers in statistics and probability by Abraham Wald (McGraw Hill Book Co., New York, 1955).

M 16, 435

Wallis, W. A., Compounding probabilities from independent significance tests, Econometrica 10, 229 (1942).

M 4, 222

- Wallis, W. A. (See C. Eisenhart) (McGraw Hill Book Co., Inc., New York, 1947).

Walsh, J. E., An extension to two populations of an analogue of Student's $t$-test using the sample range, Ann. Math. Statist. 18, 280 (1947)

M 9, 48

Walsh, J. E., On the power efficiency of a $t$-test formed by pairing sample values, Ann. Math. Statist. 18, 601 (1947).

M 9, 295

Walsh, J. E., On the use of the non-central $t$-distribution for comparing percentage points of normal populations, Ann. Math. Statist. 19, 93 (1948).

M 9, 453

Walsh, J. E., On the power function of the "best" $t$-test solution of the Behrens-Fisher problem, Ann. Math. Statist. 20, 616 (1949). M 11, 260

Walsh, J. E., Some bounded significance level properties of the equal-tail sign test, Ann. Math. Statist. 22, 408 (1951).

M 14, 298

Walsh, J. E., Analytic tests and confidence intervals for the mean value, probabilities, and percentage points of a Poisson distribution, Sankhya $\mathbf{1 4}, 25$ (1954).

M 16, 383

Walsh, J. E., Bounded significance level tests for comparing quantiles of two possibly different continuous populations, Ann. Inst. Statist. Math., Tokyo 6, 213 (1955).

M 1\%, 640

Walter, E., $\chi^{2}$-Test zur Prüfung der Symmetrie bezüglich Null, Mitteilungsblatt Math. Statist. 6, 92 (1954).
Washio, Y., On the weighted power function of some testing hypotheses, Bull. Math. Statist. 6, 11 (1955).

M 18, 870

Washio, Y., Unbiased estimation based on sufficient statisties, Bull. Math. Statist. 6, 69 (1956).

M 18, 772

Watanabe, Y., Unbiased estimate of the mean absolute deviation, J. Sci. Gakugei Fac. Tokushima Univ. 1, 17 (1950).

M 13, 367

- Watanabe, N., (See T. Kitagawa) Bull. Math. Statist. 5, 35 (1953).

-Watson, G. S. (See J. Durbin) Biometrika 38, 150 (1951).

Watson, G. S., Extreme values in samples from $m$ dependent stationary stochastic processes, $A n n$. Math. Statist. 25, 798 (1954). $\quad$ M 16, 385

-Weaver, C. L., (See C. D. Ferris) Ann. Math. Statist. 1\%, 178 (1946).

Weaver, C. L., A simple analytic proof of a general $\chi^{2}$ theorem, Amer. Math. Monthly 54, 529 (1947).

М 9, 195

Weber, E., Das Rückschlussproblem in der biologischen Statistik, Bericht über Wahrschein. $u$ Math. Stat. Oct. 1954, pp. 81-87 (Verlag Wissenschaften, Berlin, 1956).

M 18, 521

Weida, F. M., On certain distribution of functions when the law of the universe is Poisson's first law of error, Ann. Math. Statist. 6, 102 (1935).

Z 12, 113

Weiss, L., Testing one simple hypothesis against another, Ann. Math. Statist. 24, 273 (1953).

M 14, 889

Weiss, L. On confidence intervals of given length for the mean of a normal distribution with unknown variance, Ann. Math. Statist. 26, 348 (1955).

M 17, 54

Weiss, L., A certain class of tests of fit, Ann. Math. Statist. 27, 1165 (1956).

M 18, 773

-Weiss, L. (See J. R. Blum) Ann. Math. Statist. 28, 242 (1957).

Welch, B. L., Some problems in the analysis of regression among $k$ samples of two variables, Biometrika $2 \%, 145$ (1935).

Z 11, 220

Welch, B. L., Note on an extension of the $L_{1}$ test, Statist. Res. Mem. Univ. London 1, 52 (1936).

Z 14, 357

Welch, B. L., On the z-test in randomized blocks and latin squares, Biometrika 99, 21 (1937). Z 1\%, 126

Welch, B. L., The significance of the difference between two means when the population variances are unequal, Biometrika 29, 350 (1938).

Z 18, 226

Welch, B. L., On confidence limits and sufficiency, with particular reference to parameters of location, Ann. Math. Statist. 10, 58 (1939).

$\mathrm{Z} \mathbf{2 0}, 382$

Welch, B. L., On the distribution of maximum likelihood estimates, Biometrika 31, 187 (1939).

M 1, 153 and Z 21, 424

Welch, B. L., On the Studentization of several variances, Ann. Math. Statist. 18, 118 (1947).

M 8, 474 
Welch, B. L., The generalization of 'Student's' problem when several different population variances are involved, Biometrika 34, 28 (1947).

M 8, 394

Welch, B. L., On the comparison of several mean values: an alternative approach, Biometrika 38, 330 (1951).

M 13, 762

-Welch, B. L., (See W. H. Trickett) Biometrika 41, 361 (1954).

Welch, B. L., On linear combinations of several variances, J. Amer. Statist. Assoc. 51, 132 (1956).

M 1\%, 1103

-Welch, B. L., (See W. H. Trickett) Biometrika 43, 203 (1956).

Welker, E. L., The distribution of the mean, Ann. Math. Statist. 18, 111 (1947).

M 8, 476

Welker, E. L., Correlation and regression analysis, Proc. Computation Seminar, pp. 36-43 (IBM Corp. New York, 1951).

M 13, 366

Wertheimer, A., A note on confidence intervals and inverse probability, Ann. Math. Statist. 10, $74(1939)$

Z 20, 382

Westenberg, J., Mathematics of pollen diagrams. I, II, Nederl. Akad. Wetensch. Proc. 50, 509 and 640 (1947).

M 9, 151

Whittle, P., The simultaneous estimation of a time series harmonic components and covariance structure, Trabajos Estadistica 3, 43 (1952). M 14, 488

Whittle, P., Some distribution and moment formulae for the Markov chain, J. Roy. Statist. Soc. B 1\%, 235 (1955).

M 1\%, 982

Wiener, N., The theory of statistical extrapolation, Bol. Soc. Mat. Mexicana 2, 37 (1945). M $\%, 461$

Wiener, N., Nonlinear prediction and dynamics, Proc. Third Berkeley Symp. Math. Stat. \& Prob. III, 247 (1956).

M 18, 949

-Wilenski, H., (See J. Przyborowski) C. R. Acad. Sci. Paris \$00, 1460 (1935).

-Wilenski, H., (See J. Przyborowski) Biometrika 31, $313(1940)$.

Wilks, S. S., On the distributions of statistics in samples from a normal population of two variables with matched sampling of one variable, Metron 9, 87 (1932).

$\mathrm{Z} \mathrm{4,} 156$

Wilks, S. S., On the sampling distribution of the multiple correlation coefficient, Ann. Math. Statist. 3, 196 (1932).

Z 5, 73

Wilks, S. S., The standard error of a tetrad in samples from a normal population of independent variables, Proc. Nat. Acad. Sci. USA 18, 562 (1932).

Z 5, 213

-Wilks, S. S., (See E. S. Pearson) Biometrika 25, 353 (1933).

Wilks, S. S., Moment-generating operators for determinants of product moments in samples from a normal system, Ann. of Math, IIs 35, 312 (1934).

Z 9, 406

Wilks, S. S., On the independence of $k$ sets of normally distributed statistical variables, Econometrica 3, 309 (1935).

Z 12, 29

Wilks, S. S., Test criteria for statistical hypotheses involving several variables, J. Amer. Statist. Assoc. 30, 549 (1935).

Z 12, 363
Wilks, S. S., The likelihood tests of independence in contingency tables, Ann. Math. Statist. 6, 190 (1935).

Z 13, 175

Wilks, S. S., The sampling theory of systems of variances, covariances and intraclass covariances. Amer. J. Math. 58, 426 (1936). Z 14, 73

-Wilks, S. S., The sampling distribution of the criterion $\lambda_{\mathrm{H} 1}$ when the hypothesis tested is not true. Biometrika 99, 124 (1937).

Z 18, 126

Wilks, S. S., The large-sample distribution of the likelihood ratio for testing composite hypotheses, Ann. Math. Statist. 9, 60 (1938).

Z 18, 320

Wilks, S. S., Shortest average confidence intervals from large samples, Ann. Math. Statist. 9, 166 (1938)

Z 19, 357

Wilks, S. S., Fiducial distributions in fiducial inference, Ann. Math. Statist. 9, 272 (1938). Z $\mathbf{2 0 ,} 45$

-Wilks, S. S., An optimum property of confidence regions associated with the likelihood function, Ann. Math. Statist. 10, 225 (1939). M 1, 64

Wilks, S. S., Sample criteria for testing equality of means, equality of variances, and equality of covariances in a normal multivariate distribution, Ann. Math. Statist. 1\%, 257 (1946). M 8, 162

-Wilks, S. S., (See J. W. Tukey) Ann. Math. Statist. 1\%, 318 (1946).

-Wilks, S. S., (See H. Gulliksen) Psychometrika 15, 91 (1950).

Williams, E. J., Use of scores for the analysis of association in contingency tables, Biometrika $\mathbf{3 9}$, 274 (1952).

M 1\%, 641

Williams, E. J., Tests of significance for concurrent regression lines, Biometrika 40, 297 (1953).

M 1\%, 641

Williams, E. J., Significance tests for discriminant functions and linear functional relationships, Biometrika 42, 360 (1955).

M 1\%, 381

Williams, J. D., Moments of the ratio of the mean square successive difference to the mean square difference in samples from a normal universe, Ann. Math. Statist. 1\%, 239 (1941).

M 3, 7

Williams, R. M., The variance of the mean of systematic samples, Biometrika 43, 137 (1956).

M 1\%, 982

Wilson, E. B., The sampling error of the median, Science 92, 58 (1940).

Z 24, 266

Wilson, E. B., The controlled experiment and the four-fold table, Science 93, 557 (1941). M 4, 26

Wilson, E. B., On confidence intervals, Proc. Nat. Acad. Sci. USA 28, 88 (1942).

M 4, 26

Wilson, E. B., On contingency tables, Proc. Nat. Acad. Sci. USA 28, 94 (1942).

M 4, 26

Wilson, E. B., Contingency tables, Proc. Nat. Acad. Sci. USA 28, 378 (1942).

M 4, 105

-Wilson, E. B., The association of three attributes, Proc. Nat. Acad. Sci. USA 28, 384 (1942).

M 4, 106

Wilson, E. B., Note on the t-test, Proc. Nat. Acad. Sci. USA 28, 297 (1942).

M 4, 23

Wilson, E. B., Note on the t-test, Amer. Math. Monthly 51, 563 (1944). M 6, 163 
- Wishart, J., The distribution of second order moment statistics in a normal system, Proc. Cambridge Philos. Soc. 28, 455 (1932). Z 5, 406

Wishart, J., The cumulants of the $Z$ and of the logarithmic $\chi^{2}$ and $t$ distributions, Biometrika 34, 170 (1947).

M 8, 474

Wishart, J., Proof of the distributions of $\chi^{2}$, of the estimate of variance, and of the variance ratio, J. Inst. Actuaries Students' Soc. ', 98 (1947).

M 9, 295

Wishart, J., Proofs of the distribution law of the second order moment statistics, Biometrika 35, 55 (1948).

M 9, 600

Wold, H. O. A., Statistical estimation of economic relationships, Econometrica Suppl. 1\%, 1 (1949).

M 13, 481

- Wolfowitz, J., (See A. Wald), Ann. Math. Statist. 12, 118 (1941).

-Wolfowitz, J., (See A. Wald), Ann. Math. Statist. 16, 30 (1945).

Wolfowitz, J., Confidence limits for the fraction of a normal population which lies between two given limits, Ann. Math. Statist. 18, 483 (1946).

M 8, 394

Wolfowitz, J., The power of the classical tests associated with the normal distribution, Ann. Math. Statist. 20, 540 (1949).

M 11, 261

Wolfowitz, J., On Wald's proof of the consistency of the maximum likelihood estimate, Ann. Math. Statist. 20, 601 (1949).

M 11, 261

-Wolfowitz, J., (See A. Wald), Ann. Math. Statist. 21, 82 (1950).

Wolfowitz, J., Minimax estimates of the mean of a normal distribution with known variance, $A n n$. Math. Statist. 21, 218 (1950).

M 12, 36

- Wolfowitz, J., (See J. Kiefer), Ann. Math. Statist. 83, 462 (1952).

Wolfowitz, J., Estimation by the minimum distance method, Ann. Inst. Statist. Math. Tokyo 5, 9 (1953).

M 15, 452

-Wolfowitz, J., (See A. Dvoretzky), Ann. Math. Statist. 24, 254 (1953).

-Wolfowitz, J., (See A. Dvoretzky), Ann. Math. Statist. 24, 403 (1953).

Wolfowitz, J., The method of maximum likelihood and the Wald theory of decision functions, Indagationes Math. 15, 114 (1953).

M 14, 998

Wolfowitz, J., Consistent estimators of the parameters of a linear structural relation, Skand. Aktuarietidskr. 35, 132 (1953).

M 14, 776

Wolfowitz, J., Estimation of the components of stochastic structures, Proc. Nat. Acad. Sci. USA 40, 602 (1954).

$\mathrm{M} 16,55$
Wolfowitz, J., Generalization of the theorem of Glivenko-Cantelli, Ann. Math. Statist. 25, 131 (1954).

M 15, 808

-Wolfowtiz, J., (See M. Kac), Ann. Math. Statist. 26, 189 (1955).

-Wolfowitz, J., (See J. Kiefer), Naval Res. Logist. Quart. 3, 205 (1956).

- Wolfowitz, J., (See A. Dvoretzky), Ann. Math. Statist. 2\%, 642 (1956).

- Worcester, J., (See E. B. Wilson), Proc. Nat. Acad. Sci. USA 28, 297 (1942).

-Worcester, J., (See E. B. Wilson), Proc. Nat. Acad. Sci. USA 28, 378 (1942).

-Worcester, J., (See E. B. Wilson) Proc. Nat. Acad. Sci. USA 28, 384 (1942).

-Worlledge, J. P. G., (See R. C. Geary) Biometrika 34, 98 (1947).

-Wortham, A. W., (See F. A. Graybill) J. Amer. Statist. Assoc. 51, 266 (1956).

- Yaglom, A. M., (See I. M. Gel'fand) Dokl. Akad. Nauk SSSR 111, 745 (1956).

Yamamoto, S., On the theory of sampling with probabilities proportionate to given values. Ann. Inst. Statist. Math. Tokyo $\boldsymbol{7 , 2} 25$ (1955). M 17, 869

Yasukawa, K., On the deviation from normality of the frequency distributions of functions of normally distributed variates, Tôhoku Math. J. 38, 465 (1933).

Z 8, 266

Yates, F., Orthogonal functions and tests of significance in the analysis of variance, J. Roy. Statist. Soc. Suppl. 5, 177 (1938).

Z 19, 358

Yates, F., Tests of significance of the differences between regression coefficients derived from two sets of correlated variates, Proc. Roy. Soc. Edinburgh 59, 184 (1939).

M 1, 23

Yates, F., An apparent inconsistency arising from tests of significance based on fiducial distributions of unknown parameters, Proc. Cambridge Philos. Soc. 35, 579 (1939).

M 1, 153

Yates, F., Systematic sampling, Philos. Trans. Roy. Soc. London (A) 241, 345 (1948). M 10, 135

Yoneda, K., On the use of the Neyman's allocation, Yokohama Math. J. 1, 117 (1953). M 15, 240

Zeigler, R. K., A note on the asymptotic simultaneous distribution of the sample median and the mean deviation from the sample median, $A n n$. Math. Statist. 21, 452 (1950).

M 1\%, 428

Zia-ud-din, M., Development of symmetric functions and symmetric functional statistics, Proc. Pakistan Statist. Assoc. 3-4, 3 (1955).

M 1\%, 936

Zítek, F., On certain estimators of standard deviation, Zastos. Mat. 1, 342 (1954).

M 16, 1038

(Paper 66B3-80) 


\title{
Publications of the National Bureau of Standards *
}

\author{
Selected Abstracts
}

Derivation of the relaxation spectrum representation of the mechanical response function, R. S. Marvin, J. Research NBS 66A (Phys. and Chem.) No. 4 (July-Aug. 1962).

Relaxation spectra have been used in both the presentation and interpretation of measurements of the mechanical properties of rubberlike polymers.

Analysis of coaxial two-terminal conical capacitor, M. C. Selby, NBS Mono. 46, A pril 6, 1962, 20 cents.

Adjustable capacitors having electrodes in the form of coaxial cones or frustums have been used on rare occasions in the past; but their potential superiority to other types of capacitors for some important applications have been overlooked. The advantage of this geometry over cylindrical or disk forms is that the practical capacitance range is several times larger. An example cites the capacitance ranges of a disk, cylindrical, and conical type to be 10,40 , and 168 to one, respectively. An approximate equation was derived for this conical capacitor and close agreement is shown between computed and measured values of capacitance versus electrode displacement. Multiple cone and different shape electrodes are suggested to obtain large values of capacitance with an appreciable saving of space and further increased range of capacitance. The electric field is plotted and its construction steps for axial symmetry are given.

Evaluation of convolution integrals occurring in the theory of mixed path propagation, J. R. Johler and C. M. Lilley, NBS Tech. Note 132 (PB161633) (1961) \$1.00.

The theory of propagation of electromagnetic waves around a sphere treats the smooth homogeneous case, i.e., the case in which the surface impedance of the sphere is uninterrupted by an abrupt change in conductivity such as a land/sea boundary. It is known, however, that such a theory can be extended to treat inhomogeneous, irregular terrain by formulating certain convolution integrals which utilize the smooth homogeneous formulas. The evaluation of these integrals can be accomplished with dispatch on a large-scale electronic computer with the aid of numerical analysis techniques.

The particular case of a land/sea boundary in a smooth spherical surface is illustrated for a variety of cases by evaluating the convolution integrals on a large-scale computer.

Displacement and strain-energy distribution in a longitudinally vibrating cylindrical rod with a viscoelastic coating, P. Hertelendy, J. A ppl. Mechanics, No. 61-W A-30 (1962). A numerical solution by R. M. Davies of the Pochhammer frequency equation is used to determine the displacement and strain-energy distribution across the cross section of an infinite elastic circular cylindrical rod for a number of wave lengths of the first, second and third modes of symmetrical longitudinal wave propagation. With these results the effect of a thin uniform layer of viscoelastic material is investigated. The four viscoelastic parameters of the coating are reduced to one in the definition and computation of upper and lower bounds of the loss factor, and the application of results to experimental work is discussed.

A string language for symbol manipulation based on ALGOL 60, J. H. Wegstein and W. W. Youden, Commun. ACM 5, No. 1, 54-61 (Jan. 1962).

An artificial computer programming language is proposed for describing the manipulation of strings of characters and symbols. The concept of strings, introduced in the ALGOL 60 Report, is extended by adding: (1) the declaration of strings, substrings, and string arrays with explicit lengths;
(2) the ability to concatenate and shift strings; and (3) the ranking of symbols for comparing strings in Boolean relations. A primer or informal description of the language is followed by examples, a description of experiments with the language on an IBM 704 computer, and a formal description which, taken with the ALGOL 60 Report, defines the proposed string language.

Statistical problems arising in the establishment of physical standards, W. J. Youden, Proc. Fourth Berkeley Symp. on Math. Statistics and Probability III, 321-335 (1961).

The establishment and maintenance of physical standards is indispensable for scientific research, commerce, and industry. The first standards were sufficiently ahead of the existing needs so that questions of precision and accuracy were hardly raised. In recent years the requirements of research and industry have become extremely exacting. Questions of precision and accuracy are now raised on every hand.

Among the statistical problems connected with the development of improved physical standards are the estimation of measurement precision; the design of experiments to provide information on the accuracy; and the reconciliation of results obtained in the national laboratories of the countries undertaking this work. This paper reviews and illustrates by actual examples, some of the ways in which statistical methodology can make contributions in this field.

A lattice with an unusual frequency spectrum, R. J. Rubin and R. Zwanzig, J. Math. Phys. 2, No. 6, 861-864 (Nov.-Dec. 1961).

The lattice is a special rooted Cayley tree, generated by $N$ successive $m$-fold branchings. With each point of the tree are associated a mass $M$ and a position coordinate $x_{i}$. All end points are held fixed at $x_{i}=0$. The potential energy is $V=1 / 2 \Sigma_{i, j} K_{i j}\left(x_{i}-x_{i}\right)^{2}$, where $K_{i j}=K$ if $i$ and $j$ are connected neighbors and neither is an end point, $K_{i i}=\alpha K$ if $i$ and $j$ are connected neighbors and either is a branch tip point, and $K_{i j}=0$ if $i$ and $j$ are not connected neighbors. The allowed frequencies of vibration are obtained for two different cases: In the first case all springs are identical $(\alpha=1)$, and in the second case the springs connecting interior points to the branch tips are cut $(\alpha=0)$. In the case in which all force constants are the same, the allowed frequencies of vibration, in the limit of infinite, $N$, are given by $\omega(r)=(K / M)^{\frac{1}{2}}[m+1$ $\left.-2 m^{\frac{1}{2}} \cos r \pi\right]^{\frac{1}{2}}$, where $r$ is any rational number between zero and one. The fraction of all normal modes having precisely the value $\omega(r)$ is $\rho[\omega(r)]=\left(m^{a}-1\right)^{2} /\left(m^{a}-1\right)$, where $r$ is expressed as the ratio $r=p / q$ of relatively prime integers $p$ and $q$. The frequency spectrum is dense within the interval $\left(m^{\frac{1}{2}}-1, m^{\frac{1}{2}}+1\right)$; and $\rho[\omega]$ is discontinuous at every $\omega$ for which it does not vanish.

A new approach to the mechanical syntactic analysis of Russian, I. I. Rhodes, Mech. Transl. 6, 33-50 (Nov. 1961).

This paper categorically rejects the possibility of considering a word-to-word conversion as a translation. A true translation is unattainable, even by the human agent, let alone by mechanical means. However, a crude practical translation is probably achievable. The present paper deals with a scheme for the syntactic integration of Russian sentences.

Congruences for the partition function to composite moduli, M. Newman, Illinois J. Math. 6, No. 1, 59-63 (Mar. 1962). The principal result proved is that the unrestricted partition function $p(n)$ fills all residue classes modulo 65 infinitely often. Similar results are proved. 
The shape of the geomagnetic field boundary under uniform external pressure, R. J. Slutz, J. Geophys. Research 6r, No. 2, 505-513 (Feb. 1962).

A solution is given for the shape of the cavity which separates the earth's magnetic field from the interplanetary plasma, for a model which assumes the plasma pressure to be constant over the surface of the cavity (thus giving axial symmetry). It is seen that along the polar axes there are cusps extending inward which reduce the cavity size along these axes to $2 / 3$ of the size in the equatorial plane. Applying these results as an approximation in the earth-sun direction for the non-axiallysymmetric case of solar wind gives an estimate of about 9 earth radii for the distance of the boundary from the earth's center in the direction of the sun.

Inequalities for the permanent function, M. Marcus and M. Newman, Ann. Math. 75, No. 1, 47-62 (Jan. 1962).

By exhibiting the permanent function as an inner product on a suitably defined space of tensors on a unitary space, many inequalities and bounds for the permanent are obtained. Thus it is shown that if the $n \times n$ matrix $A$ is symmetric positive semi-definite and doubly stochastic, then

$$
\text { per } A \geq \frac{n !}{n^{n}}
$$

with equality if and only if $A$ is the matrix with entries all $\frac{1}{n}$. Another result shown is that if $U$ is a unitary matrix, then $\mid$ per $U \mid \leq 1$

with equality if and only if $U$ is a generalized permutation matrix.

\section{Other NBS Publications}

Journal of Research 66A (Phys. and Chem.) No. 3, (MayJune 1962) 70 cents.

Glass filters for checking performance of spectrophotometerintegrator systems of color measurement. H. J. Keegan, J. C. Schleter, and D. B. Judd.

Calibration of small grating spectrometers from 166 to 600 $\mathrm{cm}^{-1}$. L. R. Blaine, E. K. Plyler, and W. S. Benedict,

Franck-Condon factors to high vibrational quantum numbers II: $\mathrm{SiO}, \mathrm{MgO}, \mathrm{SrO}, \mathrm{AlO}, \mathrm{VO}, \mathrm{NO}$. R. W. Nicholls.

Oxidation of aldoses with bromine. H. S. Isbell.

An analysis of the solid phase behavior of the normal paraffins. M. G. Broadhurst.

Methylene groups in determination of disulfide and methylene sulfide crosslinks in polycaprolactam fibers. S. D. Bruck.

Purification by automatic gas chromatography. M. Tenenbaum and F. L. Howard.

High resolution investigation of some infrared bands of carbon disulfide. D. Agar, E. K. Plyler, and E. D. Tidwell.

Journal of Research 66A (Phys. and Chem.) No. 4 (July-Aug. 1962 ), 70 cents.

Dielectric properties of semicrystalline polychlorotrifluoroethylene. A. H. Scott, D. J. Scheiber, A. J. Curtis, J. I. Lauritzen, Jr, and J. D. Hoffman.

Thermal degradation of fractionated high and low molecular weight polystyrenes. S. L. Madorsky, D. McIntyre, J. H. O'Mara, and S. Straus.

Synthesis of 2-propoxy-5-methylbenzoic acid. G. M. Brauer and L. Simon.

Gamma-ray distribution from oriented cerium-141. J. F Schooley, D. D. Hoppes, and A. T. Hirshfeld.

Light source for producing self-reversed spectral lines. J. Sugar.

A diamond cell for X-ray diffraction studies at high pressures. G. J. Piermarini and C. E. Weir.

Thermal conductivity of gases. I. The coaxial cylinder cell. L. A. Guildner.

Thermal conductivity of gases. II. Thermal conductivity of carbon dioxide near the critical point. L. A. Guildner.

Derivation of the relaxation spectrum representation of the mechanical response function. R. S. Marvin. (See above abstract.

Intermediate phases in superconducting niobium-tin alloys. L. L. Wyman, J. R. Cuthill, G. A. Moore, J. J. Park, and H. Yakowitz.
Journal of Research $66 \mathrm{C}$ (Eng. and Instr.) No. 3 (July-Sept. 1962 ), 75 cents.

Measurement of longitudinal spherical aberration in the extra-axial region of lenses. F. E. Washer and W, R. Darling.

Spark-gap flashover measurements for steeply rising voltage impulses. J. H. Park and H. N. Cones.

Evaporated-film electric hygrometer elements. F. E. Jones.

Methods of measuring the resistivities of anisotropic conducting media in situ. S. Rush.

Corrosion of steel pilings in soils. M. Romanoff.

Corrosion rates of ferrous alloys ( $\mathrm{Fe}-\mathrm{Cr}$ and $\mathrm{Fe}-\mathrm{Cr}-\mathrm{Si}$ ) measured by polarization technique. W. J. Schwerdtfeger.

A furnace for thermocouple calibrations to $2,200{ }^{\circ} \mathrm{C}$. D. B. Thomas.

Total hemispherical emittance of coated and uncoated Inconel and types 321 and 430 stainless steel. J. C. Richmond and William N. Harrison.

"Mail Separator" control computer preliminary logical design S. Henig and E. C. Palasky.

Method of measuring emissivities of metals in the infrared. A. G. Maki and E. K. Plyler

Journal of Research 66D (Radio Prop.) No. 4 (July-Aug. 1962) 70 cents.

Propagation problems with space radio communications. $\mathrm{K}$ Rawer.

On the absolute intensity of incoherent scatter echoes from the ionosphere. K. L. Bowles, G. R. Ochs, and J. L. Green.

On the forward scattering of radio waves in the lower ionosphere. T. Hagfors.

The representation of diurnal and geographic variations of ionospheric data by numerical methods. W. B. Jones and R. M. Gallet.

The interaction between an obliquely incident plane electromagnetic wave and an electron beam in the presence of a static magnetic field of arbitrary strength. K. H. B . Wilhelmsson.

An analysis of VLF mode propagation for a variable ionospheric beight. J. R. Wait.

A method for the determination of lower ionosphere properties by means of field measurements on sferics. F. B. Harris, Jr., and R. L. Tanner.

Defocusing of radio rays by the troposphere, R. E. Wilkerson.

Magnetotelluric fields in the frequency range 0.03 to 7 cycles per kilosecond: Part I. Power spectra. C. W. Horton and A. A. J. Hoffman.

Magnetotelluric fields in the frequency range 0.03 to 7 cycles per kilosecond: Part II. Geophysical interpretation. C. W. Horton and A. A. J. Hoffman.

The impedance of a circular loop in an infinite conducting medium. M. B. Kraichman.

Standard X-ray diffraction powder patterns, H. E. Swanson, M. C. Morris, R. P. Stinchfield, and E. H. Evans, NBS Mono. 25-Section 1 (Mar. 9, 1962) 40 cents.

Tables of spectral-line intensities. Part I. Arranged by elements, W. F. Meggers, C. H. Corliss, and B. F. Scribner, NBS Mono. 32, Pt. I (Dec. 29, 1961) $\$ 4.00$.

Radiation patterns in the lower ionosphere and Fresnel zones for elevated antennas over a spherical earth, R. G. Merrill and W. V. Mansfield, NBS Mono. 38 (Apr. 2, 1962) 70 cents.

Calibration procedures for direct-current resistance apparatus, P. P. B. Brooks, NBS Mono. 39 (Mar. 1962) 40 cents.

Thermocouple materials, F. R. Caldwell, NBS Mono. 40 (Mar. 1962) 30 cents.

Theory and methods of optical pyrometry, H. J. Kostkowski and R. D. Lee, NBS Mono. 41 (Mar. 1, 1962) 25 cents.

Effect of exposure site on weather resistance of porcelain enamels exposed for three years, D. G. Moore and A. Potter, NBS Mono. 44 (Apr. 10, 1962) 15 cents.

Fire tests of precast cellular concrete floors and roofs, J. V Ryan and E. W. Bender, NBS Mono. 45 (Apr. 12, 1962) 15 cents. 
An ultraviolet multiplet table, C. E. Moore, NBS Circ. 488, Sections 3, 4, and 5 (Apr. 6, 1962) Section 3, 60 cents; Section 4, 45 cents; Section 5, 30 cents.

Standard materials issued by the National Bureau of Standards. A descriptive list with prices, NBS Misc. Publ. 241 (Mar. 12, 1962) Supersedes C 552, 3d edition, 30 cents.

A transistor-magnetic core digital circuit, E. W. Hogue, NBS Tech. Note 113 (PB161614) (1961) \$3.00.

A tabulation of the thermodynamic properties of normal hydrogen from low temperatures to $300^{\circ} \mathrm{K}$ and from 1 to 100 atmospheres, J. W. Dean, NBS Tech. Note 120 (PB161621) (1961) \$1.75.

A survey of the literature on heat transfer from solid surfaces to cryogenic fluids, R. J. Richards, W. G. Steward, and R. B. Jacobs, NBS Tech. Note 122 (PB161623) (1961) $\$ 1.25$.

Functional and design problems of the NBS RF voltage bridge, L. F. Behrent, NBS Tech. Note 123 (PB161624) (1961) $\$ 1.60$.

Provisional thermodynamic functions for para-hydrogen, H. M. Roder and R. D. Goodwin, NBS Tech. Note 130 (PB161631) (1961) \$3.00.

Photoionization of atoms and molecules, F. L. Mohler, NBS Tech. Note 131 (PB161632) (1962) \$1.25.

Historical survey of fading at medium high radio frequencies, R. K. Salaman, NBS Tech. Note 133 (PB161634) (1962) 75 cents.

Airborne television coverage in the presence of co-channel interference, M. T. Decker, NBS Tech. Note 134 (PB161635) (1962) $\$ 2.00$

Ionosonde observations of artificially produced electron clouds: firefly 1960, J. W. Wright, NBS Tech. Note 135 (PB161636) (1962) \$2.50.

Some problems of fatigue of bolts and bolted joints in aircraft applications, L. Mordfin, NBS Tech. Note 136 (PB161637) (1962) $\$ 1.25$.

Double probe measurements of ionization in active nitrogen, H. P. Broida and I. Tanaka, J. Chem. Phys. 36, No. 1, 236-238 (Jan. 1962).

Fitting refractive index data by least squares, L. E. Sutton and O. N. Stravroudis, J. Opt. Soc. Am. 51, No. 8, 901-905 (Aug. 1961).

Compton scattering by $K$-shell electrons, J. W. Motz and G. Missoni, Phys. Rev. 124, No. 5, 1458-1468 (Dec. 1961).

Intramolecular rearrangements. III. Formation of 1methylcyclobutanol in the photolysis of 2-pentanone, P. Ausloos and R. E. Rebbert, J. Am. Chem. Soc. 83, 4897-4899 (1961).

Re-examination of the polymorphism of dicalcium silicate, D. K. Smith, A. J. Majumdar, and F. Ordway, J. Am. Ceram. Soc. 44, No. 8, 405-411 (Aug. 1961).

Fluorine flame calorimetry, G. T. Armstrong, Books, Experimental Thermochemistry II, ch. 7, 129-145 (Interscience Publ., London, England, 1962).

A study of F2-layer effects as observed with a Doppler technique, K. Davies, J. M. Watts, and D. H. Zacharisen, J. Geophys. Research 6\%, 601-609 (Feb. 1962).

Ionospheric effects associated with the solar flare of September 28, 1961, K. Davies, Nature Letter 193, 763-764 (Feb. $24,1962)$

Sferic observations of the severe weather on May 19, 1960, C. A. Samson and R. F. Linfield, J. Geophys. Research 6\%, 627-635 (Feb. 1962).

On the mean temporal variations of electron density at a fixed height in the $F$ region, A. J. Hirsh and R. W. Knecht, J. Geophys. Research 67, No. 2, 595-600 (Feb. 1962).

Superconducting magnets, R. H. Kropschot and V. Arp, Cryogenics 2, No. 1, 1-15 (Sept. 1961).

Polymorphism in monobromoacetic acid and the diagram of state of dichloroacetic acid at elevated pressures, A. R. Glasgow and J. Timmermans, Bull. Soc. Chim. Belges $\mathbf{y 0}$, 623-641 (1961).

Ray-tracing formulas for uniaxial crystals, O. N. Stavroudis, J. Opt. Soc. Am. 52, No. 2, 187-191 (Feb. 1962).

Doppler studies of the ionosphere with vertical incidence, $\mathrm{K}$. Davies, Proc. IRE 50, No. 1, 94 (Jan. 1962).
An introduction to flame photometry and a review of recent studies, M. Margoshes, Book, Physical Techniques in Biological Research, W. L. Nastok, Ed., IV, 215-260 (Academic Press, New York, N.Y., 1962)

The ionization constant of $p$-nitrophenol from 0 to $60^{\circ}$, G. F. Allen, R. A. Robinson, and V. E. Bower, J. Phys. Chem. 66, No. 1, 171-172 (1962).

Parametric behavior of an ideal two-frequency varactor, G. F. Montgomery, Proc. IRE 50, No. 1, 78-80 (1962).

Oscillator models in unimolecular reactions, M. L. Vestal and H. M. Rosenstock, J. Chem. Phys. 35, No. 6, 2008-2016 (Dec. 1961).

Some physical properties of monochloro-, dichloro-, and monobromoacetic acids at 1 atmoshpere, A. R. Glasgow and J. Timmermans, Bull. Soc. Chim. Belges 70, 599-622 (1961).

Auroral zone geomagnetic micropulsations with periods of 5 to 30 seconds, W. H. Campbell and S. Matsushita, J. Geophys. Research 67, 555-573 (Feb. 1962).

On the interpretation of prominence spectra. V. The emission lines in quiescent prominences, J. T. Jefferies and F. Q. Orrall, Astrophys. J. 135, 109-121 (Jan. 1962).

Design of retarding field energy analyzers, J. A. Simpson, Rev. Sci. Instr. 22, No. 12, 1283-1293 (Dec. 1961).

Intramolecular arrangements. IV. Photolysis of 2-pentanone-4,5, 5- $d_{3}$, R. P. Borkowski and P. Ausloos, J. Phys. Chem. 65, 2257-2260 (1961).

Electrophoretic mobilities and surface adsorption in the polystyrene latex-aliphatic soap system, C. L. Sieglaff and J. Mazur, J. Colloid Sci. V, 17, No. 1, 66-85 (Jan. 1962).

An equation of state for calculating the thermodynamic properties of helium at low temperatures, R. D. MeCamy and R. B. Stewart (1962 2d Symp. Thermophysical Properties, January 24-26, 1962, Princeton University, Princeton, New Jersey), Progress in International Research on Thermodynamics and Transport Properties, Am. Soc. Mech. Engrs. (New York, N.Y.), p. 107 (1962).

Stress-strain relationships in yarns subjected to rapid impact loading. Part VIII: Shock waves, limiting breaking velocities, and critical velocities, J. C. Smith, J. M. Blandford, and K. M. Towne, Textile Research J. 32, No. 1, 67-76 (Jan. 1962).

The standards challenge, A. H. Scott, Insulation 8, No. 2, 48-50 (Feb. 1962).

Average decay laws for VLF fields, J. R. Wait, Proc. IRE 50, No. 1, 53-56 (Jan. 1962).

Radiation beam mapping with photographic film, W. L. McLaughlin, Radiology 78, No. 1, 119-120 (Jan. 1962).

Low temperature thermometry, R. P. Hudson, Experimental Cryophys., pp. 214-253 (1961).

Photolysis of acetone- $d_{6}$ in the presence of propane-2, $2-d_{2}$. Decomposition of the $n$-propyl radical, W. M. Jackson and J. R. MeNesby, J. Am. Chem. Soc. 83, 4891-4896 (1961).

Comparison of United States and Canadian free-air ionization chambers, J. H. Aitken, L. De LaVergne, W. H. Henry, and T. P. Loftus, Brit. J. Radiol. 35, No. 409, 65-70 (Jan. 1962).

Analysis of the absorption spectrum of $\mathrm{YbCl} 3 \cdot 6 \mathrm{H}_{2} \mathrm{O}$, J. C. Eisenstein, J. Chem. Phys. 35, No. 6, 2097-2100 (Dec. 1961).

National Bureau of Standards, Washington, D.C. and Boulder, Colo., C. E. Moore, Astron, J. 66, No. 10 (Dec. 1961).

Rapid method for interpolating refractive index measurements, O. N. Stavroudis and L. E. Sutton, J. Opt. Soc. Am. 51, No. 3, 368-370 (Mar. 1961).

The three-dimensional nature of boundary-laver instability, P. S. Klebanoff, K. D. Tidstrom, and L. M. Sargent, J. Fluid Mechanies 12, pt. 1, 1-34 (1962).

A specimen for use in investigating the stress-corrosion cracking of metals at elevated temperatures, H. L. Logan, Materials Research and Standards (ASTM Bull.) 2, No. 2, 98-100 (Feb. 1962).

Dynamic behavior of a simple pneumatic pressure reducer, D. H. Tsai and E. C. Cassidy, J. Basic Eng., 253-264 (June 1961).

Net heat of combustion and other properties of kerosine and related fuels, G. T. Armstrong, L. Fano, R. S. Jessup, S. Marantz, T. W. Mears, and J. A. Walker, J. Chem. Eng. Data \%, No. 1, 107-116 (Jan. 1962). 
Effect of porosity on Young's modulus of alumina, F. P. Knudsen, J. Am. Chem. Soc. 45, No. 2, 94-95 (Feb. 1962). On the thermodynamic properties of fluids, E. H. Brown, Inst. intern. du froid, Intern. Inst. of Refrigeration, Commission 1, 169-178 (1960).

Characteristic electron energy loss measurement at low temperatures, E. M. Horl and J. A. Suddeth, J. Appl. Phys. 32, No. 12, 2521-2525 (Dec. 1961).

Current-limited rectifiers, G. E. Montgomery, Proc. IRE 50, No. 2, 190-193 (Feb. 1962).

Dissociation constant of 2-ammonium-2-methyl-1, 3-propanediol in water from 0 to $50^{\circ}$ and related thermodynamic quantities, H. B. Hetzer and R. G. Bates, J. Phys. Chem. 66, 308-311 (1962).

An introduction to flame photometry and a review of recent studies, M. Margoshes, Phys. Tech. Biological Research 4, 215-260 (1962).

Research and the saving of teeth, G. C. Paffenbarger, J Prosthetic Dentistry 12, No. 2, 369-383 (Mar.-Apr. 1962).

Displacement and strain-energy distribution in a longitudinally vibrating cylindrical rod with a viscoelastic coating, $P$. Hertelendy, J. Appl. Mech. Trans. ASME 29, Series E, No. 1, 47-52 (Mar. 1962).

Properties of silico-phosphate cements, J. N. Anderson and G. C. Paffenbarger, Dental Progress 2, No. 2, 72-75 (Jan. 1962).

Comments on paper by W. D. Westfall, Prediction of VLF diurnal phase changes and solar flare effect, J. R. Wait, J. Geophys. Research 6\%, No. 2, 916-917 (Feb. 1962).

Plating standards and specifications, F. Ogburn, Electroplating Eng. Handb. 2d. ed., Ed. K. Graham, ch. 7, pp. 257-262 (Reinhold Publ. Co., New York, N.Y, 1962).

Surface effect on bond strength of steel beams embedded in concrete, J. O. Bryson and R. G. Mathey, J. Am. Concrete Inst. 59, No. 3, 397-406 (Mar. 1962).

Study of electronically excited hydroxyl radicals in the $\mathrm{H}+\mathrm{O}_{3}$ atomic flame, H. P. Broida, J. Chem. Phys. 36, No. 2, 444-448 (Jan. 1962).

Theory of thermal diffusion in dilute alloys, R. E. Howard and J. R. Manning, J. Chem. Phys. 36, No. 4, 910-916 (Feb. 1962).

Effect of monomeric reagents on the melting (contraction) and recrystallization of fibrous proteins, L. Mandelkern, W. T. Meyer, and A. F. Diorio, J. Phys. Chem. 66, 375-376 (1962).
A correction to the exospheric electron density estimate using the nose whistlers of March 19, 1959, J. H. Pope, J. Geophys. Research 67, No. 1, 412 (Jan. 1962).

Hydrogen formation in the gamma-radiolysis of ethylene, P. Ausloos and R. Gorden, Jr., J. Chem. Phys. 36, No. 1, 5-9 (Jan. 1962).

Investigation of the spectrophotometric method of measuring the ferric ion vield in the ferrous sulfate dosimeter, $K$. Scharf and R. M. Lee, Radiation Research 16, No. 2, 115-124 (Feb. 1962)

Microwave spectrum and nonplanarity of cyanamide, D. J. Millen, G. Topping, and D. R. Lide, Jr., J. Mos. Spectroscopy 8, No. 2, 153-163 (Feb. 1962).

Long-distance one-hop $F_{1}$ propagation through the auroral zone, L. H. Tveten, J. Geophys. Research 66, No. 6, 1683-1684 (June 1961).

Impurity effects in high purity metal, L. L. Wyman and G. A. Moore, (Symp. Major Effects of Minor Constituents on the Properties of Materials. Sixty-fourth annual meeting ASTM, Atlantic City, N.J., June 26, 1961), ASTM Spec. Tech. Publ. No. 304-ASTM Material Sci. Series 2, 3-16 (June 26, 1961).

Preparation of and electroplating of uranium, D. E. Couch, Plating 49, No. 4, 363-367 (Apr. 1962).

Vibration-rotation interactions in cyanimide; the question of planarity of amides, D. R. Lide, Jr., J. Mol. Spectroscopy 8, No. 2, 142-152 (Feb. 1962).

Tensile strength and modulus of elasticity of tooth structure and several restorative materials, R. L. Bowen and M. S. Rodriguez, J. Am. Dental Assoc. 64, No. 3, 378-387 (Mar. 1962).

Vacuum ultraviolet photochemistry. III. Primary processes in the vacuum ultraviolet photolysis of water and ammonia, J. R. MeNesby, I. Tanaka, and H. Okabe, J. Chem. Phys. 36, No. 3, 605-607 (Feb. 1962).

Accuracy of analytical procedures, W. J. Youden, J. Assoc. Official Agricultural Chemists 45, No. 1, 160-173 (Feb. 1962).

*Publications for which a price is indicated (except for Technical Notes) are available only from the Superintendent of Documents, U.S. Government Printing Office, Washington 2.5, D.C. (foreign postage, one-fourth additional). Technical Notes are available only from the Office of Technical Services, U.S. Department of Commerce, Washington 25, D.C. (order by $P B$ number). Reprints from outside journals and the NBS Journal of Research may often be obtained directly from the authors. 